\title{
Anti-Corrosion Performance of Primer and Top Coat Formulations for Metal Substrates
}

\author{
A Project Report \\ presented to \\ the Faculty of California Polytechnic State University, \\ San Luis Obispo \\ In Partial Fulfillment \\ of the Requirements for the Degree \\ Master of Science in Polymers and Coatings \\ by \\ Laural Elizabeth Hargrove
}

August 2012 
(C) 2012

Laural Elizabeth Hargrove

ALL RIGHTS RESERVED 


\section{COMMITTEE MEMBERSHIP}

TITLE:

AUTHOR:

DATE SUBMITTED

COMMITTEE CHAIR:

COMMITTEE MEMBER:

COMMITTEE MEMBER:
Anti-Corrosion Performance of Primer and Top Coat Formulations for Metal Substrates

Laural Elizabeth Hargrove

August, 15, 2012

Raymond H. Fernando, Professor

Dane R. Jones, Professor

Todd Wirdzek, VP of Product Development at Kelly-Moore Paint Company 


\begin{abstract}
Anti-Corrosion Performance of Primer and Top Coat Formulations for Metal Substrates
\end{abstract}

\author{
Laural Elizabeth Hargrove
}

This project involved the improvement of several properties of the current "universal" primer coating sold by Kelly-Moore Paint Company. This formulation is an all purpose primer used both for interior and exterior applications. However, its corrosion resistance has room for improvement. The addition of sodium nitrite, an aminocarboxylate salt, and a zinc phosphate-based additive were all tested as corrosion inhibitors. In addition, during the project the coating binder was changed to improve adhesion. After a systematic experimental program, a new "universal" primer with increased corrosion resistance and adhesion was formulated.

A direct to metal top coat formulation sold by Kelly-Moore Paint Company was reformulated in order to produce a coating with better corrosion resistance and gloss retention. Five new latexes were investigated. Each formulation was tested for several properties including adhesion to metal substrates, water immersion resistance, accelerated UV exposure resistance, and outdoor exposure resistance. This effort resulted in a formulation that showed promise as a replacement for the current product; however, its adhesion was inadequate. Further work is needed to improve this coating. 


\section{ACKNOWLEDEMENTS}

I would like to thank Kelly-Moore Paint Company for their support and funding with this project. In particular I would like to thank the member of my Committee, Dr. Dane Jones and Todd Wirdzek, for their support and guidance. Finally, I would like to thank Dr. Raymond Fernando for his years of guidance, patience, and support. 


\section{TABLE OF CONTENTS}

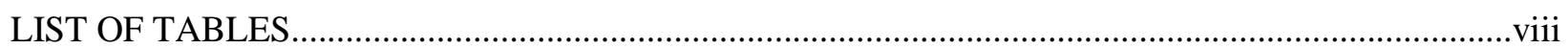

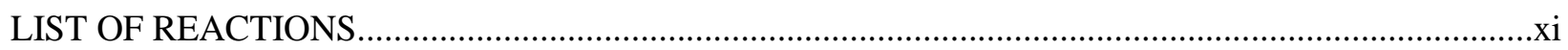

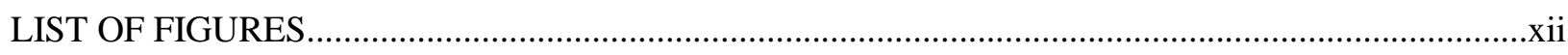

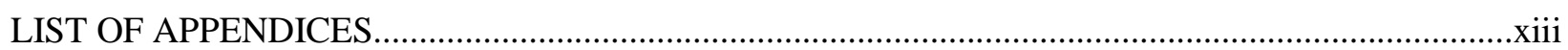

1. Introduction

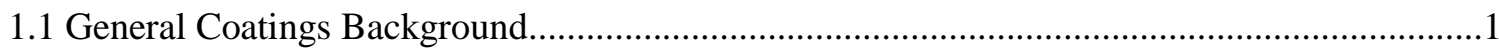

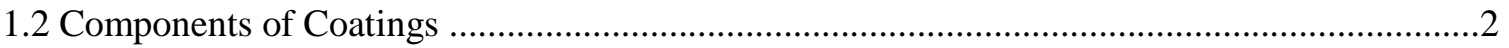

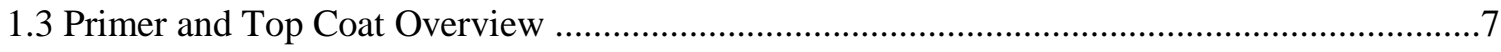

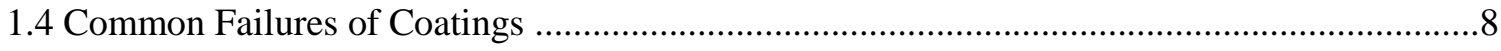

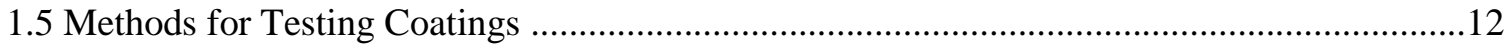

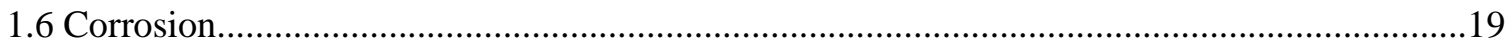

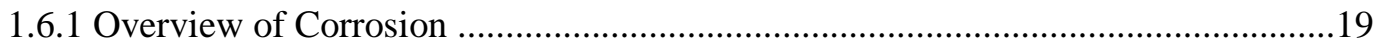

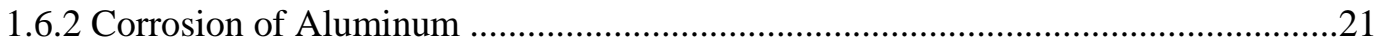

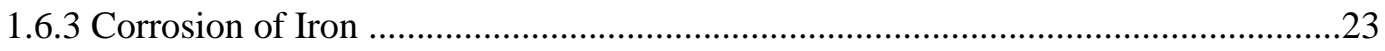

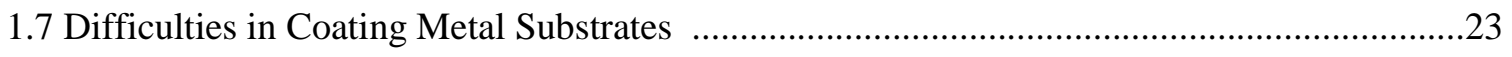

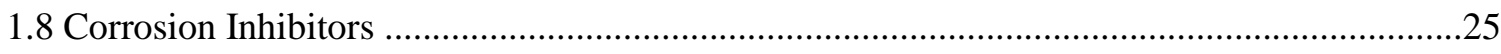

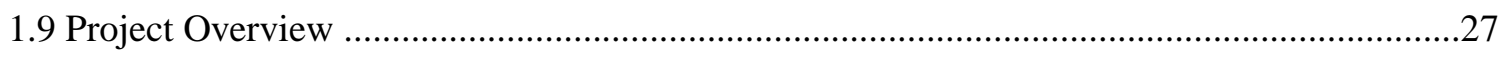

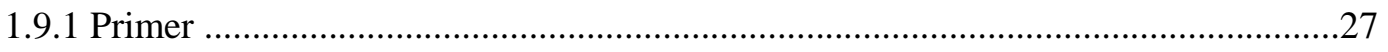

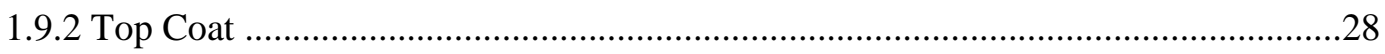

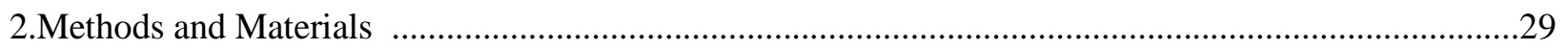

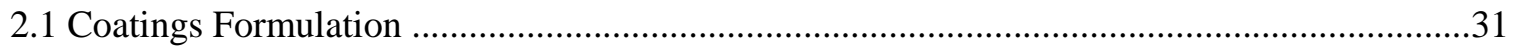

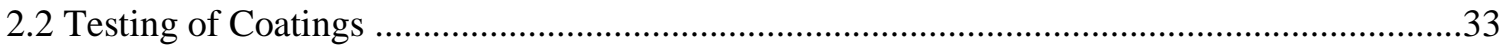

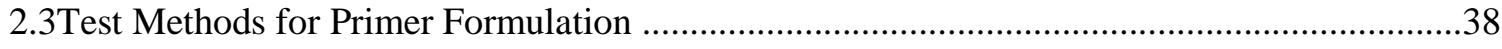

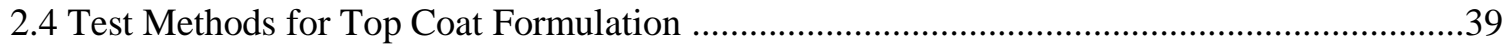




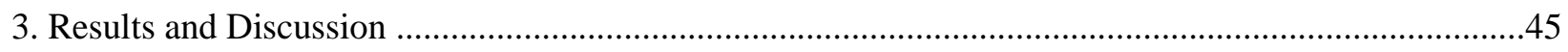

3.1 Testing of "Universal" Primer Formulation..........................................................................45

3.2 Testing of Direct to Metal Top Coat Formulation ............................................................49

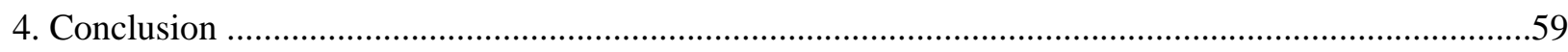

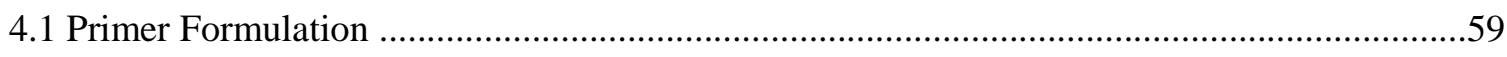

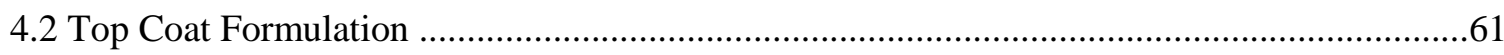

5. Future Work

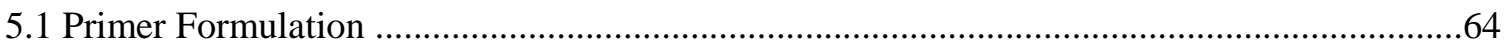

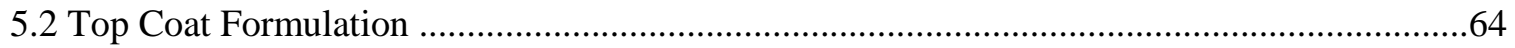

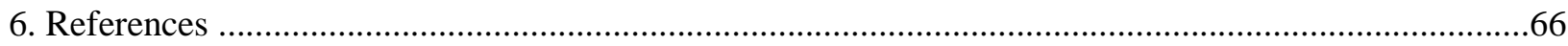

7. Appendix A - Generic Formulations for Primer Testing …...............................................................70

8. Appendix B - Generic Formulations for Top Coat Testing …........................................................73

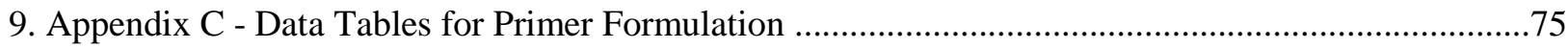

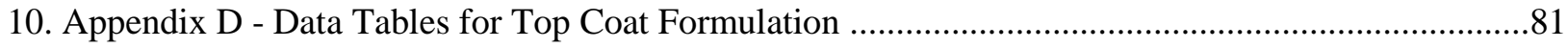




\section{LIST OF TABLES}

Table

Page

$2.1 \quad$ Generic Formulation of $5880 \quad 29$

3.1 Components of 295A, 295AB, and 295ABC 46

3.2 General Testing Results of Formulation 295, 295A, 295AB, and $295 \mathrm{ABC}$

3.3 Important Test Results for 1725-295, New 295, and 295

$3.4 \quad$ Description of Binder Systems Tested in Top Coat 49

3.5 Test Results for Formulation 5 and 7 in Comparison to 5880

3.6 Important Testing Results for Formulations 8 and 9 and Their $\quad 54$ Derivates

3.7 Test General Results of Physical Properties of Formulations 10, 11 , and 12

3.8 Important Test Results of Formulations 13, 14, and 9C 57

C.1 Complete Adhesion Results for 295, 295A, 295AB, and 295ABC 74

C.2 Complete Results for 295, 295A, 295AB, and 295ABC QUV 75

Accelerated Weathering

C.3 Complete Results for 295, 295A, 295AB, and 295ABC Exterior 75 Exposure Testing

C.4 Complete Adhesion Results for 1725-295, New 295, and 295

C.5 Complete Results for 1725-295 and 295 QUV Accelerated 77 Weathering Testing

C.6 Complete Results for 1725-295 and 295 Exterior Exposure 77

C.7 Complete Results for Chemical Resistance of 1725-295 and $295 \quad 78$

C.8 Complete Results of Hand Lotion Resistance of 1725-295 79 and 295 
D.1 Complete Adhesion Testing Results for Formulations 5 and

D.2 Complete Results for QUV Exterior Exposure Testing of 5880,

Formulation 5, and Formulation 7

D.3 Complete Results for Exterior Exposure Testing of 5880,

Formulation 5, and Formulation 7

D.4 Complete Adhesion Testing Results for 8A and 9B

D.5 Complete Results for QUV Exposure Testing of 5880,

82

Formulation 8A, and Formulation 9A

D.6 Complete Results for Exterior Exposure Testing of 5880,

Formulation 8A, and Formulation 9A

D.7 Chemical Resistance of 5880 and Formulation 9C After One

84

Hour of Exposure and Twenty Four Hours of Exposure and One Hour Recovery Values

D.8 Hand Lotion Resistance of 5880 and Formulation 9C After One Hour of Exposure and Twenty Four Hours of Exposure and One Hour Recovery Values

D.9 Results for Adhesion of 5880 and 9C Formulations With and Without Primer

D.10 Gloss Measurements of Tinted 9C Formulations Over Three

Weeks of Aging at Room Temperature and $120^{\circ} \mathrm{F}$

D.11 Results of Syneresis and Color Float Testing On Oven Samples

D.12 Results for Initial Tinting 9C Compared to Initial Tinting of 5880

D.13 9C Room Temperature Aged Overnight Versus Initial 9C Tinting Values

D.14 9C Elevated Temperature Aged Overnight Versus Initial 9C

Tinting Values

D.15 5880 Room Temperature Aged Overnight Versus Initial 5880 
D.16 5880 Elevated Temperature Aged Overnight Versus Initial 5880 Tinting Values

D.17 9C Room Temperature Aged One Week Versus Initial 9C Tinting Values

D.18 9C Elevated Temperature Aged One Week Versus Initial 9C

Tinting Values

D.19 5880 Room Temperature Aged One Week Versus Initial 5880

D.20 9C Room Temperature Aged Two Week Versus Initial 9C

Tinting Values

D.21 9C Room Temperature Aged Two Week Versus Initial 9C

Tinting Values

D.22 9C Elevated Temperature Aged Two Week Versus Initial 9C

Tinting Values

D.23 5880 Room Temperature Aged Two Week Versus Initial 5880

Tinting Values

D.24 5880 Elevated Temperature Aged Two Week Versus Initial 5880 Tinting Values

D.25 9C Room Temperature Aged Three Week Versus Initial 9C Tinting Values

D.26 9C Elevated Temperature Aged Three Week Versus Initial

9C Tinting Values

D.27 5880 Room Temperature Aged Three Week Versus Initial 5880

92

Tinting Values

D.28 5880 Elevated Temperature Aged Three Week Versus Initial 5880

92 Tinting Values 


\section{LIST OF REACTIONS}

Table $\quad$ Page

1.1 Oxidation Reaction of Aluminum to Form Aluminum Oxide 22

1.2 Oxidation Reaction of Iron to Form Iron III Oxide 23 


\section{LIST OF FIGURES}

Figure $\quad$ Page

Examples of Stormer Type Viscometer (left) and Cone and $\quad 13$ Plate Viscometer (right) Used for This Experiment

Examples of Pencil Hardness Kit and Sward Rocker Hardness 14 Tester

$1.3 \quad$ Ratings System for Adhesion Test Results, ASTM D3359 16

$1.4 \quad$ Q-Lab QUV Accelerated Weathering Tester $\quad 18$

1.5 Schematic of $\mathrm{Al}_{2} \mathrm{O}_{3}$ Passivity Layer on Aluminum Metal 22

2.1 Example of Drawdown Setup Using Vacuum Plate, Drawdown 35 Bar, and Byko Chart 
A - General Formulations for Primer Testing ...............................................................................69

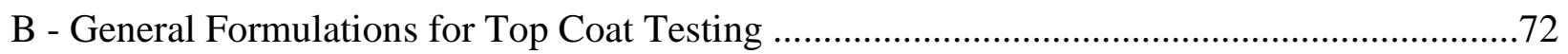

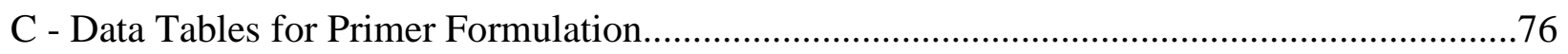

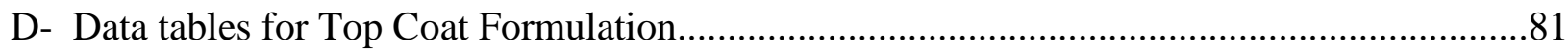




\section{INTRODUCTION}

\subsection{General Coatings Background}

Coating refers to a broad category of substances which are generally considered to be a liquid, are applied to a substrate as a thin film, which dry into a solid film. The uses of coatings are extensive, covering everything from walls and cars, to electrical wires and soda cans. The term coating is a broad term, while paint is used to describe specifically household and architectural coatings.

Paints were probably first used for decorative purposes in cave paintings. The paint used in cave paintings was much simpler than what is thought of as paint today. Substances like charcoal and ochre were used to bring color and shape to paintings on cave walls. Today paint is still used in a purely artistic manner, however it has also come to serve many useful, more practical purposes. (Curtis, 2007)

Different applications of coatings can be seen everywhere, not simply on walls. Coatings allow eye glasses and watches to be scratch resistant. Reflective coatings on the road indicate boundaries between lanes of traffic. Coatings are also used every day by women who wear nail polish, foundation, and mascara. Coatings have many interesting applications both in use and in development. A coating on a spacecraft helps to protect against extreme temperatures, high ultraviolet light exposure, and are highly durable. The medical industry has incorporated antimicrobial coatings on surgical instruments to prevent from infection. Conductive coatings are being developed for applications in printed electronics and photovoltaic panels.

Every day we come into contact with hundreds of coatings and may not even realize it. Below, many aspects of paint including its components, methods of testing, as well as common failures by coatings are discussed. 
The three main uses of paint are to decorate, to protect, or to perform some other functional purpose. The paint applied to cars is used to both provide decoration and to protect the metal of the car from rusting. Some functional purposes of paints include keeping the bottom of ships clear of marine life, providing scratch resistance to lenses, and corrosion prevention on bridges.

\subsection{Components of Coatings}

Modern coatings have four main components: volatile components, binder, pigment and additives. The volatile components of the paint allow a paint to flow during application. After a paint is applied, the volatile components evaporate, leaving behind a dry film. The binder of the paint is the polymer based resin which holds all the components together and forms the dry film. Binders are typically clear when they dry, so pigments are added in order to give the dry film opacity and color. Additives serve a wide variety of purposes and vary greatly between different paints.

The volatile component, or solvent, of paint is the liquid portion which allows the paint to flow during application, and then evaporates during or after the application process. Before 1945, most volatile components consisted of low molecular weight organic compounds. Modern coatings however, have reduced amounts of volatile organic compounds (VOC) due to their negative effects on the environment. Regulations have been established by the United States Environmental Protection Agency (EPA) which limit the amount of VOC in paint, as well as other household products. The California Air Resources Board puts even stricter regulations on VOC in coatings than the national EPA regulations. Many modern paints have reduced the amount of VOC by replacing them with water. Although the amount of VOC in modern paints is often small, they still greatly affect the properties of the final film including: sagging, leveling, adhesion, corrosion resistance, and exterior durability. (Wicks, 2007) 
For many anti-corrosive coatings, an epoxy and polyurethane binder system is used. Unfortunately this system has a high VOC content, largely in part to the incorporation of isocyanates. Alternative binder systems are being studied which could decrease the VOC content of a coating without decreasing its ability to prevent corrosion. One such binder system is an epoxy-siloxane binder. The replacement of urethane with siloxane allows for a reduction in VOC levels due to the high solids content associated with siloxane's low viscosity. Work is still being conducted on this new binder system, however results are promising. Testing of this epoxysiloxane binder show comparable corrosion resistance with exterior exposure testing and accelerated weathering testing. Corrosion testing, including exterior exposure testing and accelerated weathering testing, are discussed in detail later. (Diaz, 2010)

The binder portion of paint is the component which forms the actual solid film, and is typically composed of organic polymers. The binder adheres to the substrate, suspends the pigment, and greatly affects many of the properties of the dry film. Properties that are affected by the binder include the gloss, durability, and toughness of the coating. Both organic and inorganic binders are used. The most popular type of organic binder used is epoxies, but polyurethanes are very popular too. The most common inorganic binders are derived from tetraethyl orthosilicate. (Wicks, 2007)

Latex coatings are waterborne coatings whose binder system consists of emulsified polymers. In an emulsion polymer system, polymers chains are suspended in droplets throughout a solution with the use of amphiphilic surfactants. These surfactants keep the polymer chains separated through electrostatic and steric forces. In electrostatic stabilization, surfactants dissociate and provide an ionic charge on the surface of the droplet. These ionic charges repel each other and stabilize the polymer droplets. A large change in ionic strength with the addition 
of electrolytes can induce coagulation. Latex binders create films through the process of coalescence. After application, the volatile component evaporates, allowing for the emulsified polymers to soften as they are drawn together. As the polymers soften, they combine into a single network, forming a film. All coatings which use a synthetic polymer as a binder are latex coatings. (Anderson, 2003; Marrion, 2004)

One way to categorize other binder systems is by the method by which they form a film. Binders can form films either by drying or curing. Thermoplastics form a coating by drying into a solid film as their solvent evaporates. Thermosets form a coating by undergoing a chemical reaction as their solvent evaporates, and require less solvent. The final film of a thermoset is crosslinked. (Wicks, 2007)

After the binder has dried, they form a clear coating. Pigments are insoluble solid particles that are dispersed throughout the binder. White pigments provide opacity while colored pigments give color to a coating. Pigments also affect properties of the dry film. (Winkler, 2003) The amount of pigments incorporated into a paint affects many properties of the dry film. The pigment volume concentration (PVC) refers to the ratio of pigments and fillers to binder within the dry coating. When pigments are incorporated into a coating, latex particles separate them in a process called wetting. When the concentration of pigments increases beyond the capacity of the binder, voids within the coating are created. The voids incorporated into the coating are defects and weaken the dry film. The concentration at which the binder reaches its maximum wetting capacity, is called the critical pigment volume concentration. (Schuerman, 1989; Tracton, 2006; Marrion, 2004)

Colored pigments work by reflecting some wavelengths of light and absorbing others. White pigments work by scattering light. Titanium dioxide $\left(\mathrm{TiO}_{2}\right)$, is the most commonly used 
white pigment in paint. There are two forms of $\mathrm{TiO}_{2}$ used in coatings, anatase and rutile. The two forms of $\mathrm{TiO}_{2}$ differ only in the crystalline structure. When exposed to heat anatase $\mathrm{TiO}_{2}$ revert to the rutile $\mathrm{TiO}_{2}$ crystalline form. When mining for $\mathrm{TiO}_{2}$ was done, anatase $\mathrm{TiO}_{2}$ was found first and consequently utilized as a pigment first. (Winkler, 2003)

When anatase $\mathrm{TiO}_{2}$ was first used in paints, it was discovered that it promoted chalking. Chalking is the formation of a white powder on the surface of a dry film due to the degradation of a binder. Today the anatase form of $\mathrm{TiO}_{2}$ is used only in small amounts for exterior paints, where chalking can have a self cleaning effect. (Winkler, 2003)

When the rutile form of $\mathrm{TiO}_{2}$ became available, the benefits became immediately popular. Rutile $\mathrm{TiO}_{2}$ does not promote chalking as readily as the anatase form, and scatters light more effectively. (Winkler, 2003)

Fillers, like pigments, are small particles, but do not interact with light. Fillers are much less expensive than pigments, and help to increase the PVC of a paint without significantly increasing the price. The flexibility, mechanical strength, and porosity of a coating can all be positively affected with the addition of fillers. (Gysau, 2006)

The majority of paints consists of the three components previously described, however, small amounts of additives can have profound effects on the final coating. Even minute amounts of additives can mean the difference between a viable paint and a useless paint. The most common additives include biocides, rheology modifiers, and surface active agents.

Microorganisms attack paints in many ways, and can have detrimental effects. When microorganisms attack a paint, many failures can occur. One such failure is fungal growth. Microorganisms can attack thickeners and surfactants causing a paint to decrease in viscosity. As the microorganisms breakdown components of the paint, they produce methane gas, giving 
the coating a bad odor. Not only do microorganism attack wet paint, they continue to attack a coating once it is dry. Fungi and algae can both grow on a dry coatings, causing the coating to fail. The addition of a biocide is crucial to protecting coatings from the problems described above. (Marrion, 2004, Davidson, 2002, Bielman, 2008; Florio, 2004)

Surface active agents is a broad category of additives which affect both the wet paint and dry coating. Surface active agents can help to suspend pigments. Without the use of surface active agents, the dry film can appear seedy. When a dry coating appears to have small clumps of un-dispersed pigment, it is considered seedy. Trapped air within a coating can also be prevented with the use of surface active agents. During the mixing process, air can be incorporated into a paint. Air bubbles trapped within a coating results in voids. These voids within a dry film are weak points. Another thing which surface active agents can affect within a coating, is the dry film's adhesion to the substrate. Surface active agents can work as adhesion promoters. The addition of too much surface active agents can cause negative effects on a coating, such as cratering. (Marrion, 2004, Davidson, 2002, Bielman, 2008; Florio, 2004)

The flow of a paint is very important. Paint must be easily applied to a substrate, but it must also not run once applied. In order to modify a paint's viscosity, rheology modifiers can be added. A shear rate is the rate at which a liquid flows when a shear stress is applied. Paint application has a higher shear rate than paint dripping. When a paint is applied to a substrate a strong force allows the paint to flow into a film. Once applied the force of gravity has too small of a shear force to cause the coating to flow. The addition of rheology modifiers allows a coating to flow easily during application and resist flow after application. (Marrion, 2004, Davidson, 2002, Bielman, 2008; Florio, 2004) 
Above are several common additives found in architectural paints. Many other types of additives exist. For metal substrates, the use of corrosion inhibitors is necessary. Corrosion inhibitors will be discussed in detail later in this paper.

\subsection{Primer and Top Coat Overview}

Protection of the substrate is the main job of a topcoat. Topcoats are designed to protect the substrate from environmental factors such as: weathering, chemicals, dirt, scrubbing, and staining. Once a substrate is painted, the layer of paint acts as a barrier between the substrate and the environment. Each substrate has its own unique set of factors which a coating should protect against. The coating used for a living room wall, for instance, would need high scrub resistant and good color retention. The coating for a car, however, needs to protect against the elements such as ultraviolet light and rain, protect the car from corrosion, and would need to stand up to constant impact from loose particles on the road. Each specific property that a coating must stand up to requires changes within its formulation.

Most architectural top coats are required to be visually appealing, and maintain their appearance for many years. This requirement often limits a top coat's ability to protect a substrate, due to certain additives detracting from decorative properties. In order to mediate the protective needs and decorative requirements of a coating, a primer can be used in addition to a top coat. A primer coat does not have the same decorative requirements, and thus can contain protective additives that would otherwise withdraw from a decorative properties. (Banov, 1978)

Primers are used to pre-coat a substrate before a topcoat is applied. The main task of a primer is to increase the adhesion of the top coat to the substrate, however, primers can also aid in the protection of the substrate. In order to promote good wetting of the substrate, it is important for the primer to have a lower surface tension. The adhesion of the primer to the 
substrate is increased when a primer has a low viscosity as well as a low drying/curing rate. A low viscosity and slow drying/curing allows time for the primer to work its way into cracks and crevices within the substrate. (Wicks, 2007)

Primers are used to increase the adhesion of the topcoat, enhance the topcoat durability, and add an extra layer of protection to the substrate. Good adhesion between the top coat and primer can be promoted with a high PVC. When a coating has a PVC that is at or slightly above the critical PVC, the coating will have low gloss and a rough surface. For primers used on metal substrates, a PVC that is below the critical PVC is desired in order to maintain low permeability. A primer with a rough surface has a larger surface area for the top coat to adhere to. (Wicks, 2007; Florio, 2004; Marrion, 2004; Bielman, 2008)

Primers not only aid in top coat adhesion and substrate protection, they can also aid in the hiding of the substrate. Although primers are not meant to be seen, tinting them can help reduce the number of layers of top coat needed. (Wicks, 2007; Banov, 1978)

The components of coatings, as well as the different attributes of top coats and primers have been discussed in detail. Unfortunately, over time, coatings fail. The failure of a coating can mean loss of protection to the substrate or loss of its decorative function. Below are some common failures seen in coatings.

\subsection{Common Failures of Coatings}

The failure of a coating can mean many things, and the cause of coating failures can come from many sources. The failure of a coating can come from many sources including an improperly cleaned substrate, an improperly used coating, or environmental exposure. An 
improperly used coating is a coating which is designed for one purpose but utilized for a different purpose.

Many environmental aspects can cause a coating to fail. One very common source of failure is water. For a two-layer coating system, a mismatch in the permeability of water can cause premature corrosion. If the permeability of a top coat is lower than the permeability of a primer, water can gets trapped below the top coat, resulting in corrosion. One main reason for a difference in permeability between the two layers of a coating system is the PVC. A higher PVC increases the rate of permeability of water. Thus if a top coat has a higher PVC than a primer, water becomes trapped within the primer layer. In order to prevent corrosion caused by the permeation of water, the top coat should always have a lower PVC than the primer. A lower permeability for the top coat can also cause mildew, peeling, and blistering. (Banov,1978; Orr 1998; Gysau, 2006)

Along with a coating's ability to allow water to permeate through it, a coating can also absorb water if it contains hydrophilic materials. The absorption of water can cause blistering as well as the loss of water soluble components from the coating. As water is absorbed and unabsorbed by the coating, water soluble additives can be released. The voids created by the loss of water soluble components are weak spots in the coating, and work as pores to allow for more water permeability through the coating. (Banov,1978; Orr 1998; Gysau, 2006)

Although permeability and absorption of water can cause damage to a coating, they can also be beneficial. Substrates that are porous benefit from having a coating which is permeable or can absorb water. Also, coatings which are in an environment that is often humid, such as laundry rooms and kitchens, can benefit from having coatings which absorb some of the excess 
moisture in the air and release it once the humidity has gone down. (Banov,1978; Orr 1998; Gysau, 2006)

Chalking is the deterioration of the binder and is caused by the exposure of a coating to moisture, ultraviolet light, and heat. Chalking occurs when the binder of a coating is oxidized, resulting in a white powder. The presence of anatase $\mathrm{TiO}_{2}$ can help to accelerate the process. Chalking can be useful in exterior coating because it can be self cleaning. Chalking, however, is not always uniform and can produce unwanted visual patterns in the coatings. Chalking also leads to a deterioration in a coating's gloss and can change its color. (Banov,1978; Orr 1998; Gysau, 2006)

Corrosion is a very large problem for metal substrates, and is one of the main focuses of this paper. With the proper substrate preparation and a protective coating, corrosion can be prevented. Corrosion is the deterioration of a substrate, usually a metal, through oxidation and will be explained in depth later in this report. Corrosion is a broad term, and several different kinds of corrosion exist. Flash rusting occurs when water comes into contact with metal, such as the application of a waterborne paint, and rusting immediately occurs. During the drying process of a waterborne coating, water soluble rust particles can permeate through the coating, leaving a stain. Additives can be used in a paint which prevent flash rusting from occurring. Flash rust inhibitors work in a sacrificial manner, meaning they prevent corrosion by oxidizing preferentially to the substrate. Sodium nitrite is one example of a flash rust inhibitor. (Schweitzer, 2001; Forsgren, 2006)

Spot rusting is rust that occurs in small quantities and is usually caused by defects within the coating. When a coating has a defect, such as a crack, water is able to come in contact with 
the substrate, and cause localized corrosion. Spot rusting is most commonly found in corners and edges where a coating with low flexibility or impact resistance is likely to fail. Sometimes, spot rusting can be removed with rust cleaner and repainted. (Banov, 1978; Schweitzer, 2001;

Forsgren, 2006)

Corrosion that occurs throughout a coating can often be attributed to improper cleaning of the metal substrate before it was painted. When a metal substrate is not well cleaned before paint application, bad adhesion can occur causing weakness within the coating system. (Banov, 1978; Schweitzer, 2001; Forsgren, 2006)

Surface defects are sometimes a sign of a coating failing on both a decorative and protective level. Cracks within a coating's surface can appear in many different forms. General cracks are considered cracks in which at least one entire top coat layer has been breached. Cracks which do not penetrate one entire topcoat layer are considered hair cracks. Cratering is caused by low surface tension impurities being introduced during the drying process. Lifting is seen when there is more than a single layer of coating. As the multiple layers become incompatible, the top coat will lift off from the coating underneath. Incompatibility between coating layers can be caused by the bottom coat not being completely dry or general incompatibility between two different coatings. (Banov, 1978; Schweitzer, 2001; Forsgren, 2006)

Many other coatings failures exist, however the important failures have been detailed. Coatings manufacturers want to produce a product that resist failure as long as possible. Below are several common testes used by manufacturers on coatings. 


\subsection{Methods for Testing Coatings}

Paint manufacturers test their products in many ways during the formulation and production processes. ASTM and other standard test methods have been established in order to keep testing consistent between different sources. Some coatings laboratories also develop their own test methods, or make adjustments to ASTM type standard test methods, which better suite their laboratories. (Weldon, 2009; Koleske, 1995)

The viscosity of a paint indicates not only how it will flow during application, but can also indicate some mistakes that occur during the production process. Although the viscosity of paint changes with different shear rates, two standard shear rates are commonly tested in the laboratory. High shear viscosity is commonly measured using a cone and plate viscometer according to ASTM D4287. Low shear viscosity is measured with a stormer-type viscometer according to ASTM D562. High shear viscosity relates to how a paint flows during application while low shear viscosity indicates a wet film's properties after application. Leveling and sag are two commonly tested properties of a drying paint. Leveling is a paints ability to create a smooth surface after application, while sag indicated the maximum thickness a coating can produce without gravity causing it to drip. 

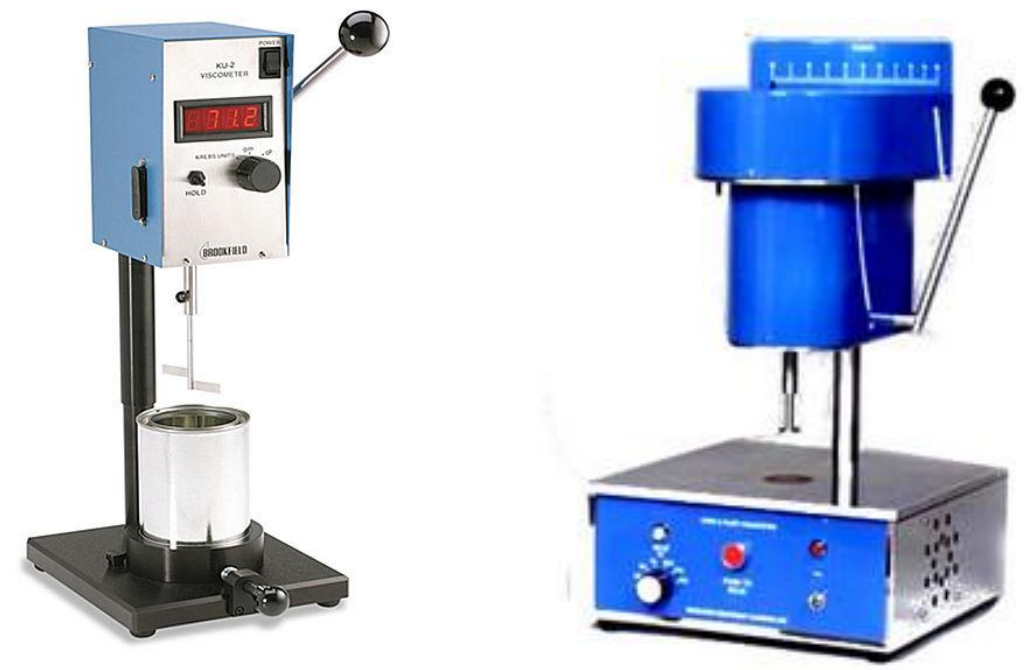

Figure 1.1: Examples of Stormer Type Viscometer (left) and Cone and Plate Viscometer (right) Used for This Experiment (Direct Industry, n.d.)

The density of a paint is another important property which can indicate if a mistake was made during the production process. Density is measured used a pycnometer. A pycnometer is a small cup with a specific volume. When the pycnometer is filled with paint, the mass of the paint used to fill the cup measured in grams is the weight per gallon of the paint, sometimes off by a factor of ten or 100, depending of the size of pycnometer used. A standard test method for measuring density is ASTM D1475.

The gloss of a paint can be measured at many angles, however the most common angles are $20^{\circ}, 60^{\circ}$, and $85^{\circ}$. A standard test method for measure gloss is ASTM D523. The gloss of a dry coating is commonly measured using a gloss meter and indicates the relative reflectiveness of the coating.

The ability of a coating to create a smooth film is very important. If a dry coating has defects or cracks, then the coating cannot adequately protect the substrate. Coalescence of a latex 
is tested by creating a thick film and allowing it to dry at either room temperature or at a low temperature. A smooth surface in the dry film indicates a coating has a good ability to coalesce. The presence of cracks in the dry coating indicate the coatings has bad coalesce. A standard test method for coalescence is ASTM D7306.

A coating's hardness can be tested with the pencil hardness test or the sward rocker hardness test among others. The pencil hardness test involves using pencils with leads of varying hardness and pushing them into the surface of the paint. The softest pencil which does not leave a scratch in the coatings surface is the rated hardness of the coating. ASTM D3363 is a standard test method for pencil hardness testing. The sward rocker hardness test involves counting the number of oscillations a standard sward rocker instrument makes on the coating after being tipped to a certain angle. The harder the coating, the more the rocker will oscillate. The number of oscillations before the rocker comes to a standstill determines the hardness of the coating. A standard test method for the sward rocker test is ASTM D2134.
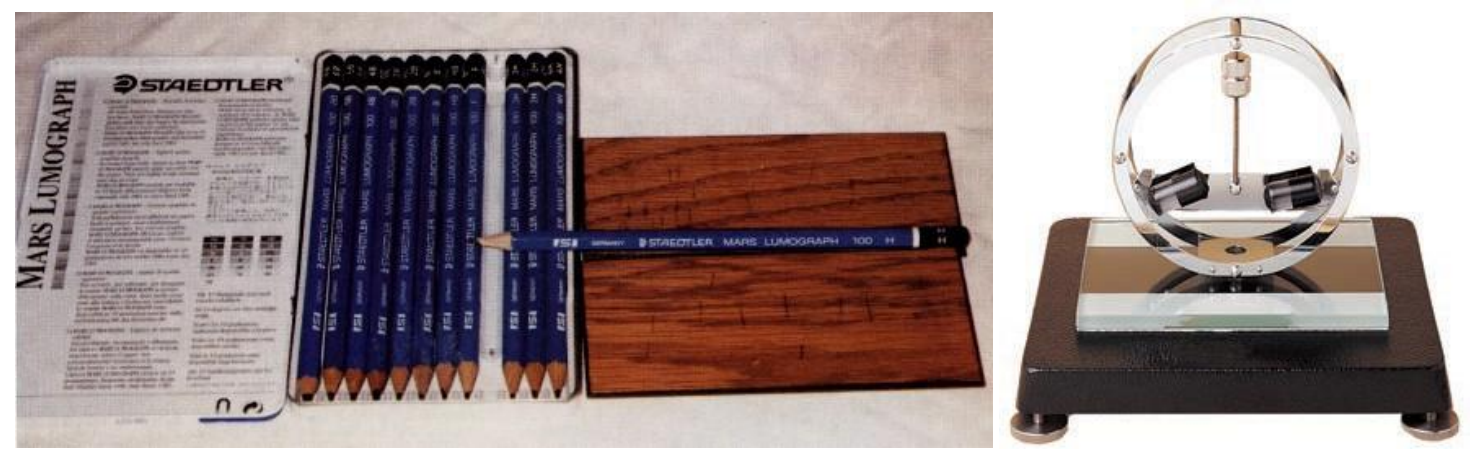

Figure 1.2: Examples of Pencil Hardness Kit (left) and Sward Rocker Hardness Tester (right). (The Pencil Pages, 2002; Gardco Company, n.d.)

The impact resistance is a measurement of a coatings ability to withstand a sudden impact without deformation. One test for impact resistance involves a 2 or $4 \mathrm{lb}$ weight being dropped 
onto the coating from a specific height. After impact the coating should show no signs of flaking, cracking, or deformation. The Gardner Heavy Duty Variable Impact Tester is a machine built to guide the weight onto the coated panel. A standard test method for impact resistance is ASTM D1709.

The adhesion of a coating is tested by making 6 or 11 parallel cuts into the surface of the coating and then 6 or 11 more parallel cuts perpendicular from the original cuts, creating a checker board pattern with 25 or 100 squares. A piece of adhesion test tape is then pressed into the film and torn off rapidly. The adhesion of the coating to the substrate is rated by the amount of coating left on the grid of squares. For adhesion testing, a cross cut adhesion tool can be used. A standard test method for this test is ASTM D3359. The ratings system for judging adhesion is also contained in ASTM D3359. (Lucas, 2011) 
ISO Class: 0/ASTM Class: 5B

The edges of the cuts are completely smooth; none of the squares of the lattice is detached.

ISO Class: 1/ASTM Class: 4B

Detachment of small flakes of the coating at the intersections of the cuts. A crosscut area not significantly greater than $5 \%$ is affected.

ISO Class: 2/ASTM Class: 3B

The coating has flaked along the edges and/or at the intersections of the cuts. A cross-cut area significantly greater than $5 \%$, but not significantly greater than $15 \%$, is affected.

ISO Class: 3/ASTM Class: 2B

The coating has flaked along the edges of the cuts partly or wholly in large ribbons, and/or it has flaked partly or wholly on different parts of the squares. A cross-cut area significantly greater than $15 \%$, but not significantly greater than $35 \%$, is affected.

ISO Class:4/ASTM Class: 1B

The coating has flaked along the edges of the cuts in large ribbons, and/or some squares have detached partly or wholly. A cross-cut area significantly greater than $35 \%$, but not significantly greater than $65 \%$, is affected.

ISO Class: 5/ASTM Class: OB

Any degree of flaking that cannot even be classified by classification 4 .

Figure 1.3: Ratings System for Adhesion Test Results, ASTM D3359

A coating's ability to resist the permeability and absorption of different substances is also an important characteristic to test. An immersion test involves immerging coated glass with slits cut into the coating, into water. Good immersion resistance is indicated by a smooth film adhering to the glass substrate. The presence of blistering and delaminating of the coating from the glass plate indicates a coating's lack of water resistance. A standard test method for testing 
water immersion is ASTM D714. Blistering results for water immersion can be rated according to ASTM D870.

Chemical resistance can be tested in many ways, depending on the environment intended for the coating. Two ways in which chemical resistance can be tested are with immersion or by placing a small amount of the chemical onto the coating for a set period of time. For solvent immersion, the coating is tested in the same manner as water immersion testing. For nonimmersion testing, the coating is exposed to a chemical for a set period of time, the coating is cleaned, and then tested for softening, blistering, loss of gloss, and discoloration. Results are rated on a scale of $1-5$, where 5 is no effect seen. A standard test method for evaluating resistance to chemicals is ASTM D3730.

For coatings which are intended for metal substrates, it is important to test for corrosion resistance. There are many test methods which are intended to reproduce weathering conditions at an accelerated rate, however none are capable of accurately describing how a coating will endure in natural weathering. Accelerated weathering is best used for comparison purposes. Exposure to excessive ultraviolet light and high humidity is one way of testing a coating. A QUV accelerated weathering testers sold by Q-lab is the most common accelerated weathering tester . The QUV instrument exposes coatings to high levels of ultraviolet light, high temperatures, and high humidity conditions. The Q-Panel is a panel made from cold rolled steel, and made specifically for testing in the QUV accelerated weathering test chamber. The company Q-lab also manufactures these Q-Panels. Other similar panels are sold, however all testing for this project was done using Q-lab Q-Panels. In order to test a coating's resistance to UV light and high humidity, a Q-Panel is coated and allowed to dry for one week. After drying for one week, the gloss measurements of the coating are recorded, the edges of the panels are taped off using anti- 
corrosion tape, and the panel is placed in the QUV accelerated weathering machine. After a predetermined amount of time, the Q-Panel is removed, the gloss measurements and any defects are recorded. The Q-Panel can then be placed back into the QUV accelerated weathering tester, for further testing. A standard method for testing accelerated weathering using a QUV accelerated tester is by ASTM D4587. A standard test method for using the QUV accelerated tester in conjunction with a Salt Spray Testing Machine is ASTM D5894. A salt spray tester is a chamber which creates an environment with high humidity and salt content in order to induce corrosion at an accelerated rate.

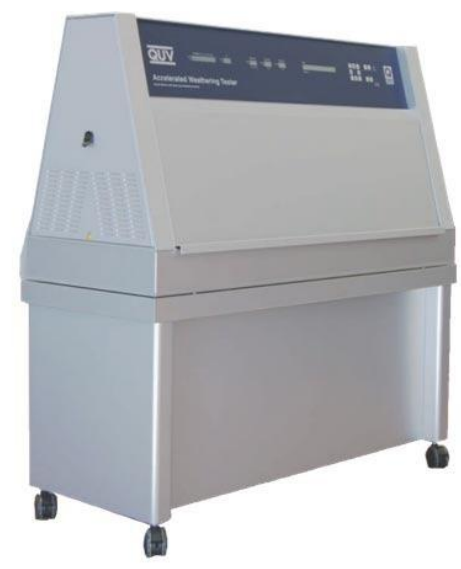

Figure 1.4: Q-Lab QUV Accelerated Weathering Tester (Premier Colorscan, n.d.)

Another way to compare how two different coatings will resist corrosion is with an exterior exposure test. Coatings are prepared in the same manner for an exterior exposure test as they are for a QUV accelerated weathering test. Q-Panels are coated, aged for a week, and the edges of the Q-Panel are taped off using anti-corrosion tape. After aging for one week the gloss of the coating is recorded before the Q-Panel is placed on the roof of a building, or another exterior location. A roof of a building is typically used because it contains the least amount of 
shadows which would reduce exposure. Exterior exposure tests should be run on the roof of building where no shadows will reduce their exposure to sunlight. After a pre-determined period of aging, the panels are removed, their gloss measurement recorded, and any signs of weathering noted. Panels can then be returned to the roof top for further testing. For this type of exterior exposure testing, exposure is dependent on location and weather, and thus only comparisons between two coatings tested at the same time in the same location can be done. For a more severe exterior exposure testing, Q-panels can be sent to areas of extreme weather. Within the United States, testing locations include Florida and Arizona.

\subsection{Corrosion}

This study focuses on improving the corrosion resistance of coatings applied to metal substrates. Corrosion is the degradation of a substrate through oxidation. In the United States alone, corrosion costs over one trillion dollars in 2012 (G2MT, n.d.). With corrosion being such a large problem, many resources are spent in order to better understand and better prevent corrosion.

\subsubsection{Overview of Corrosion}

Corrosion is "a chemical or electrochemical reaction between a material, usually a metal, and its environment that produces a deterioration of the material and its properties." (ASTM International, n.d. ) Corrosion requires four things: an anode, a cathode, an ionic current path, and an electrical path. Corrosion is a four step process which starts with metal atoms releasing electrons and becoming metal ions. The electrons then travel from the anode, through the ionic current path, to the cathode. The electrons then reduce a different metal or metal ion at the cathode. The positive charge created at the anode is then transferred along the electrical path, completing the circuit. The method by which corrosion is described here is very generic, and 
many specific forms of corrosion exist. Several specific forms of corrosion are detailed below. (Schweitzer, 200; Forsgren, 2006)

Uniform corrosion occurs when the entire surface of a material experiences a uniform loss of thickness due to corrosion. Metals which do not have passivity tend to undergo uniform corrosion. Passivity is the tendency of a metal to form a layer of oxidized metal at its surface that does not dislodge from the bulk, and acts as a protective layer. The most common form of corrosion is uniform corrosion. Conveniently, the rate of destruction can be calculated, and therefore, the lifetime of the metal undergoing uniform corrosion can be determined. (Schweitzer, 2001; Forsgren, 2006)

Pitting corrosion is characterized by narrow circular pits with a radius equal or less than the depth of the pit. Pitting corrosion is most commonly found in aluminum, because it forms a passive layer. When an aggressive anion penetrates via an irregularity in the passive film, a pit is formed. An environment with close to neutral $\mathrm{pH}$ and aggressive anions promotes pitting. (Schweitzer, 2001; Forsgren, 2006)

Crevice corrosion occurs when a crack in the substrate becomes large enough for liquid to penetrate. Once water is able to penetrate a crack, oxidation within the crack will occur. Galvanic corrosion occurs when two metals of different anodic index are in contact within an electrolytic solution. The anodic index of a metal is the voltage created between that metal and gold. An electrolytic solution is any solution which can carry a charge. One common electrolytic solution is salt water. Other types of corrosion exist and are specific to the environment in which the substrate exists. (Schweitzer, 2001; Forsgren, 2006) 
There are many methods that can be utilized to prevent corrosion of a metal substrate. Many anti-corrosion additives have been developed for the use in coatings for metals. The pigment zinc phosphate has some anti-corrosive properties and is commonly used for protection of steel. The best corrosion inhibitor on the market is hexavalent chromium, utilized in the form of hexavalent chromium compounds. Hexavalent chromium is such a good corrosion inhibitor that it is used in aerospace coatings; however the high level of toxicity produced by hexavalent chromium is an area of concern. Hexavalent chromium is highly water soluble, which makes leaching from coatings a large problem. Once hexavalent chromium is leaked into the environment, environmental cleanups are needed to mediate the damage. Hexavalant chromium is also a known carcinogen. Due to its many adverse effects on both people and the environment, many regulations have been established limiting hexavalent chromium's use. (Guertin, 2004)

\subsubsection{Corrosion of Aluminum}

Aluminum became very popular in the $20^{\text {th }}$ century with the mass production of aluminum car engines, conductive wiring for energy networks, and air planes. Aluminum is light weight, conductive, and resistant to corrosion - all of which allows it to have many household applications. Aluminum is found in mirrors, cooking utensils, and serving trays. In today's market, aluminum is second only to steel as the most common metal used in manufacturing. Aluminum also lends itself to many alloys of varying strength and flexibility. (Davis, 1999;

Ghali, 2010) 


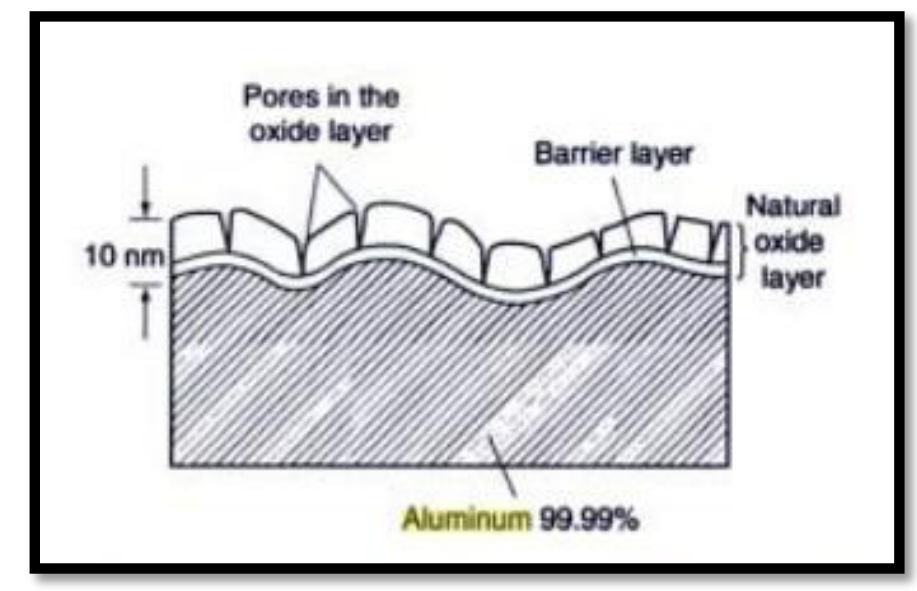

Figure 1.5: Schematic of $\mathrm{Al}_{2} \mathrm{O}_{3}$ Passivity Layer on Aluminum Metal (Davis, 1999)

Generally aluminum is very resistant to corrosion, even in environments of seawater, most chemicals, and foods. The anti-corrosive properties of aluminum come from the production of aluminum oxide at its surface. When aluminum oxide is formed, it does not flake off exposing the layer of pure aluminum underneath, but rather acts as a layer of protection for the underlying aluminum. The chemical reaction by which aluminum is oxidized into aluminum oxide is shown below. (Davis, 1999; Ghali, 2010)

$$
4 \mathrm{Al}+3 \mathrm{O}_{2} \rightarrow 2 \mathrm{Al}_{2} \mathrm{O}_{3}
$$

\section{Reaction 1.1: Oxidation Reaction of Aluminum to Form Aluminum Oxide}

When corrosion of aluminum does occur, it is usually localized and caused by pitting or contact with other conductive metals. Large scale corrosion of aluminum is very rare and typically occurs only in environments of high acidity or alkalinity, or when the protective aluminum oxide is soluble in the surrounding environment. (Davis, 1999; Ghali, 2010) 


\subsubsection{Corrosion of Iron}

The metal iron has been used since ancient times. Iron is a soft metal, but can be strengthened with the addition of certain impurities. For instance adding between $0.2 \%-2.1 \%$ carbon can increase the strength of iron by 1000 times, creating the alloy steel. Iron is the most widely used metal in the world because of its low cost and high strength properties (when used as steel). Iron is used in the production of automobiles, ship hulls, buildings, and many other products. (Revie, 2008)

Rust is a generic term used to describe the corrosion of iron. When iron reacts with oxygen and water, it creates iron oxide. Several forms of iron oxide exist, and can be differentiated visually. Iron II hydroxide has a greenish color. Iron III oxide $\left(\mathrm{Fe}(\mathrm{OH})_{3}\right)$ is the red flaky solid associated with the word rust. Unlike aluminum, the layer of oxidized iron does not protect the underlying iron, but flakes off and exposes the remaining bulk iron. The chemical formula for the production of Iron III Oxide is shown below. (Revie, 2008)

$$
4 \mathrm{Fe}+3 \mathrm{O}_{2}+6 \mathrm{H}_{2} \mathrm{O} \rightarrow 2 \mathrm{Fe}_{2} \mathrm{O}_{3} \cdot 3 \mathrm{H}_{2} \mathrm{O}
$$

\section{Reaction 1.2: Oxidation Reaction of Iron to Form Iron III Oxide}

\subsection{Difficulties in Coating Metal Substrates}

For this study several common metals were used for testing. Cold rolled steel was used for testing corrosion resistance of coatings as well as adhesion. Adhesion testing was also conducted on aluminum and several different galvanized steel panels. Below is a description of the common metals used in this study, as well as some of their properties.

Steel which is rolled into a sheet at room temperature is called cold rolled steel. Performing this process at room temperature creates a stronger metal and smoother finish. Steel 
is very easily oxidized, and thus is often sold with a protective layer of oil applied. Before steel can have a protective coating applied, this oil must be removed or proper adhesion cannot be achieved. Once cold rolled steel has been properly cleaned, adhesion of a protective coating should be easy, however improper cleaning can result in bad adhesion between the coating and substrate.

The most abundant metal in the Earth's crust, aluminum, is malleable, durable, and is resistant to corrosion. Aluminum has many uses including applications in transportation, construction, packaging, as well as many other areas. When exposed to air, aluminum reacts to form a thin layer of aluminum oxide, which is bonded to the aluminum body. This thin film of aluminum oxide prevents further oxidation of the remaining aluminum. General corrosion of aluminum only occurs in highly acidic or alkaline environments. Properly cleaned and prepared aluminum is a good surface for the adhesion of coatings. Although a topcoat can be applied directly to aluminum, better performance can be obtained with the use of a primer. (Davis, 1999)

Galvanized steel is steel metal with a zinc coating. The zinc acts as a corrosion inhibitor by forming a chemical bond with the steel and creating a passive layer. The process of galvanizing steel helps to increase the corrosion resistance. Galvanized steel is a common architectural metal that is used in things such as: gutters, roofs, and ducts. When exposed to weathering, the zinc becomes oxidized. Painting galvanized steel in order to protect it from weathering can be difficult. If the galvanized surface is too smooth or covered in oil, it can prevent proper adhesion of the paint. In order to improve adhesion, some galvanized steel is also treated with a coating which improves adhesion. Hexavalent chromium is sometimes used to prevent the oxidation of zinc on galvanized steel, but does not provide good adhesion, cannot be painted, and also has toxicity issues. Alkyd primers are not recommended for painting 
galvanized metals because the zinc will react with fatty acids, reducing adhesion over time.

(Guertin, 2004; Revie 2008)

One study compares silane pretreated steel substrates to the typical phosphate pretreated steel substrates. Different silane solutions were used to pretreat steel substrates, which were then covered with an alkyd/polyester aminoplast based paint. Results indicated that certain silane pretreatments had comparable effectiveness at preventing corrosion to typical phosphate pretreatments. (Chico, 2012)

\subsection{Corrosion Inhibitors}

Any paint which is used to coat and protect a metal substrate must protect against corrosion. Corrosion inhibitors represent a broad category of paint additives which help to prevent the corrosion of metal substrates. The addition of corrosion inhibitors is used in both primers and top coats. Corrosion inhibitors protected against oxidizing agents such as: oxygen, carbon dioxide, and hydrogen sulfide. (Florio, 2004; Forgren, 2006; Bieleman, 2008, Sastri 1998)

Corrosion inhibitors currently on the market include flash rust, inorganic based, organic based, and hybrid corrosion inhibitors. When metal is exposed to water, rust can form within minutes. This kind of quick oxidation is called flash rusting. Flash rusting is a particular problem for waterborne coatings used for metals. When a waterborne coating is applied to a surface, flash rusting can occur while the coating is drying. Without the presence of flash rust inhibitors, the rust particles can migrate to the surface of the coating during the drying process. Flash rust inhibitors work by preventing corrosion sacrificially, while the coating is drying. Examples of 
flash rust inhibitors include ammonium benzoate, sodium nitrite, and aminocarboxylate salt. (Florio, 2004; Forgren, 2006; Bieleman, 2008, Sastri 1998)

Although inorganic corrosion inhibitors are highly effective, toxicity issues have caused their use to be regulated. In particular the use of lead and hexavalent chromium compounds are slowly being phased out of coatings. Less toxic metal pigments however, can still be used. Some examples of less toxic inorganic corrosion inhibitors are calcium phosphate, zinc phosphate, and inorganic nitrite salts. (Florio, 2004; Forgren, 2006; Bieleman, 2008, Sastri 1998)

New regulations on coatings occur all the time. This constant increase in regulations drives the development of new additives which can meet regulations, without compromising a coating's performance expectations. Since inorganic corrosion inhibitors are being phased out, the development of organic corrosion inhibitors is necessary. In addition to anti-corrosive properties, organic corrosion inhibitors can also help to improve adhesion of the coating. Some examples of organic corrosion inhibitors on the market include amines and nitrite salts. (Florio, 2004; Forgren, 2006; Bieleman, 2008, Sastri 1998)

Combinations of inorganic and organic corrosion inhibitors can also be used. The combination of two anti-corrosion mechanisms in a single additive package boosts the effectiveness. Since organic corrosion inhibitors are less cost effective, the use of a hybrid corrosion inhibitor provides the most economic system. In particular, the combination of anticorrosive pigments with organic corrosion inhibitors offers comparable corrosion resistance to inorganic corrosion inhibitors. (Florio, 2004; Forgren, 2006; Bieleman, 2008, Sastri 1998)

One study showed that the renewable polymers, exopolysaccharides, could also be used as anti-corrosive additives. This type of additive could be used alternatively of zinc phosphate. 
Exopolysaccharides is thought to work by forming a protective layer on metal substrates from a carboxylic acid group and oxidized iron complex. (Scheerder, 2012)

\subsection{Project Overview}

A two part project involving anti-corrosion coatings was conducted. In the first part, the corrosion resistance of a "universal" primer sold by Kelly-Moore Paint Company was improved. In the second part, the adhesion of a "direct-to-metal" top coat was improved.

\subsubsection{Primer}

Initially it was thought that the addition of corrosion inhibitors to the "universal" primer formulation would be sufficient to increase its corrosion resistance. A "universal" primer is intended for a variety of architectural applications, not for use on automobiles or aircrafts. The three different corrosion inhibitors tested were all corrosion inhibitors already utilized in other Kelly-Moore Paint Company formulations. Sodium nitrite, an inorganic corrosion inhibitor, works by forming a chemical bond with the metal substrate which acts as a protective layer and works sacrificially. In environments with heavy flow of air or water, the nitrite is oxidized to nitrate and becomes useless as a corrosion inhibitor. An aminocarboxylate salt was also used in combination with sodium nitrite. The organic aminocarboxylate salt works as both a flash rust and corrosion inhibitor. The final corrosion inhibitor tested was zinc phosphate based, and used in combination with sodium nitrite and the aminocarboxylate salt. The inorganic zinc phosphate corrosion inhibitor was an anti-corrosion pigment which works by precipitation and anodic passivity. Anodic passivity occurs when the corrosion inhibitor oxidizes more readily than the metal substrate. Precipitation corrosion inhibitors work by forming a thin protective film on the substrate, thereby protecting oxidants from coming in contact with the substrate. 
It was later discovered that the latex utilized in the "universal" primer system had inadequate adhesion to wood substrates. The latex used in a metal primer system was then incorporated into the "universal" primer formulation. The final formulation combined the pigments and fillers from the original formulation, the latex from a metal primer formulation, and the sodium nitrite and zinc phosphate corrosion inhibitors. The newly developed "universal" primer system was tested and shown to be superior to the original "universal" primer system.

\subsubsection{Top Coat}

Kelly-Moore Paint Company sells many different coatings. Their research laboratory constantly tests new ways to improve their products already on the market, as well as develop new and better coating products. The direct-to-metal top coat system for metal substrates, formulation 5880, was tested in order to improve its adhesion. A direct-to-metal top coat is intended to provide adequate protection for metal substrates without the incorporation of a primer. The use of a primer in addition to the 5880 top coat, can be used to improve the coating system.

Five new binder systems were tested. Each binder system was incorporated into the 5880 formulation. Once a formulation was made, testing was conducted. If a weakness was discovered, changes in the formulation were made. In order to create a better formulation, typical laboratory procedures were followed. If a particular weakness in a coating could not be overcome, it was no longer considered. The formulations were tested for adhesion, water immersion, QUV accelerated weathering resistance, and exterior exposure resistance. After all testing was complete, no formulation developed was superior to the original direct-to-metal formulation. 


\section{METHODS AND MATERIALS}

This study used many techniques in order to improve the performance properties of two coatings. The two formulations were studied simultaneously and in similar manners. The corrosion resistance of a "universal" primer formulation was improved with the addition of corrosion inhibitors. The adhesion of a top coat formulation intended for metal substrates was also improved.

First is the generic formulation of the top coat formulation. A description of how this formulation is made is included. Generic formulations for some primer formulations can be found in Appendix A. Generic formulations for top coat formulations can be found in Appendix B. All other formulations were made similarly as described below, following their particular formulation.

Once formulated, each coating was tested. No specific order of testing was followed. A description of each test conducted is included below. Also included is a list of each formulation made along with the specific tests performed on them. 
Table 2.1: Generic Formulation of 5880

Grind

Water

Dispersant 1

29\% Ammonia

Surfactant A

Dispersant 2

Rheology Modifier A

Biocide

Anti-Foamer

Titanium Dioxide Slurry

Let Down

Latex A

Water

Coalescent

Corrosion Inhibitor 2

Premix A

Premix B

Rheology Modifier B

Rheology Modifier C

Surfactant B

Defoamer

Water lbs

49.98

14.62

3.00

2.15

0.50

17.40

1.50

1.65

200.27

552.45

8.33

32.31

10.01

17.66

26.43

17.34

0.09

0.50

3.78

67.21

1027.18
Premix A

Water 16.66

Corrosion Inhibitor 1

1.00

Premix B

cross linking agent

10.10

Water

16.33

PVC

15.58

Solids by Weight (\%) $\quad 48$

Solids by Volume (\%) $\quad 38$

Weight per Gallon (lbs.)

9.9 


\subsection{Coatings Formulation}

Once a formulation was decided upon, all components were gathered. All materials were provided by Kelly-Moore Paint Company. The formulation described below is Kelly-Moore Paint Company's 5880 High Performance Acrylic Gloss Enamel. The balance used to measure all components for this experiment was a Denver Instrument's XE3100D. All mixing was done on a Delta brand drill press with a dispersion blade attachment.

First, components of the grind were weighed out and added into a 1 gallon steel beaker. The grind included water, as a volatile component for the system. Dispersant was added in order to help wet-out dry pigments and fillers. Ammonia was added in order to change the $\mathrm{pH}$ of the formulation. Surfactant was added to decrease surface tension, increase the shelf life of paints, and increase the wetting ability of the final formulation. In order to prevent the incorporation of excess air, an anti-foamer was added. A biocide was added to the grind in order to prevent bacteria from destroying the wet paint as well as protect the dry coating from algae and fungi. The key component of a grind is titanium dioxide, which is the white pigment. In other formulations, fillers are also incorporated at this point. Once all components of the grind were added into the steel beaker, they were mixed at a high rate for thirty minutes. After thirty minutes, a stainless steel Hegman-Type gage was used to measure the fineness of grind according to ASTM D1210. If the grind was rated 3 Hegman units or higher, than the let down portion can be added. If the grind is not rated at 3 Hegman units, then mixing is continued at a high rate until a grind of 3 Hegman units is obtained.

The same formulation was followed both in the research lab and on the manufacturing scale. At the manufacturing scale, the grind was made in a tank located above the let down tank. 
Once the grind was complete, gravity was used to feed it into the let down tank, which already contained binder and water. Water was then used to rinse any leftover grind from the grind tank. In a lab scale formulation, the binder was added directly into the grind under low speed mixing. The water portion of the let down was also added directly in the steel beaker containing the grind, under low mixing speed. Once the let down of the formulation was added, the formulation was mixed at low speed until the formulation looked homogenous.

The next four components of the 5880 formulation were added straight into the steel beaker while mixing at a medium speed. Coalescent was added in order to create a smooth final coatings. Defoamer was added in order to allow for trapped air within the formulation to escape more easily.

Before the corrosion inhibitor, sodium nitrite, was added, it is premixed with water for two minutes (Premix A). The addition of sodium nitrite solution was done while mixing at medium speed. At this point, the formulation was allowed to mix for twenty minutes, before any more additions were made. After twenty minutes the $\mathrm{pH}$ of the formulation was tested. If the $\mathrm{pH}$ of the formulation was below 9, it was raised with ammonia before the next components were added.

While the coating was mixing for twenty minutes, the next two components must be premixed for seven minutes before addition (Premix B). The cross-linking agent was used in order to help increase the dry coating's water resistance, heat resistance, and film hardness. This cross-linker was premixed in order to help with a smooth incorporation within the formulation. Water was then used to rinse the paper cup in which the cross-linking agent was premixed with water. The formulation was then mixed at a high rate for ten minutes. 
After the formulation mixed for ten minutes, the speed of mixing decreased to a medium speed, and the final components were added. Additional surfactant, rheology modifiers, and defoamer were added at this point. Finally more water was added and the formulation was allowed to mix at medium speed for one hour.

All other formulations created for this project were made in a similar manner using the similar materials and equipment.

\subsection{Testing of Coatings}

Once the formulation finished mixing, its low shear viscosity was tested. All low shear viscosity measurements were made using a Brookfield KU-2 viscometer utilizing a KU1-10 Krebs Spindle following ASTM D562. The viscosity was also measured in the same manner after allowing the formulation to age overnight. When a large increase in viscosity was seen, additional viscosity measurement were taken. High shear viscosity was measured after the paint was allowed to rest overnight. For high shear viscosity, a 3900 A7 ICI Cone and Plate Viscometer produced by Research Equipment (London) Limited was used.

Often times during formulation, rheology modifiers were left out. If the low shear viscosity measurements indicated the formulation was too thin, thickeners were added to a portion of the formulation. After thickener was added, the formulation was then shaken, and the viscosity re-tested. Once the low shear viscosity was in an appropriate range as judged by KellyMoore Paint Company's guidelines, further testing was conducted.

Drawdowns are a method of testing a dry coating's properties in a controlled manner. Drawdowns are used in measuring a coating's gloss, adhesion, chemical resistance, hand lotion resistance, as well as many other properties. Many different substrates can be used for 
drawdowns, most commonly Byko brand drawdown charts are used, however metal panels are also used. The thickness of the final drawdown coating depends both on the solid's content of the paint and the thickness value of the drawdown bar used. The higher the solid's content of the paint the thicker the dry film will be. Drawdown bars come in many different thicknesses, lengths, and types. The drawdown thickness refers to the thickness of the wet coating. When the coating dries, the film will decrease in thickness as the volatile component evaporates. All bars used in this experiment were Byk-Gardner stainless steel drawdown bars.

In order to actually make a drawdown, the substrate must be perfectly still. Vacuum plates attached to vacuum pumps are used in order to hold the substrate still while the drawdown is made. If the substrate is too large for a vacuum plate or no vacuum pump is available, tape or clips can also be used. Once the drawdown bar is placed on the substrate appropriately, an excess of paint should be applied. The actual drawdown motion should be a pull with a constantly applied light pressure throughout the drawdown. Once the drawdown is created, the substrate can be transferred and allowed to dry either hanging vertically or laying flat. 


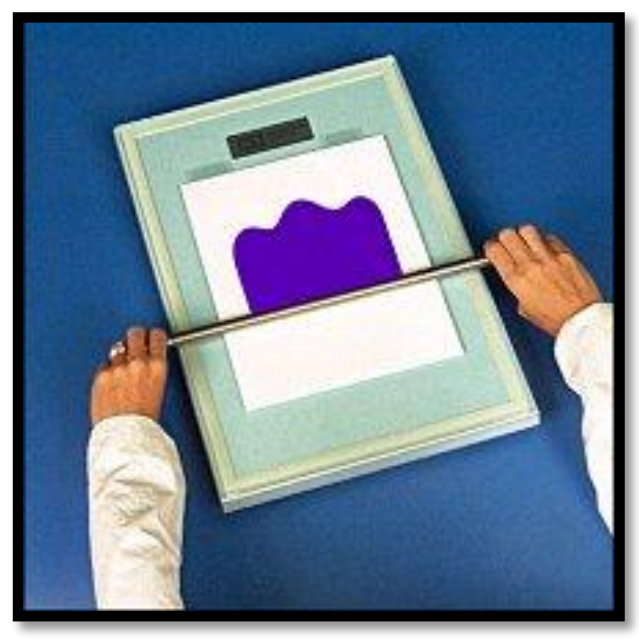

Figure 2.1: Example of Drawdown Setup Using Vacuum Plate, Drawdown Bar, and Byko Chart (Longfield, 2010)

Drawdowns for gloss measurements were often made the same day as the formulation was prepared. All gloss measurements were taken using a Micro-tri-gloss gloss meter on 3 mil drawdowns over penopac 1A Byko charts following ASTM D523.

All other testing was done was conducted once viscosity and gloss measurements were acceptable. Not each formulation was tested with every method discussed below.

Both direct and indirect impact resistance were tested on 3 mil coatings on cold rolled steel (CRS). An impact resistance tester was used, dropping the weight form a height of 20 inches. The resulting deformations created by impact resistance were observed under a microscope and rated based on 5 being good impact resistance and 1 being no impact resistance.

Blocking resistance was tested following ASTM D4946. For block resistance brushout WDX Byko Charts were used with 7 mil drawdowns of the coatings. 
Mud Cracking was tested in accordance to ASTM D7306. For low temperature mud cracking, a 20 mil drawdown was prepared on a Penopac 1A Byko chart. For ambient temperature mud cracking a 50 mil drawdown was prepared on a Penopac 1A Byko chart. Mud cracking was evaluated on a 1-5 scale in which 5 was good coalescence and 1 was the presence of mud cracking throughout the dry film.

Adhesion was tested following ASTM D3359 on 3 mil drawdowns over various substrates. For adhesion a 10x10 cross hatch pattern was cut into the coating using a box cutter and metal plate with 11 parallel slits in it. A cross cut tester is a common tool used for creating the cross hatch pattern for adhesion testing, however, it was not used for this experiment. The tape used for adhesion testing was $3 \mathrm{M}$ brand 600 tape. The results of the adhesion test were judged according to ASTM D3359, in which 5B is near perfect adhesion and 1B is bad adhesion.

All metal panels used were pre-cleaned prior to being utilized. Cold rolled steel (CRS) panels were cleaned first with a degreaser, then with soap and water, and finally with methyl ethyl ketone. All other metals were cleaned with only methyl ethyl ketone. Non-metal substrates were simply wiped with a dry paper towel before use. The metal substrates that were used for adhesion included CRS, galvanized spangled steel (GSS), hot dip galvanized steel (HDG), and electrocoated zinc galvanized steel (EZG), aluminum, and copper. Non-metal substrates included aged alkyl sheets, hardie board, glass, PVC pipe, and tile. Aged alkyl sheets are a prepared in Kelly-Moore Paint Company's research and development lab from an alkyl resin. Hardie board is a cement siding product.

All density tests were performed in accordance with ASTM D1475 using a pycnometer on coatings which had been placed in a centrifuge for five minutes. 
For testing QUV resistance, a Q-lab QUV accelerated weathering tester was used with 8 hour cycles alternating between QUV lamp illumination and high humidity. For exterior exposure, panels were placed on the roof of Kelly-Moore Paint Company's facilities in San Carlos, CA. For both QUV and exterior exposures, 3 mil thick coatings were drawn down on cold rolled steel panels. The edges of the CRS panels and edges between different coatings on the same panel were taped using 3M Scotchrap All-Weather Corrosion Protection Tape.

Water immersion testing was done on 3 mil drawdowns over glass plates. After aging either overnight or for seven days under laboratory conditions, the drawdowns had three lines cut into them using a razor blade in the shape of three sides of a rectangle. The water used for immersion testing was tap water, and the blisters formed were judges according to ASTM D714. The water immersion test was performed in accordance to ASTM D870.

Paints were tinted using Kelly-Moore Paint Company's color system. Once tinted, paints were shaken for five minutes using a Red Devil brand Classic 1400 Twin-Arm Shaker. The tinted paints were then either aged at ambient temperature or in an oven set to $120^{\circ} \mathrm{F}$. To evaluate the tint strength of each coating, 3 mil drawdowns on Penopac 1A Byko charts were tested using a Datacolor 650 instrument. The gloss of each tinted coating was also tested in accordance to ASTM D523.

Each coating that was produced was tested differently. Once a coating failed to meet the expectations of a single test, a resolution to this problem was attempted. If no resolution could be found, no further testing was conducted. The most important tests were conducted first. In this project, corrosion resistance and adhesion were of high importance. Once a coating showed good adhesion and corrosion resistance, further testing was conducted. 


\subsection{Test Methods for Primer Formulation}

Formulations 295, 205A, 205B, and 295ABC.

Viscosity (KU): Initial, Overnight

Gloss: $20^{\circ}, 60^{\circ}, 85^{\circ}$

Adhesion: Aged alkyl (Kelly-Moors Paint Company's specific), CRS, Aluminum, GSS, EZG, HDG

Water Immersion: Overnight Cure, Seven Day Cure

QUV Exposure: Two Weeks

Exterior Exposure: Two Weeks

1725-295:

Density

Viscosity (KU): Initial, Overnight

Viscosity (ICI): Overnight

Contrast Ratio

SAG: 4-24 mils

Low Temperature Coalescence

Mud Cracking: Room Temperature, Low Temperature

Adhesion: GSS, CRS, Aged Alkyl, HDG, EZG, Aluminum, Glass, Tile, PVC Pipe, Wood, Copper

Impact Resistance: Direct, Indirect

Water Immersion: Overnight, Seven Day Cure 
Chemical Resistance: Water, Vinegar, Isoproponal, F409, Ammonia, Windex, Ketchup, Mustard

Hand Lotion Resistance: Vaseline Intensive Care, Baby Magic Lotion, Coppertone, Lubriderm

Exterior Exposure: Two Weeks

QUV Exposure: Two Weeks

New-295:

Viscosity (KU): Initial

Gloss: $20^{\circ}, 60^{\circ}, 85^{\circ}$

Exterior Exposure: Two Weeks

QUV Exposure: Two Weeks

Adhesion: CRS, GSS

Water Immersion: Overnight, Seven Day Cure

\subsection{Test Methods for Top Coat Formulation}

Formulations 1-4: None

Formulation 5:

Viscosity (KU): Initial, Overnight

Gloss: $20^{\circ}, 60^{\circ}, 85^{\circ}$

Mud Cracking: Low Temperature

Block Resistance: Room Temperature, Hot Block

Adhesion: Aged Alkyl, Aluminum, EZG, HDG, GSS, CRS

QUV Exposure: Aluminum (Four Weeks), CRS (Four Weeks) 
Exterior Exposure: Four Weeks

Chemical Resistance: Ammonia, Caustic Soda, F409, Isopropanol, Vinegar, Water, Xylene, Lacquer Thinner, Mineral Spirit, Windex

Hand Lotion Resistance: Vaseline Intensive Care, Baby Magic Lotion, Coppertone, Lubriderm

Formulation 5A:

Viscosity (KU): Initial, Overnight, Two Day, Three Day, Four Day

Gloss: $20^{\circ}, 60^{\circ}, 85^{\circ}$

Density

Formulation 6:

Viscosity (KU): Initial, Overnight

Formulation 7:

Viscosity (KU): Initial, Overnight

Gloss: $20^{\circ}, 60^{\circ}, 85^{\circ}$

Mud Cracking: Low Temperature

Block Resistance: Room Temperature, Hot Block

Adhesion: Aged Alkyl, Aluminum, EZG, HDG, GSS, CRS

QUV Exposure: Aluminum (Four Weeks), CRS (Four Weeks)

Exterior Exposure: Four Weeks

Chemical Resistance: Ammonia, Caustic Soda, F409, Isopropanol, Vinegar, Water, Xylene, Lacquer Thinner, Mineral Spirit, Windex 
Hand Lotion Resistance: Vaseline Intensive Care, Baby Magic Lotion, Coppertone, Lubriderm

Formulation 7A:

Viscosity (KU): Initial, Overnight, Two Day, Three Day, Four Day

Gloss: $20^{\circ}, 60^{\circ}, 85^{\circ}$

Density

Formulation 8:

Viscosity (KU): Initial

Gloss: $20^{\circ}, 60^{\circ}, 85^{\circ}$

Formulation 8A:

Viscosity (KU): Initial

Gloss: $20^{\circ}, 60^{\circ}, 85^{\circ}$

Mud Cracking: Low Temperature

Adhesion: Aged Alkyl, CRS, GSS

Block Resistance: Room Temperature, Hot Block

QUV Exposure: Two Weeks

Exterior Exposure: Two Weeks

Formulation 8B:

Viscosity (KU): Initial, Overnight

Gloss: $20^{\circ}, 60^{\circ}, 85^{\circ}$

Water Immersion: Overnight Cure, Seven Day Cure 
Formulation 9:

Viscosity (KU): Initial

Gloss: $20^{\circ}, 60^{\circ}, 85^{\circ}$

Formulation 9A:

Viscosity (KU): Initial, Overnight

Gloss: $20^{\circ}, 60^{\circ}, 85^{\circ}$

Mud Cracking: Low Temperature

QUV Exposure: Two weeks

Exterior Exposure: Two Weeks

Formulation 9B:

Viscosity (KU): Initial, Overnight

Gloss: $20^{\circ}, 60^{\circ}, 85^{\circ}$

Mud Cracking: Low Temperature

Adhesion: Aged Alkyl, CRS, GSS

Block Resistance: Room Temperature, Hot Block

Water Immersion: Overnight Cure, Seven Day Cure

Formulation 9C:

Adhesion: CRS, GSS

Water Immersion: Overnight Cure, Seven Day Cure

Formulation 9C+:

Water Immersion: Overnight Cure, Seven Day Cure 
Mud Cracking: Low Temperature

Adhesion: CRS, GSS, Aged Alkyl, HDG, EZG, Aluminum, Copper TFS

Tinting: CIE Lab Values, Tint Strength, Gloss, Syneresis, Color Float (3 weeks)

Chemical Resistance: Water, Vinegar, Isopropanol, F409, Ammonia, Windex, Ketchup, Mustard

Hand Lotion Resistance: Vaseline Intensive Care, Baby Magic Lotion, Coppertone, Lubriderm

Formulation 10:

Viscosity (KU): Initial, Overnight

Gloss: $20^{\circ}, 60^{\circ}, 85^{\circ}$

Mud Cracking: Low Temperature

Formulation 10B:

Viscosity (KU): Initial, Overnight

Gloss: $20^{\circ}, 60^{\circ}, 85^{\circ}$

Mud Cracking: Low Temperature

Adhesion: CRS, GSS

Water Immersion: Overnight Cure

Formulation 10C:

Viscosity (KU): Initial

Gloss: $20^{\circ}, 60^{\circ}, 85^{\circ}$

Mud Cracking: Low Temperature 
Formulation 11:

Viscosity (KU): Initial, Overnight, Two Day

Gloss: $20^{\circ}, 60^{\circ}, 85^{\circ}$

Mud Cracking: Low Temperature

Adhesion: CRS, GSS

Water Immersion: Overnight Cure

Formulation 12:

Viscosity (KU): Initial, Overnight, Two Day

Gloss: $20^{\circ}, 60^{\circ}, 85^{\circ}$

Mud Cracking: Low Temperature

Formulation 13:

Viscosity (KU): Initial, Overnight, Two Day

Gloss: $20^{\circ}, 60^{\circ}, 85^{\circ}$

Mud Cracking: Low Temperature

Formulation 14:

Adhesion: CRS, GSS

Water Immersion: Overnight Cure, Seven Day Cure 


\section{RESULTS AND DISCUSSION}

\subsection{Testing of "Universal" Primer Formulation}

Generic formulations for each coating made can be found in Appendix A.

The Kelly-Moore Paint Company's "universal" primer 295 was originally to be tested against "universal" primers supplied by other manufactures as is and with the addition of corrosion inhibitors. Three different corrosion inhibitors were tested; sodium nitrite (A), aminocarboxylate salt (B), and zinc phosphate (C). The percent weight of each corrosion inhibitor to be used was predetermined to be $1 \%, 1 \%$ and $2 \%$ by weight respectively as recommended by their suppliers. In order to combine the stock 295 formulation with the different corrosion inhibitors, around $1000 \mathrm{~g}$ of stock 295 was weighed into a quart sized paint can. Once the exact amount of 295 formulation weighed into each quart was determined, calculations were done in order to determine the amount of each corrosion inhibitor needed. The first formulation combined only Corrosion Inhibitor A with 295, and the new formulation was noted as 295A. The second formulation combined Corrosion Inhibitor A, Corrosion Inhibitor B, and 295 to create the new formulation 295AB. The third formulation combined Corrosion Inhibitor A, Corrosion Inhibitor B, Corrosion Inhibitor C, and 295 to create the formulation 295ABC. The exact amounts of each component within the three new formulation is specified below. Once combined, the new formulations were put in a shaker for five minutes and allowed to age overnight before being tested. 
Table 3.1: Components of 295A, 295AB, and 295ABC

\begin{tabular}{|l|c|c|c|c|}
\hline Coating & $\begin{array}{l}\text { Amount of "Universal" } \\
\text { Primer 295 (g) }\end{array}$ & $\begin{array}{l}\text { Amount of Corrosion } \\
\text { Inhibitor A (g) }\end{array}$ & $\begin{array}{l}\text { Amount of Corrosion } \\
\text { Inhibitor B (g) }\end{array}$ & $\begin{array}{l}\text { Amount of Corrosion } \\
\text { Inhibitor C (g) }\end{array}$ \\
\hline $295 \mathrm{~A}$ & 980.4 & 9.9 & 0 & 0 \\
\hline $295 \mathrm{AB}$ & 1101.5 & 11.24 & 11.24 & 0 \\
\hline $295 \mathrm{ABC}$ & 1045.4 & 10.9 & 10.9 & 21.78 \\
\hline
\end{tabular}

Each formulation was tested for viscosity, gloss, adhesion, water immersion, QUV exposure, and exterior exposure. The adhesion of each formulation was tested on aged alkyl, cold rolled steel (CRS), aluminum, galvanized spangled steel (GSS), electro coated zinc galvanized steel (EZG), and hot dipped galvanized steel (HDG). General results can be found in Table 3.2 below, while full results can be seen in Appendix C, Table C.1-C.3. General results include viscosity and gloss data, the overall adhesion test value, and the blister ratings from water immersion testing. Testing parameters were discussed in detail in previous section. 
Table 3.2: General Testing Results of Formulation 295, 295A, 295AB, and 295ABC

\begin{tabular}{|c|c|c|c|c|}
\hline & 295 & 295A & 295AB & 295ABC \\
\hline \multicolumn{5}{|l|}{ Physical Properties } \\
\hline Viscosity, KU Initial & 105 & 102 & 102 & 109 \\
\hline Viscosity, KU 2 day & 106 & 102 & 103 & 112 \\
\hline Gloss @ 20。 & 1.4 & 1.4 & 1.5 & 1.3 \\
\hline Gloss@60。 & 4.4 & 4.4 & 4.8 & 4.1 \\
\hline Gloss@ @ 85。 & 16.5 & 16.7 & 17.7 & 13.3 \\
\hline \multicolumn{5}{|l|}{ Adhesion } \\
\hline Total (180) & 55 & 50 & 50 & 52 \\
\hline Percentage Adhesion & $30.56 \%$ & $27.78 \%$ & $27.78 \%$ & $28.89 \%$ \\
\hline \multicolumn{5}{|l|}{$\begin{array}{l}\text { Overnight Cure } \\
\text { Water Immersion }\end{array}$} \\
\hline 1 Hour & $8 \mathrm{~F}$ & $8 \mathrm{~F}$ & $8 \mathrm{~F}$ & $8 \mathrm{~F}$ \\
\hline 7 Day & $6 \mathrm{D}$ & $6 \mathrm{D}$ & $6 \mathrm{MD}$ & $2 \mathrm{D}$ \\
\hline Recovery & 10 & 10 & 10 & 10 \\
\hline \multicolumn{5}{|l|}{$\begin{array}{l}7 \text { Day Cure } \\
\text { Water Immersion }\end{array}$} \\
\hline 1 Hour & $8 \mathrm{MD}$ & $6 \mathrm{D}$ & $6 \mathrm{MD}$ & $6 \mathrm{D}$ \\
\hline 7 Day & 4D & $3 \mathrm{D}$ & $3 \mathrm{D}$ & 5D \\
\hline Recovery & 10 & 10 & 10 & 10 \\
\hline
\end{tabular}

At this point outside testing revealed that the latex used in formulation $295 \mathrm{had}$

inadequate adhesion to wood substrates. It was then determined that instead of simply comparing formulation 295 with other "universal" primers, a new formulation incorporating a different latex would be developed. The formulation for Kelly-Moore Paint Company's rust inhibiting primer, formulation 1725, was used as a basis for the new formulation. The latex and additives of the 1725 formulation were combined with the pigments and fillers of the 295 formulation. Both Corrosion Inhibitors A and C were already incorporated into the 1725 formulation. Corrosion Inhibitor B was not incorporated into the new formulation. The new formulation which combined 1725 with 295 was called 1725-295.

The new 1725-295 formulation was then tested against 295. The density, high shear and low shear viscosities, mud cracking, and adhesion were tested. The adhesion was tested on aged alkyl, HDG, EZG, aluminum, glass, tile, copper, wood, hardie, and PVC pipe. Important results can be seen in Table 3.3 below, while full results can be seen in Appendix C, Tables C.4-C.8. 
It was determined from outside testing that Corrosion Inhibitor $\mathrm{C}$ reduced the adhesion to GSS. The formulation 1725-295 was remade leaving out this component. The new formulation was called New-295 or N295. It was assumed that the loss of Corrosion Inhibitor C would not affect any of the previously tested properties except adhesion to GSS, and thus they were not retested. The resulting coating had very low viscosity. In order to thicken the coating, 1.61 grams of a rheology modifier were added to help increase the viscosity.

The coating N295 was tested against 295 in adhesion, water immersion, QUV exposure, and exterior exposure. The adhesion was tested on CRS, GSS. Important results can be seen in Table 3.3 below, while full results can be seen in Appendix C, Tables C.4-C.6.

Table 3.3: Important Test Results for 1725-295, New-295, and 295

\begin{tabular}{|c|c|c|c|}
\hline & $1725-295$ & New-295 & 295 \\
\hline \multicolumn{4}{|l|}{ Physical Properties } \\
\hline Density (lbs./Gal) & 10.77 & 20.84 & - \\
\hline Viscosity (KU) & 109 & 86 & 97 \\
\hline Viscosity (ICI) & 1.5 & 1.4 & - \\
\hline Gloss $20^{\circ}$ & 1.6 & 1.4 & 1.4 \\
\hline Gloss $60^{\circ}$ & 7.0 & 4.5 & 4.2 \\
\hline Gloss $85^{\circ}$ & 8.0 & 15.5 & 15.0 \\
\hline Mud Cracking at RT & 5 & 5 & 5 \\
\hline Mud Cracking at LT & 5 & 5 & 5 \\
\hline \multicolumn{4}{|l|}{$\begin{array}{c}\text { Adhesion } \\
(\text { CRS, GSS })\end{array}$} \\
\hline Total (60) & 41 & 36 & 19 \\
\hline Percentage & $68.33 \%$ & $60.00 \%$ & $31.67 \%$ \\
\hline \multicolumn{4}{|l|}{$\begin{array}{c}\text { Overnight Cure } \\
\text { Water Immersion }\end{array}$} \\
\hline 1 Hour & $8 \mathrm{D}$ & $8 \mathrm{M}$ & $8 \mathrm{D}$ \\
\hline 7 Day & $2 \mathrm{D}$ & 4MD & 4D \\
\hline Recovery & 10 & 6 & 10 \\
\hline \multicolumn{4}{|l|}{$\begin{array}{c}7 \text { Day Cure } \\
\text { Water Immersion }\end{array}$} \\
\hline I Hour & $8 \mathrm{M}$ & 10 & $8 \mathrm{~F}$ \\
\hline 7 Day & $8 \mathrm{~F}$ & $8 \mathrm{~F}$ & $8 \mathrm{M}$ \\
\hline Recovery & 10 & 10 & 10 \\
\hline
\end{tabular}




\subsection{Testing of Direct-to-Metal Top Coat Formulation}

The direct-to-metal top coat formulation 5880, produced by Kelly-Moore Paint

Company, needed improved corrosion resistance. It was decided that that a new binder system would be the most efficient method to improve the corrosion resistance. Generic formulations for each coating made can be found in Appendix C. Below is a brief description of the different binder systems used for this experiment.

Table 3.4: Description of Binder Systems Tested in Top Coat Formulation

\begin{tabular}{|l|l|l|}
\hline & Binder Systems Tested & Formulations \\
\hline A & $\begin{array}{l}\text { Aqueous self-cross linking/styrene copolymer } \\
\text { dispersion }\end{array}$ & 5880,15 \\
\hline B & Polyester-Polyurethane Dispersion & $1-7,14$ \\
\hline C & Acrylic & 8 \\
\hline D & Acrylic & 9 \\
\hline E & Urethane & 10,12 \\
\hline F & Self cross linking acrylic & 11 \\
\hline
\end{tabular}

Formulation 1 followed 5880 replacing the original latex with Latex B and not adding the cross linking agent. The final formulation was too high in viscosity. The next formulation once again followed the 5880 formulation replacing the original latex with Latex B, not adding in the cross linking agent, and not adding either rheological modifier. The resulting formulation was 
too low in viscosity. In order to increase the viscosity of the second formulation, five grams of $29 \%$ ammonia solution was added. The addition of ammonia caused a dramatic increase in viscosity, making the coating unusable.

The third formulation again followed the stock 5880 formulation replacing the stock latex with Latex B, removing both rheology modifiers and the cross linking agent, as well as replacing the coalescent with two different coalescent aids. In this formulation 32 grams of a single coalescent aid was replaced by 16 grams each of two different coalescing aids. Once again the formulation's viscosity was too high to be used. The addition of ammonia was found to cause Latex B to have a large increase in viscosity, producing an unusable coating.

The fourth formulation utilized Latex B, replaced coalescent with two different coalescing aids. The formulation also removed ammonia, both rheological modifiers, the cross linking agent, and a dispersant. The 32 grams of a single coalescent were replaced with 16 grams of two different coalescing aids. For this formulation 50 grams of Latex B were also added into the grind portion of the coating. The initial viscosity of this coating was in a usable range; however after aging overnight its viscosity became too high to be used.

The fifth formulation was the first one which had a controllable viscosity. The formulation utilized Latex B, incorporating a small amount into the grind. The formulation also left out dispersant, ammonia, replaced defoamer with additional defoamer, replaced the coalescent with two different coalescing aids, removing the cross linking agent, and removing both rheological modifiers.

The sixth and seventh formulations produced were the same as formulation five above, however each had an additional different dispersant added into the grind. Overnight, the sixth 
formulation's viscosity became too high, and it was unusable. Formulation seven however, had a good viscosity and was usable.

For formulations 5 and 7 initial viscosity, overnight viscosity, and gloss were all tested. The initial viscosities of formulation 5 and 7 were low. In order to raise their viscosities, a rheology modifier was added.

Formulations 5, 7, and 5880 were then tested. The three formulations were tested for block resistance, gloss, adhesion, QUV exposure, and exterior exposure. The QUV accelerated weathering was also tested on aluminum, in addition to the typical cold rolled steel panels. The adhesion was tested on aged alkyl, aluminum, EZG, HDG, GSS, and CRS. General results can be seen below in Table 3.5, while full results can be seen in Appendix D, Table D.1-D.3. 
Table 3.5: Test Results for Formulation 5 and 7 in Comparison to 5880

\begin{tabular}{|c|c|c|c|}
\hline & 5880 & 5 & 7 \\
\hline \multicolumn{4}{|l|}{ Physical Properties } \\
\hline Viscosity, KU & 98 & 79 & 78 \\
\hline Viscosity, KU overnight & - & 90 & 91 \\
\hline Gloss $20^{\circ}$ & 47.9 & 69.2 & 67.3 \\
\hline Gloss $60^{\circ}$ & 80.0 & 88.2 & 89.3 \\
\hline Gloss $85^{\circ}$ & - & 100.0 & 99.8 \\
\hline Low Temperature Mud Cracking & 5 & 5 & 5 \\
\hline \multicolumn{4}{|l|}{ Block Resistance Total } \\
\hline $120^{\circ} \mathrm{F}$ & 14 & 18 & 18 \\
\hline Room Temperature & 19 & 26 & 24 \\
\hline \multicolumn{4}{|l|}{ Adhesion } \\
\hline Total (180) & 77 & 149 & 146 \\
\hline Percentage & $36.67 \%$ & $70.95 \%$ & $69.52 \%$ \\
\hline \multicolumn{4}{|l|}{$\begin{array}{c}\text { Overnight Cure } \\
\text { Water Immersion }\end{array}$} \\
\hline 1 Hour & 10 & 10 & 10 \\
\hline 7 Days & $8 \mathrm{M}$ & $6 \mathrm{D}$ & $6 \mathrm{D}$ \\
\hline Recovery & 10 & Peeled & Peeled \\
\hline \multicolumn{4}{|l|}{$\begin{array}{c}7 \text { Day Cure } \\
\text { Water Immersion }\end{array}$} \\
\hline 1 Hour & 10 & 10 & 10 \\
\hline 1 Days & $8 \mathrm{D}$ & 1 & 1 \\
\hline Recovery & 10 & Peeled & Peeled \\
\hline
\end{tabular}

Undispersed pigments were observed in both formulations 5 and 7. It was thought that the seediness was caused by insolubility of one of the replacement coalescing aids. Coalescent aids can affect the solubility of pigments by interacting with the surface charges incorporated in pigments which increase their solubility. The formulations were then remade. During formulation the two additional coalescing aids were premixed with water before addition. The pigments of the resulting formulations were better dispersed. Eventually all formulations incorporating Latex B became unusable due to an increase in viscosity. A formulation incorporating Latex B was then requested from the manufacturer.

Formulations 8 and 9 were produced using Latex $\mathrm{C}$ and Latex D respectively. The two formulations followed 5880, replacing the binder system and removing the rheological modifier. 
Both formulations were too thin so rheological modifier was added after the formulations were mixed. Although 17.34 grams of rheological modifier per 1000 grams of formulation is used in the 5880 formulation, only 10 grams of rheological modifier per 1000 grams of formulation was added. Formulation 8 with the additional rheological modifier was too thick, it was thinned out by adding additional Formulation 8 to create Formulation 8 A. Formulation 9 with the addition of rheological modifier was named Formulation 9A.

Testing was conducting on formulations $8 \mathrm{~A}$ and $9 \mathrm{~A}$. Tests included viscosity, gloss, mud cracking, QUV accelerated weathering, and exterior exposure. The results of the mud cracking test indicated Formulation 9A needed more coalescing aid. Formulation 8A was also tested for adhesion and blocking resistance. The adhesion of Formulation 8A was tested on aged alkyl, CRS, and GSS.

In order to improve the coalescence of Formulation 9A, coalescent aid was added. The new formulation was recorded as Formulation 9B. The 9B formulation was tested for adhesion, gloss, mud cracking, viscosity, and blocking resistance. The adhesion of 9B was tested on aged alkyl, CRS, and GSS. General results can be seen in Table 3.6 below, and full results can be seen in Appendix D, Table D.7. 
Table 3.6: Important Testing Results for Formulations 8 and 9 and Their Derivates

\begin{tabular}{|c|c|c|c|c|c|}
\hline & 8 & $\mathbf{8 A}$ & 9 & 9A & 9B \\
\hline & & $\begin{array}{l}\text { Rheological } \\
\text { modifier }\end{array}$ & & $\begin{array}{l}\text { Rheological } \\
\text { modifier }\end{array}$ & $\begin{array}{c}\text { Coalescent \& } \\
\text { rheological } \\
\text { modifier } \\
\end{array}$ \\
\hline \multicolumn{6}{|l|}{ Physical Properties } \\
\hline Viscosity, KU & 70 & 100 & 60 & 111 & 116 \\
\hline Viscosity, KU overnight & & 100 & & 111 & 114 \\
\hline Gloss $20^{\circ}$ & 39.6 & 44.4 & 44.4 & 41.5 & 41.9 \\
\hline Gloss $60^{\circ}$ & 77.8 & 80.3 & 80.3 & 77.6 & 78.6 \\
\hline Gloss $85^{\circ}$ & 97.3 & 96.8 & 96.8 & 95.5 & 96.5 \\
\hline Low Temperature Mud Cracking & & 5 & & 1 & 5 \\
\hline \multicolumn{6}{|l|}{ Block Resistance Total } \\
\hline $120^{\circ} \mathrm{F}$ & & 14 & & & 25 \\
\hline Room Temperature & & 29 & & & 27 \\
\hline \multicolumn{6}{|l|}{ Adhesion (CRS, GSS, Alkyl) } \\
\hline Total (90) & & 49 & & & 28 \\
\hline Percentage & & $54.44 \%$ & & & $31.11 \%$ \\
\hline \multicolumn{6}{|l|}{$\begin{array}{l}\text { Overnight Cure } \\
\text { Water Immersion }\end{array}$} \\
\hline $1 \mathrm{Hr}$ & & 10 & & 10 & \\
\hline 7 Day & & $6 \mathrm{D}$ & & $6 \mathrm{D}$ & \\
\hline Recovery & & 10 & & 10 & \\
\hline \multicolumn{6}{|l|}{$\begin{array}{c}7 \text { Day Cure } \\
\text { Water Immersion }\end{array}$} \\
\hline $1 \mathrm{Hr}$ & & $8 \mathrm{D}$ & & 10 & \\
\hline 7 Day & & $6 \mathrm{D}$ & & $6 \mathrm{D}$ & \\
\hline Recovery & & Dimples & & Dimples & \\
\hline
\end{tabular}

Formulation 10 deviated substantially from the 5880 formulation based on manufacturer recommendations of Latex E. The only specific components from the 5880 formulation's grind that remained the same were water, biocide, and titanium dioxide slurry. For the rest of the formulation, the only additives which remained the same were defoamer and rheology modifier. Formulation 10 was then tested for viscosity, water immersion, adhesion to CRS and GSS, gloss, and mud cracking. The resulting coating had a low viscosity and created films which had cracks. Both thickener and coalescent were added in order to help create a better coating, however the level of coalescent needed to create a smooth film was higher than desired. The coating was intended to be a low volatile organic compound coating, and Latex E was too hard to 
accommodate this. Another formulation incorporating Latex E, formulation 12, was attempted. The resulting formulation was too thin and also had alligator cracking. No further testing was done with Latex E.

The 11th formulation used Latex F. The grind portion of this formulation was the same as the grind of 5880. Once again coalescent was replaced by two different coalescents as utilized in previous formulation. During formulation the coalescents were premixed with water, ammonia, dispersant, and a new coalescing agent. The new coalescing agent was utilized in order to prevent undispersed pigment seen in previous formulations. The two components from 5880 which were left out were the cross linking agent and rheology modifier. Formulation 11 was tested for viscosity, adhesion, gloss, and water immersion. The adhesion of formulation 11 was tested on CRS and GSS. General results can be seen in Table 3.7 below. 
Table 3.7: Test General Results of Physical Properties of Formulations 10, 11, and 12

\begin{tabular}{|c|c|c|c|}
\hline & 10 & 11 & 12 \\
\hline \multicolumn{4}{|l|}{ Physical Properties } \\
\hline Viscosity (KU) & 70 & 93 & 53 \\
\hline Overnight Viscosity (KU) & 71 & 104 & 52 \\
\hline Gloss $20^{\circ}$ & 21.3 & 38.9 & 12.1 \\
\hline Gloss $60^{\circ}$ & 65.3 & 72.4 & 54 \\
\hline Gloss $85^{\circ}$ & 96 & 94.2 & 89.3 \\
\hline Low Temperature Mud Cracking & 1 & 5 & 1 \\
\hline \multicolumn{4}{|l|}{ Adhesion (CRS, GSS) } \\
\hline Total (60) & 0 & 0 & \\
\hline Percentage & $0.00 \%$ & $0.00 \%$ & \\
\hline \multicolumn{4}{|l|}{$\begin{array}{c}\text { Overnight Cure } \\
\text { Water Immersion }\end{array}$} \\
\hline \multicolumn{4}{|l|}{1 Hour } \\
\hline \multicolumn{4}{|l|}{7 days } \\
\hline Recovery & 10 & Peeled & \\
\hline \multicolumn{4}{|l|}{$\begin{array}{c}7 \text { Day Cure } \\
\text { Water Immersion }\end{array}$} \\
\hline 1 Hour & 9 & 6 & \\
\hline 7 days & 0 & $6 \mathrm{~F}$ & \\
\hline Recovery & Peeled & Peeled & \\
\hline
\end{tabular}

A formulation from the manufacturer of Latex B was received. The formulation provided had a very low viscosity. Rheology modifier was added to the formulation to increase its viscosity. Formulation 13 was 95.0 grams of the supplier's formulation mixed with 0.50 grams of rheology modifier. Formulation 13 was tested for water immersion resistance and adhesion to CRS and GSS. The general results can be seen in Table 3.8.

An attempt to improve the stock 5880 formulation was made. A new coalescent which helped to solubilize grease and oils was added to increase the adhesion to GSS. The new formulation was called Formulation 14. The formulation was tested form adhesion on CRS and GSS. The general results can be seen in Table 3.8.

It was decided that formulation 9B had the most potential as a replacement for 5880, however its adhesion to GSS needed improvement. Formulation 9C was produced by adding a 
coalescent which helps to solubilize grease and oils to formulation 9B. The formulation 9C was tested for adhesion, water immersion, chemical resistance, and hand lotion resistance. The adhesion of 9C was tested directly to the substrate as well as over primer on CRS, GSS, aged alkyl, HDG, EZG, aluminum, and copper. In comparison the stock 5880 formulation was also tested directly and over primed substrates. Important test results for 9C can be seen in Table 3.8 while full results can be seen in Appendix D, Tables D.7-D.9.

Table 3.8: Important Test Results of Formulations 13, 14, and 9C

\begin{tabular}{|c|c|c|c|}
\hline & $9 \mathrm{C}$ & 13 & 14 \\
\hline \multicolumn{4}{|c|}{ Adhesion (CRS, GSS) } \\
\hline Total (60) & 18 & 34 & 17 \\
\hline Percentage & $56.67 \%$ & $30.0 \%$ & $28.33 \%$ \\
\hline \multicolumn{4}{|c|}{$\begin{array}{c}\text { Overnight Cure } \\
\text { Water Immersion }\end{array}$} \\
\hline 1 Hour & 9 & 10 & 10 \\
\hline 7 days & 0 & 0 & $6 \mathrm{D}$ \\
\hline Recovery & 8 & Peeled & 8 \\
\hline \multicolumn{4}{|c|}{$\begin{array}{c}7 \text { Day Cure } \\
\text { Water Immersion }\end{array}$} \\
\hline 1 Hour & 10 & 10 & 10 \\
\hline 7 days & $8 \mathrm{D}$ & 0 & $0 / 8 \mathrm{D}$ \\
\hline Recovery & 10 & Peeled & $\begin{array}{c}\text { Peeled } \\
\text { Edges }\end{array}$ \\
\hline
\end{tabular}

The two formulation 9C and 5880 were then tinted with Kelly-Moore Paint Company's colorant system. Eleven different colorants were used. The amount of colorant used was based on the density of both the paint and the colorant. After being tinted, each colored sample was shaken for five minutes. Samples were then tested for gloss, CIE lab values, and tint strength. A portion of each sample was then placed into a glass vial which was put into the oven at $120^{\circ} \mathrm{F}$. The remaining portion of each sample was left at ambient temperature on a laboratory bench top. After aging overnight, seven days, fourteen days, and twenty-one days all samples were tested again for gloss, CIE lab values, tint strength, syneresis, and color float. Results for gloss can be 
seen in Appendix D, Table D.10. Results for CIE lab values can be seen in Appendix D, Table D.12-D.28. Results for syneresis and color float can be seen in Appendix D, Table D.11. 


\section{CONCLUSION}

\subsection{Primer Formulation}

The Kelly-Moore Paint Company's formulation 295 is a "universal" primer. As a general primer, 295 works very well. As a primer for metal substrates, the 295 formulation needed improvement in corrosion resistance. The corrosion resistance of coatings can be improved with the addition of corrosion inhibitors. For this formulation, the corrosion inhibitors sodium nitrite, aminocarboxylate salt, and zinc phosphate were tested. These corrosion inhibitors were chosen because they were already utilized in other coatings produced by Kelly-Moore Paint Company.

The first formulation tested, 295A, added sodium nitrite to the 295 formulation. The new formulation had comparable adhesion, water immersion resistance, and QUV accelerated weathering resistance. The exterior exposure resistance of the formulation, however, showed that sodium nitrite it had improved the corrosion resistance of 295. Sodium nitrite works in a self sacrificing manner, meaning that is oxidizes preferentially to the metal substrate.

The second formulation, 295AB, which incorporated both sodium nitrite and aminocarboxylate salt with 295. This formulation did not show any improvements in corrosion resistance over 295A. This aminocarboxylate salt also works in a sacrificial manner. It is not surprising that this corrosion inhibitor did not show improved corrosion resistance when combined with a corrosion inhibitor which works in the same manner.

The third formulation, 295ABC, incorporated sodium nitrite, aminocarboxylate salt, and zinc phosphate into 295. Testing revealed that this formulation had comparable adhesion, water immersion resistance, and QUV accelerated weathering resistance to 295. Exterior exposure testing revealed that $295 \mathrm{ABC}$ had superior corrosion resistance compared to 295 . The corrosion resistance of $295 \mathrm{ABC}$ was the best of all formulations tested. 
The addition of sodium phosphate and zinc phosphate both showed an improvement in corrosion resistance to the 295 formulation. After testing was done, it was determined that the binder system used in 295 was not adequate. The binder system which is used in a primer for metal substrates formulation, 1725, was then substituted into the 295 formulation. The new formulation, 1725-295, combined the latex and additives of 1725 with the pigments and fillers of 295. The corrosion inhibitors sodium nitrite and zinc phosphate were already incorporated into 1725.

The new formulation, 1725-295, was then tested in comparison to 295 . The two formulations had comparable water immersion resistance, QUV accelerated weathering resistance, chemical resistance, and hand lotion resistance. The adhesion and corrosion resistance of 1725-295 showed improvement over the 295 formulation. It was determined through outside testing that one of the fillers used in 1725 reduced adhesion to GSS. The 1725-295 formulation was then remade removing the filler that was shown to reduce adhesion. The new formulation, New-295, was then tested in comparison to 295. The newest formulation was shown to have improved adhesion over 295. The water immersion resistance of New-295 was shown to be comparable to 295. The QUV accelerated weathering resistance and exterior exposure resistance both showed that the corrosion resistance of New-295 was much higher than the corrosion resistance of 295 .

This experiment was done in order to improve the corrosion resistance of the "universal" primer 295. The resulting formulation New-295, not only improved the corrosion resistance, but also the adhesion. New-295 incorporated a new latex, and the two corrosion inhibitors sodium nitrite and zinc phosphate. 


\subsection{Top Coat Formulation}

The Kelly-Moore Paint Company's formulation 5880 is an interior/exterior acrylic high gloss enamel paint which can be applied directly to metals. This formulation is known to have good abrasion resistance and resistance to exterior and interior exposures. This formulation is recommended for commercial, residential, and small scale industrial applications. The adhesion of 5880 needed improvement in order to make it a better direct-to-metal coating. It was decided that a change in the latex used in the paint could lead to a stronger direct-to-metal paint formulation.

Latex B, a polyurethane dispersion was the first latex considered. A polyurethane based binder system was considered first because of the high abrasion resistance, good chemical resistance, and good mechanical properties associated with polyurethanes. When Latex B was incorporated into the 5880 formulation, problems with the viscosity were encountered. It was determined through experimentation that ammonia caused this latex to increase in viscosity. This increase in viscosity occurred because Latex B was an emulsion polymer system with ionic surfactants used to stabilize the polymer droplets. When ammonia was added, the electrostatic charges used to keep polymer droplets apart was overcome, and the droplets coalesced within solution.

Once ammonia was removed from the formulation incorporating Latex B, a usable formulation was developed. Formulation incorporating Latex B showed good adhesion and corrosion resistance, however did not have good water immersion resistance. After aging for one week, all formulation using Latex B, became unusable due to an increase in viscosity.

A formulation incorporating Latex B was then requested from the manufacturer. The formulation showed similar increases in adhesion and corrosion resistance to 5880, however 
water immersion resistance was still poor. It was then decided that Latex B would not form a film that would be an improvement upon 5880.

In the next round of testing two different binder systems were tested, Latex $\mathrm{C}$ and Latex D. Formulation 8 was made with Latex $\mathrm{C}$ while formulation 9 was made with Latex $\mathrm{D}$. Both formulations needed additives in order to improve their properties. Formulation 8 had additional rheological modifier while Formulation 9 had additional rheological modifier and coalescent. The two formulations were tested in comparison to 5880. The corrosion resistance of both formulations were shown to be comparable to 5880. The adhesion of formulation 8 and 9 showed improvement over 5880, however the adhesion to GSS was not good.

Latex $\mathrm{E}$ is an aliphatic waterborne urethane dispersion used in formulations 10 and 12. The original formulation 10 was too thin and had cracks, so a thickener and a coalescent were added. It was desired to keep the VOC level of the coating below $100 \mathrm{~g} / \mathrm{L}$, and the maximum amount of VOC's still resulted in cracks. The adhesion of formulation 10 was also bad, resulting in no further testing being conducted. Formulation 12, used a different coalescing aid in order to stop the cracks, however the maximum amount still did not prevent the formation of cracks.

Latex $\mathrm{F}$ is a self cross linking acrylic polymer, and incorporated into Formulation 11 . The testing of Formulation 11 showed that it had no adhesion to any substrate tested. The wet adhesion test also showed that the this formulation blistered when exposed to moisture.

The original latex was also tested in formulation 15, with glycol ether added in order to increase adhesion to GSS. No increase in adhesion was seen, and no further testing was done in order to improve the adhesion of Latex A.

After evaluation of all 6 latexes tested, it was thought that Latex D had the most potential, if its adhesion to galvanized spangled steel could be improved. After many different tests were 
conducted on the galvanized spangled steel, it was shown that the addition of propylene glycol nbutyl ether helped to increase the adhesion in some formulations. Formulation $9 \mathrm{C}$ was then produced by adding propylene glycol n-butyl ether to the Formulation 9B. More extensive testing was then conducted on $9 \mathrm{C}$, comparing it to the stock 5880 formulation. The adhesion of 9C was worse than the adhesion of 5880 when applied directly to metal, however the adhesion over a primed substrates was comparable. The formulation $9 \mathrm{C}$ was shown to be superior to the stock 5880 formulation for scrub resistance, exterior exposure, QUV, chemical resistance, and hand lotion resistance. In all other tests done, 9C was comparable to 5880.

Color acceptance testing was also done on both 5880 and 9C. After being tinted with eleven different colorants, both 5880 and $9 \mathrm{C}$ showed no significant changes in gloss, even after three weeks of aging at room temperature and elevated temperature. $\mathrm{A} \pm 5 \%$ change in tint strength constituted a significant change according to Kelly-Moore Paint Company's testing parameters. Formulation 9C showed no significant change in average tint strength, even after three weeks of aging at room temperature and elevated temperature. The stock 5880 formulation showed a significant change in tint strength after aging at room temperature overnight, and after aging seven days or more at elevated temperatures. The color float and syneresis of the two paints was comparable. Overall, $9 \mathrm{C}$ was shown to be a good candidate for replacing 5880, but not as a "non-direct-to-metal" paint. 


\section{FUTURE WORK}

\subsection{Primer Formulation}

The resulting "universal" primer, New-295, showed improved corrosion resistance and adhesion compared to the original 295 formulation. The corrosion inhibitors utilized in New-295, were used at manufacturer specifications. In order to reduce the cost of the formulation, further testing on the amount of corrosion inhibitor added into the formulation should be done. A small decrease in the amount of corrosion inhibitor utilized in the formulation, without detracting from the corrosion resistance of the coating, could result in a significant decrease in manufacturing cost for the coating.

Testing for this project was done over a five month period. Exterior exposure testing was only conducted over a two week period. Accelerated weathering testing was conducted, however this does not produce results that are comparable to actual weathering. Testing should be done with natural weathering for an extended period of time.

No tinting of New-295 was done. Although primers are not always tinted, occasional tinting them helps to decrease the number of top coat layers needed. Testing on New-295 tint strength and color acceptance should be done.

\subsection{Top Coat Formulation}

The final formulation, 9C, showed some improvement is corrosion resistance and gloss retention, however $9 \mathrm{C}$ had a decrease in adhesion compared to 5880 . The formulation developed is not a "direct-to-metal" top coat formulation. In order to develop this formulation into a "directto-metal " formulation, more research should be done to increase the adhesion. 
Although corrosion resistance was improved with the $9 \mathrm{C}$ formulation, further improvements could be made. Improving the corrosion resistance of a coating intended for metal substrates should be conducted regularly. New corrosion resistance additives are developed frequently and should be considered. 


\section{REFERENCES}

Anderson, Christopher; Daniels, Eric, "Emulsion Pilymerisation and Latex Applications," Volume 14, Number 4, Rapa Review Reports, iSmithers Rapra Publishing, 2003.

ASM International: The Materials Information Society, n.d., Corrosion, visited 26 May 2012. http://www.asminternational.org/portal/site/www/SubjectGuideItem/?vgnextoid=f 018c8636b49d210VgnVCM100000621e010aRCRD

ASTM Standard D523, 2008, "Standard Test Method for Specular Gloss," ASTM International, West Conshohocken, PA, 2008, DOI: 10.1520/D0523-08.

ASTM Standard D562, 2010, "Standard Test Method for Consistency of Paints Measuring Krebs Unit (KU) Viscosity Using a Stormer-Type Viscometer," ASTM International, West Conshohocken, PA, 2010, DOI: 10.1520/D0562-10.

ASTM Standard D714, 2009, "Standard Test Method for Evaluating Degree of Blistering of Paints," ASTM International, West Cons hohocken, PA, 2010, DOI: 10.1520/D0714-02R09.

ASTM Standard D870, 2009, "Standard Practice for Testing Water Resistance of Coatings Using Water Immersion," ASTM International, West Conshohocken, PA, 2010, DOI: $10.1520 / \mathrm{D} 0870-09$.

ASTM Standard D1475, 2008, "Standard Test Method for Density of Liquid Coatings, Inks, and Related Products," ASTM International, West Conshohocken, PA, 2010, DOI: 10.1520/D1475-98R08.

ASTM Standard D1709, 2009, "Standard Test Method for Impact Resistance of Plastic Film by the Free-Falling Dart Method," ASTM International, West Conshohocken, PA, 2007, DOI: 10.1520/D1709-09.

ASTM Standard D2134, 1993, "Standard Test Method for Determining the Hardness of Organic Coatings with a Sward-Type Hardness Rocker," ASTM International, West Conshohocken, PA, 2007, DOI: 10.1520/D2134-93R07.

ASTM Standard D2486, 2012, "Standard Test Methods for Scrub Resistance of Wall Paints," ASTM International, West Conshohocken, PA, 2010, DOI: 10.1520/D2486-06R12E01.

ASTM Standard D3359, 2009, "Standard Test Method for Measuring Adhesion by Tape Test," ASTM International, West Conshokocken, PA, 2009, DOI: 10.1250/D3359-09E02.

ASTM Standard D3363, 2005, "Standard Test Method for Film Hardness by Pencil Test," ASTM International, West Conshohocken, PA, 2008, DOI: 10.1520/D336305R11E02. 
ASTM Standard D4287, 2000, "Standard Test Method for High-Shear Viscosity Using a Cone/Plate Viscometer," ASTM International, West Conshohocken, PA, 2010, DOI: 10.1520/D4287-00R10.

ASTM Standard D4587, 2011, "Standard Test Method for Fluorescent UV-Condensation Exposures of Paint and Related Coatings," ASTM International, West Conshohocken, PA, 2011, DOI: 10.1520/D4587-11

ASTM Standard D4946, 2008, "Standard Test Method for Blocking Resistance of Architectural Paints," ASTM International, West Conshohocken, PA, 2010, DOI: 10.1520/D4946-89R08E01.

ASTM Standard D5894, 2010, "Standard Test Method for Cyclic Salt Fog/UV Exposure of Painted Metal, (Alternating Exposures in a Fog/Dry Cabinet and UV/COndensation Cabinet)," ASTM International, West Conshohocken, PA, 2010, DOI: 10.1520/D5894-10.

ASTM Standard D7306, 2007, "Standard Test Method for Testing Low Temperature Film-Formation of Latex Paints by Visual Observation," ASTM International, West Conshohocken, PA, 2008, DOI: 10.1520/D7306-07.

Banov, Abel, “ Paints \& Coatings Handbook," Second Edition, Structures Publishing Company, Michigan, 1978.

Bieleman, Johan, "Additives for Coatings," John Wiley \& Sons, Hoboken, New Jersey, 2008.

Chico, Belen; de la Fuente, D.; Perez, M. L.; Morcillo, M., "Corrosion Resistance of Steel Treated with Different Silane/Paint System," Journal of Coatings Technology and Research, 9.1, 2012.

Curtis, Gregory, "The Cave Painters: Probing the Mysteries of the World's First Artist," Anchor Books, New York, 2007.

Davidson, Gerry; Lane, Bruce. " Additives in Water-Borne Coatings," The Royal Society of Chemistry, Cambridge, UK, 2002.

Davis, Joseph; "Corrosion of Aluminum and Aluminum Alloys," ASTM International, Materials Park, OH, 1999.

Diaz, I.; Chico, B.; de la Fuente, D.; Simancas, J.; Vega, J.M.; Morcillo, M., "Corrosion Resistance of New Epoxy-Siloxane Hybrid Coatings. A Laboratory Study," Progress in Organic Coatings, 69.3, 278-286, 2010.

Direct Industry: The Virtual Industrial Exhibition, n.d., KU-2 Viscometer for Paint and Coatings Application, visited 26 May, 2012. http://news.directindustry.com/press/brookfield/ku-2-viscometer-for-paint-andcoatings-application-20805-368109.html 
Florio, John; Miller, Daniel. "Handbook of Coating Additives." Marcel Dekker, Inc., New York, NY, 2004.

Forsgren, Amy, "Corrosion Control Through Organic Coatings," CRC Press, Boca Raton, Florida, 2006.

Gardco Company, Inc. n.d., 703 Sward Type Hardness Rocker, visited 26 May, 2012. http://www.gardco.com/pages/hardness/703swardhardness.cfm

Generation 2 Materials Technology, n.d., Cost of Corrosion, visited 26 May, 2012. http://www.g2mtlabs.com/cost-of-corrosion/

Ghali, Edward, "Corrosion Resistance of Aluminum and Magnesium Alloys: Understanding, Performance, and Testing," John Wiley \& Sons, Hoboken, New Jersey, 2010.

Guertin, Jacques; Jacobs, James; Avakian, Cynthia, "Chromium (VI) Handbook," CRC Press, Boca Raton, Florida, 2004.

Gysau, Detlef, "Fillers for Paints: Fundamentals and Applications," Vincentz Network GmbH \& Co KG, Hannover, Germany, 2006.

Koleske, J.V., "Paint and Coating Testing Manual," Fourteenth Edition, ASTM International, Missouri, 1995

Longfield: Precision Coating Bar System, 2010, Laboratory Products, visited 26 May, 2012. http://www.longfield-coating.com/laboratory.htm

Lucas Filipe Martins Silva, Andreas Öchsner, Robert D. Adams, "Handbook of Adhesion Technology" Volume 2, Springer Publishing, New York, NY, 2011.

Marrion, Alastair, "The Chemistry and Physics of Coatings," Second Edition, The Royal Society of Chemistry, Cambridge, UK, 2004.

Orr, Edward, "Performance Enhancement in Coatings," Hanser Gardner Publications Inc., Cincinnati, Ohio, 1998.

Premier Colorscan: COmplete Laboratory Solution for Color Industry, n.d., Q-Lab Weathering and Light Fastness Testers, visited 26 May, 2012.

http://www.indiamart.com/premiercolorscan/weathering-light-fastnesstesters.html

Revie, Winston; Uhlig, Herbert; "Corrosion and Corrosion Control," 4th Edition, Wiley \& Sons, Hoboken, New Jersey, 2008.

Sastri, V.S.; " Corrosion Inhibitors: Principles and Applications," Wiley \& Sons, Hoboken, New Jersey, 1998. 
Scheerder, Jurgen; Breur, Rik; Slaghek, Ted; Holtman, Wessel; Vennik, Marco; Ferrari, Babrielle, "Exopolysaccharides as Anti-Corrosive Additives for Coatings," Progress in Organic Coatings, 75.3, 224-230, 2012.

Schuerman, George, and Raymond Bruzan. "Chemistry of Paint." J. Chem. Educ, 66.4 (1989): 327.

Schweitzer, Philip. "Corrosion-Resistant Linings and Coatings.” Marcel Dekker, Inc., New York, NY, 2001.

The Pencil Pages, 2002, The Pencil Hardness Test, visited 26 May, 2012.http://www.pencilpages.com/articles/simmons.htm Tracton, Arthur, "Coatings Technology Handbook," Third edition, Taylor and Francis Group, Boca Raton, FL, 2006.

Wicks, Zeno; Jones, Frank; Pappas, Peter; Wicks, Douglas, "Organic Coatings: Science and Technology" Third Edition. John Wiley \& Sons, Inc., Hoboken, New Jersey, 2007.

Weldon, Dwight, "Failure Analysis of Paints and Coatings," John Wiley \& Sons, Hoboken, New Jersey, 2009.

Winkler, Jochen, " Titanium Dioxide," Vincentz Network GmbH \& Co KG, Hannover, Germany, 2003. 


\section{Appendix A - General Formulations for Primer Testing}

Generic Formulation for 295

Grind

Stabilizer

Biocide

Water

Surfactant

Dispersant 2

Antifoamer

Titanium Dioxide

Slurry

Filler 1

Filler 2 lbs.

18.14

1.50

116.62

3.02

13.20

1.00

125.00

50.00

190.00

Let Down

Acrylic Latex

295.60

Water

8.33

2.23

53.94

Premix

29\% Ammonia

Rheology Modifier 1

Rheology Modifier 2

Water

12.99

7.29

87.56

1005.07

Premix: lbs.

Coalescent 1

22.16

Coalescent $2 \quad 15.12$

Water 16.66

Properties:

PVC

36.86

Solids by Weight (\%)

Solids by Volume

(\%)

51

35

Weight per Gallon

(lbs.)

10.9 


\section{Generic Formulation for $\mathbf{1 7 2 5}$}

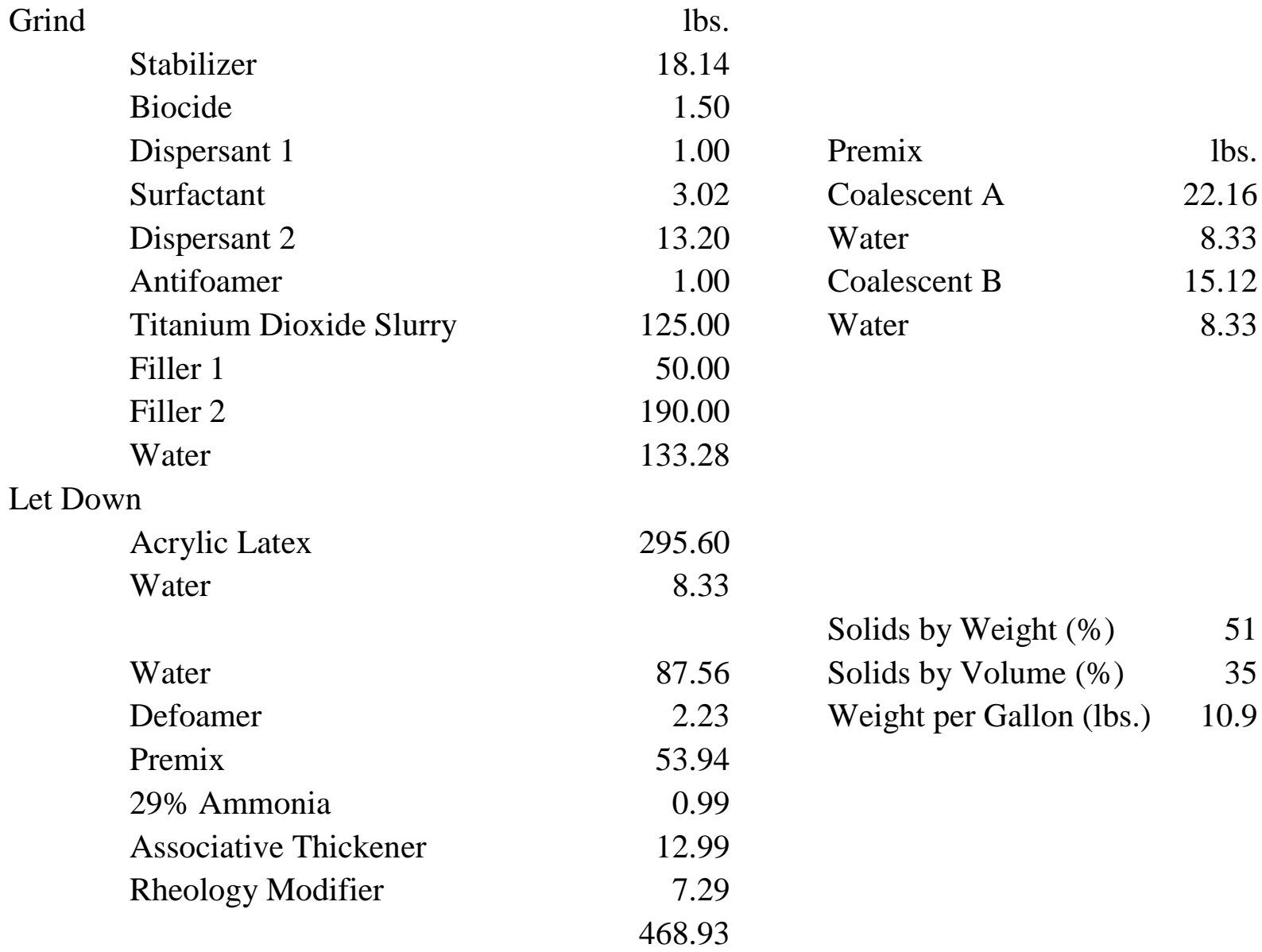




\section{General Formulation of New-295}

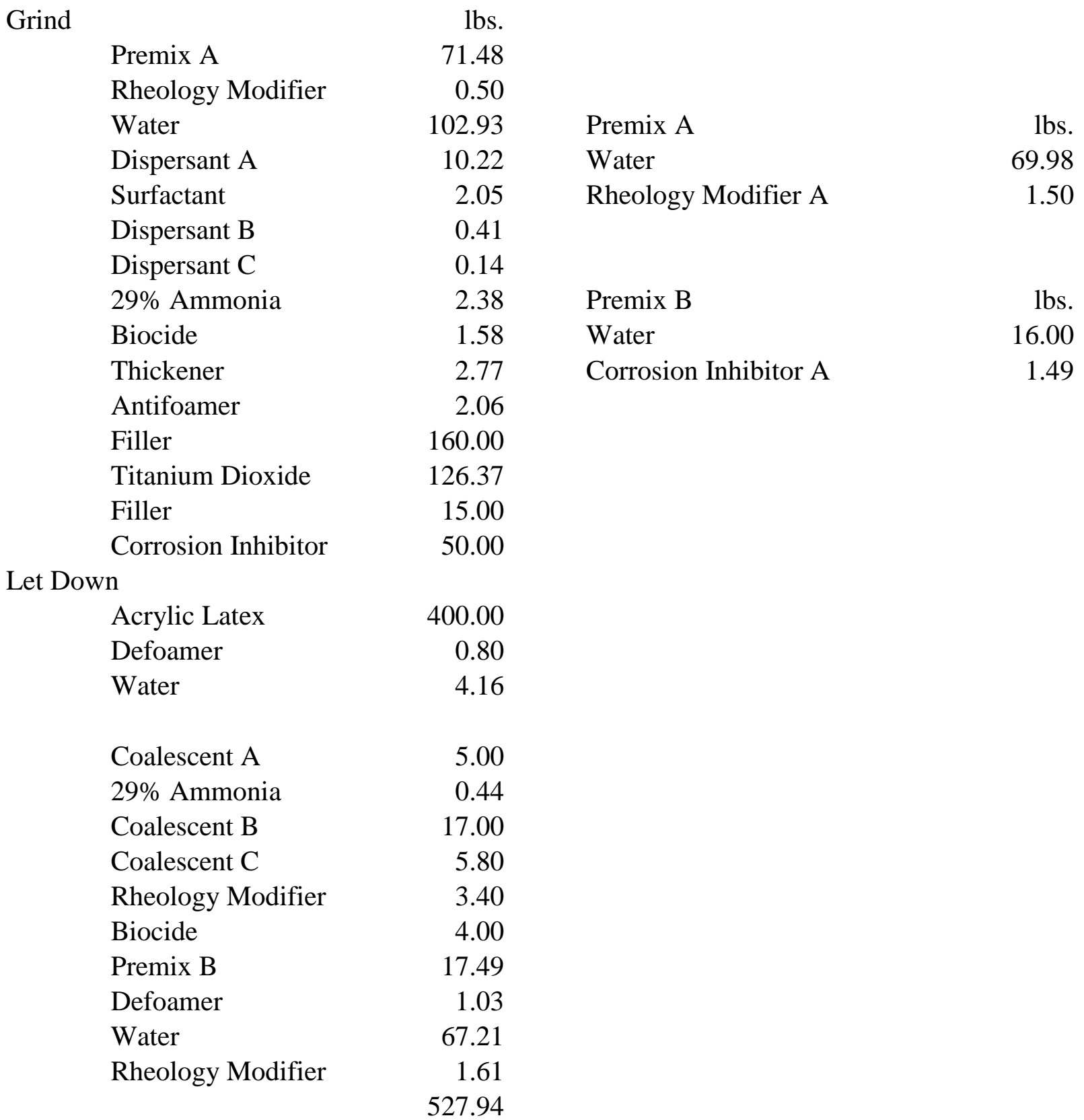




\section{Appendix B - Generic Formulations for Top Coat Testing}

\section{General Formulation for 5}

Grind

Water

Surfactant

Dispersant

Antifoamer

Rheology Modifier A

Biocide

Titanium Dioxide Slurry

Latex B

Let Dow
Latex B

Water

Water

Defoamer

Rheology Modifier B

Surfactant

Corrosion Inhibitor

Premix lbs.

75.93

2.15

0.50

Premix

lbs.

2.60

Water

8.33

17.40

Corrosion Inhibitor

1.00
1.50

200.00

32.45

520.00

8.33

81.64

2.63

5.00

0.50

10.44

9.33

970.40 


\section{General Formulation for 9C}

Grind

Water

Dispersant

29\% Ammonia

Surfactant

Dispersant

Rheology Modifier

Biocide

Antifoamer

Titanium Dioxide

Slurry

Water

Let Down

Acrylic Latex

Water

Adhesion Promoter

Water

Coalescent

Coalescent

Corrosion Inhibitor

Defoamer

Premix A

Premix B

Rheology Modifier

Surfactant

Defoamer lbs.

49.98

14.62

3.00

2.15

0.50

17.40

1.50

1.65

Premix B

lbs.

10.10

16.66
200.27

8.33

565.78

8.33

5.00

57.21

26.50

7.00

10.01

1.68

19.33

26.76

10.00

0.50

2.10

1039.60 


\section{Appendix C - Data Tables for Primer Formulation}

Table C.1: Complete Adhesion Results for 295, 295A, 295AB, and 295ABC

\begin{tabular}{|c|c|c|c|c|c|}
\hline & & 295 & 295A & 295AB & 295ABC \\
\hline \multicolumn{6}{|c|}{ Dry Adhesion } \\
\hline \multirow[t]{3}{*}{ Aged Alkyl } & Overnight & 4 & 2 & 4 & 4 \\
\hline & 4 Day & 5 & 5 & 5 & 5 \\
\hline & 7 Day & 5 & 5 & 5 & 5 \\
\hline \multirow[t]{3}{*}{ CRS } & Overnight & 0 & 0 & 0 & 0 \\
\hline & 4 Day & 3 & 2 & 2 & 3 \\
\hline & 7 Day & 3 & 3 & 3 & 5 \\
\hline \multirow[t]{3}{*}{ Aluminum } & Overnight & 0 & 0 & 0 & 0 \\
\hline & 4 Day & 5 & 5 & 5 & 5 \\
\hline & 7 Day & 5 & 5 & 4 & 4 \\
\hline \multirow[t]{3}{*}{ GSS } & Overnight & 3 & 2 & 2 & 3 \\
\hline & 4 Day & 0 & 0 & 0 & 3 \\
\hline & 7 Day & 3 & 0 & 0 & 0 \\
\hline \multirow[t]{3}{*}{ EZG } & Overnight & 0 & 0 & 0 & 0 \\
\hline & 4 Day & 0 & 2 & 2 & 2 \\
\hline & 7 Day & 0 & 2 & 4 & 4 \\
\hline \multirow[t]{3}{*}{ HDG } & Overnight & 0 & 0 & 0 & 0 \\
\hline & 4 Day & 0 & 0 & 0 & 1 \\
\hline & 7 Day & 0 & 0 & 0 & 0 \\
\hline \multicolumn{6}{|c|}{ Wet Adhesion } \\
\hline \multirow[t]{3}{*}{ Aged Alkyl } & Overnight & 0 & 0 & 0 & 0 \\
\hline & 4 Day & 3 & 2 & 1 & 0 \\
\hline & 7 Day & 2 & 2 & 2 & 1 \\
\hline \multirow[t]{3}{*}{ CRS } & Overnight & 0 & 0 & 0 & 0 \\
\hline & 4 Day & 0 & 0 & 0 & 0 \\
\hline & 7 Day & 0 & 0 & 0 & 0 \\
\hline \multirow[t]{3}{*}{ Aluminum } & Overnight & 2 & 0 & 1 & 0 \\
\hline & 4 Day & 3 & 1 & 1 & 1 \\
\hline & 7 Day & 2 & 2 & 2 & 1 \\
\hline \multirow[t]{3}{*}{ GSS } & Overnight & 2 & 0 & 0 & 0 \\
\hline & 4 Day & 2 & 2 & 2 & 0 \\
\hline & 7 Day & 0 & 0 & 0 & 0 \\
\hline \multirow[t]{3}{*}{$\mathrm{EZG}$} & Overnight & 1 & 1 & 0 & 2 \\
\hline & 4 Day & 1 & 2 & 0 & 1 \\
\hline & 7 Day & 0 & 2 & 0 & 2 \\
\hline \multirow[t]{3}{*}{ HDG } & Overnight & 1 & 2 & 2 & 0 \\
\hline & 4 Day & 0 & 1 & 2 & 0 \\
\hline & 7 Day & 0 & 0 & 1 & 0 \\
\hline Total & & 55 & 50 & 50 & 52 \\
\hline Percentage & & $30.56 \%$ & $27.78 \%$ & $27.78 \%$ & $28.89 \%$ \\
\hline
\end{tabular}


Table C.2: Complete Results for 295, 295A, 295AB, and 295ABC QUV Accelerated Weathering

\begin{tabular}{|l|l|c|c|c|c|}
\hline & Gloss & 295 & $295 \mathrm{~A}$ & $295 \mathrm{AB}$ & $295 \mathrm{ABC}$ \\
\hline Initial & $20^{\circ}$ & 1.4 & 1.4 & 1.4 & 1.4 \\
\hline & $60^{\circ}$ & 4.9 & 4.6 & 4.6 & 4.2 \\
\hline & $85^{\circ}$ & 17.9 & 16.8 & 16.0 & 13.4 \\
\hline 14 Day Exposed & $20^{\circ}$ & 1.3 & 1.3 & 1.3 & 1.4 \\
\hline & $60^{\circ}$ & 3.7 & 3.5 & 3.8 & 4.1 \\
\hline & $85^{\circ}$ & 11.2 & 12.6 & 11.6 & 13.2 \\
\hline
\end{tabular}

Table C.3: Complete Results for 295, 295A, 295AB, and 295ABC Exterior Exposure Testing

\begin{tabular}{|l|l|c|c|c|c|}
\hline & Gloss & 295 & $295 \mathrm{~A}$ & $295 \mathrm{AB}$ & $295 \mathrm{ABC}$ \\
\hline Initial & $20^{\circ}$ & 1.4 & 1.5 & 1.4 & 1.3 \\
\hline & $60^{\circ}$ & 4.6 & 5.0 & 4.9 & 4.2 \\
\hline & $85^{\circ}$ & 15.0 & 15.5 & 16.0 & 12.2 \\
\hline & $20^{\circ}$ & 1.4 & 1.3 & 1.4 & 1.3 \\
\hline & $60^{\circ}$ & 4.2 & 3.7 & 4.3 & 3.5 \\
\hline & $85^{\circ}$ & 15.6 & 6.2 & 7.5 & 10.5 \\
\hline & Obay Exposed & $\begin{array}{c}\text { Blisters, } \\
\text { rust spots }\end{array}$ & $\begin{array}{c}\text { Blisters, } \\
\text { rust spots }\end{array}$ & $\begin{array}{c}\text { Blisters, } \\
\text { rust spots }\end{array}$ & Some rust \\
\hline
\end{tabular}


Table C.4: Complete Adhesion Results for 1725-295, New 295, and 295

\begin{tabular}{|c|c|c|c|c|c|c|c|c|c|}
\hline & & $\begin{array}{c}1725- \\
295\end{array}$ & 295 stock & New 295 & & & $\begin{array}{c}1725- \\
295\end{array}$ & 295 stock & New 295 \\
\hline Dry Adhesion & & & & & Wet Adhesion & & & & \\
\hline \multirow[t]{3}{*}{ CRS } & 1 Day & 4 & 3 & 4 & CRS & 1 Day & 4 & 3 & 4 \\
\hline & 5 Day & 4 & 3 & 4 & & 5 Day & 3 & 0 & 3 \\
\hline & 7 Day & 4 & 3 & 4 & & 7 Day & 3 & 0 & 3 \\
\hline \multirow[t]{3}{*}{ GSS } & 1 Day & 2 & 0 & 0 & GSS & 1 Day & 2 & 2 & 2 \\
\hline & 5 Day & 4 & 0 & 3 & & 5 Day & 4 & 3 & 3 \\
\hline & 7 Day & 3 & 0 & 3 & & 7 Day & 4 & 0 & 3 \\
\hline \multirow[t]{3}{*}{ Aged Alkyd } & 1 Day & 3 & 0 & & Aged Alkyd & 1 Day & 0 & 0 & \\
\hline & 5 Day & 4 & 0 & & & 5 Day & 0 & 0 & \\
\hline & 7 Day & 4 & 0 & & & 7 Day & 0 & 0 & \\
\hline \multirow[t]{3}{*}{ HDG } & 1 Day & 3 & 0 & & HDG & 1 Day & 3 & 2 & \\
\hline & 5 Day & 3 & 0 & & & 5 Day & 3 & 1 & \\
\hline & 7 Day & 4 & 0 & & & 7 Day & 3 & 0 & \\
\hline \multirow[t]{3}{*}{ EZG } & 1 Day & 5 & 3 & & EZG & 1 Day & 4 & 3 & \\
\hline & 5 Day & 4 & 1 & & & 5 Day & 4 & 1 & \\
\hline & 7 Day & 5 & 3 & & & 7 Day & 4 & 0 & \\
\hline \multirow[t]{3}{*}{ Aluminum } & 1 Day & 4 & 4 & & Aluminum & 1 Day & 4 & 3 & \\
\hline & 5 Day & 4 & 4 & & & 5 Day & 4 & 2 & \\
\hline & 7 Day & 4 & 5 & & & 7 Day & 4 & 3 & \\
\hline \multirow[t]{3}{*}{ Glass } & 1 Day & 2 & 2 & & Glass & 1 Day & 0 & 0 & \\
\hline & 5 Day & 3 & 2 & & & 5 Day & 0 & 0 & \\
\hline & 7 Day & 4 & 3 & & & 7 Day & 0 & 0 & \\
\hline \multirow[t]{3}{*}{ Tile } & 1 Day & 3 & 5 & & Tile & 1 Day & 0 & 0 & \\
\hline & 5 Day & 3 & 5 & & & 5 Day & 0 & 0 & \\
\hline & 7 Day & 4 & 5 & & & 7 Day & 0 & 0 & \\
\hline \multirow[t]{3}{*}{ PVC Pipe } & 1 Day & 0 & 0 & & PVC Pipe & 1 Day & 3 & 0 & \\
\hline & 5 Day & 0 & 0 & & & 5 Day & 2 & 0 & \\
\hline & 7 Day & 0 & 0 & & & 7 Day & 0 & 2 & \\
\hline \multirow[t]{3}{*}{ Wood } & 1 Day & 4 & 4 & & Wood & 1 Day & 4 & 4 & \\
\hline & 5 Day & 4 & 4 & & & 5 Day & 4 & 4 & \\
\hline & 7 Day & 5 & 5 & & & 7 Day & 5 & 5 & \\
\hline \multirow[t]{3}{*}{ Hardie } & 1 Day & 5 & 5 & & Hardie & 1 Day & 5 & 5 & \\
\hline & 5 Day & 5 & 5 & & & 5 Day & 5 & 5 & \\
\hline & 7 Day & 5 & 5 & & & 7 Day & 5 & 5 & \\
\hline \multirow[t]{3}{*}{ Copper } & 1 Day & 0 & 4 & & Copper & 1 Day & 0 & 3 & \\
\hline & 5 Day & 0 & 5 & & & 5 Day & 0 & 5 & \\
\hline & 7 Day & 0 & 5 & & & 7 Day & 0 & 5 & \\
\hline Total (180) & & 115 & 93 & 18 & Total (180) & & 86 & 66 & 18 \\
\hline Percentage & & $63.89 \%$ & $51.67 \%$ & $60.00 \%$ & Percentage & & $47.78 \%$ & $36.67 \%$ & $60.00 \%$ \\
\hline
\end{tabular}


Table C.5: Complete Results for 1725-295 and 295 QUV Accelerated Weathering Testing

\begin{tabular}{|l|c|c|c|}
\hline & Gloss & $1725-295$ & 295 \\
\hline Initial & $20^{\circ}$ & 1.3 & 1.3 \\
\hline & $60^{\circ}$ & 3.9 & 4.0 \\
\hline & $85^{\circ}$ & 11.4 & 15.0 \\
\hline 14 Day Exposed & $20^{\circ}$ & 1.2 & 1.3 \\
\hline & $60^{\circ}$ & 3.8 & 4.1 \\
\hline & $85^{\circ}$ & 9.3 & 13.3 \\
\hline & Observations & Yellow spots & Faint spots \\
\hline
\end{tabular}

Table C.6: Complete Results for 1725-295 and 295 Exterior Exposure

\begin{tabular}{|l|l|c|c|}
\hline & Gloss & $1725-295$ & 295 \\
\hline Initial & $20^{\circ}$ & 1.3 & 1.3 \\
\hline & $60^{\circ}$ & 3.9 & 4.0 \\
\hline & $85^{\circ}$ & 11.6 & 13.3 \\
\hline 14 Day Exposed & $20^{\circ}$ & 1.2 & 1.2 \\
\hline & $60^{\circ}$ & 3.8 & 3.4 \\
\hline & $85^{\circ}$ & 13.2 & 10.8 \\
\hline & Observations & Faint rust spots & Many rust spots \\
\hline
\end{tabular}


Table C.7: Complete Results for Chemical Resistance of 1725-295 and 295

\begin{tabular}{|c|c|c|c|c|c|c|c|c|}
\hline Product & \multicolumn{2}{|c|}{$1725-295$} & \multicolumn{2}{|c|}{295} & \multicolumn{2}{|c|}{$1725-295$} & \multicolumn{2}{|c|}{295} \\
\hline & \multicolumn{2}{|c|}{1 Hour } & \multicolumn{2}{|c|}{1 Hour } & \multicolumn{2}{|c|}{24 Hour } & \multicolumn{2}{|c|}{24 Hour } \\
\hline WATER & Initial & $1 \mathrm{hr}$. rec. & Initial & $1 \mathrm{hr}$. rec. & Initial & $1 \mathrm{hr}$. rec. & Initial & $1 \mathrm{hr}$. rec. \\
\hline Softening & 4 & 4 & 2 & 5 & 4 & 4 & 3 & 4 \\
\hline Swelling & 2 & 5 & 3 & 4 & 1 & 5 & 4 & 5 \\
\hline Loss of Gloss & 4 & 5 & 3 & 5 & 2 & 4 & 5 & 5 \\
\hline Stain & 4 & 4 & 4 & 5 & 4 & 5 & 4 & 4 \\
\hline VINEGAR & Initial & 1 hr. rec. & Initial & 1 hr. rec. & Initial & 1 hr. rec. & Initial & $1 \mathrm{hr}$. rec. \\
\hline Softening & 4 & 4 & 2 & 4 & 1 & 2 & 4 & 4 \\
\hline Swelling & 3 & 5 & 5 & 5 & 2 & 3 & 2 & 2 \\
\hline Loss of Gloss & 2 & 5 & 5 & 5 & 1 & 3 & 1 & 1 \\
\hline Stain & 3 & 5 & 5 & 5 & 4 & 4 & 2 & 2 \\
\hline ISOPROPANOL & Initial & $1 \mathrm{hr} . \mathrm{rec}$. & Initial & 1 hr. rec. & Initial & 1 hr. rec. & Initial & $1 \mathrm{hr}$. rec. \\
\hline Softening & 1 & 1 & 1 & 3 & 5 & 5 & 5 & 5 \\
\hline Swelling & 5 & 5 & 2 & 5 & 5 & 5 & 3 & 3 \\
\hline Loss of Gloss & 5 & 5 & 2 & 5 & 5 & 5 & 2 & 2 \\
\hline Stain & 5 & 5 & 5 & 5 & 5 & 5 & 2 & 3 \\
\hline F409 & Initial & $1 \mathrm{hr} . \mathrm{rec}$. & Initial & 1 hr. rec. & Initial & 1 hr. rec. & Initial & $1 \mathrm{hr}$. rec. \\
\hline Softening & 4 & 5 & 3 & 5 & 1 & 4 & 5 & 5 \\
\hline Swelling & 4 & 4 & 5 & 5 & 2 & 2 & 3 & 3 \\
\hline Loss of Gloss & 2 & 5 & 4 & 5 & 2 & 2 & 2 & 2 \\
\hline Stain & 4 & 5 & 5 & 5 & 4 & 4 & 3 & 3 \\
\hline AMMONIA & Initial & $1 \mathrm{hr} . \mathrm{rec}$. & Initial & 1 hr. rec. & Initial & 1 hr. rec. & Initial & $1 \mathrm{hr}$. rec. \\
\hline Softening & 3 & 5 & 2 & 5 & 2 & 5 & 3 & 4 \\
\hline Swelling & 4 & 5 & 5 & 5 & 2 & 5 & 5 & 5 \\
\hline Loss of Gloss & 3 & 5 & 5 & 5 & 1 & 5 & 5 & 5 \\
\hline Stain & 4 & 5 & 5 & 5 & 5 & 5 & 5 & 5 \\
\hline WINDEX & Initial & $1 \mathrm{hr} . \mathrm{rec}$. & Initial & $1 \mathrm{hr} . \mathrm{rec}$. & Initial & 1 hr. rec. & Initial & $1 \mathrm{hr}$. rec. \\
\hline Softening & 2 & 5 & 2 & 5 & 3 & 4 & 5 & 5 \\
\hline Swelling & 4 & 5 & 5 & 5 & 3 & 4 & 2 & 3 \\
\hline Loss of Gloss & 5 & 5 & 5 & 5 & 3 & 4 & 1 & 1 \\
\hline Stain & 5 & 5 & 5 & 5 & 5 & 5 & 1 & 1 \\
\hline KETCHUP & Initial & $1 \mathrm{hr}$. rec. & Initial & $1 \mathrm{hr}$. rec. & Initial & $1 \mathrm{hr}$. rec. & Initial & $1 \mathrm{hr}$. rec. \\
\hline Softening & 3 & 5 & 5 & 5 & 3 & 4 & 4 & 5 \\
\hline Swelling & 5 & 5 & 5 & 5 & 3 & 4 & 5 & 5 \\
\hline Loss of Gloss & 5 & 5 & 5 & 5 & 4 & 4 & 5 & 5 \\
\hline Stain & 5 & 5 & 5 & 5 & 3 & 3 & 2 & 2 \\
\hline MUSTARD & Initial & $1 \mathrm{hr}$. rec. & Initial & $1 \mathrm{hr}$. rec. & Initial & $1 \mathrm{hr}$. rec. & Initial & $1 \mathrm{hr}$. rec. \\
\hline Softening & 2 & 5 & 5 & 5 & 3 & 5 & 2 & 4 \\
\hline Swelling & 4 & 4 & 5 & 5 & 3 & 4 & 2 & 5 \\
\hline Loss of Gloss & 3 & 3 & 5 & 5 & 5 & 5 & 5 & 5 \\
\hline Stain & 2 & 4 & 5 & 5 & 1 & 1 & 1 & 1 \\
\hline Total & 115 & 148 & 130 & 156 & 97 & 129 & 103 & 114 \\
\hline 320 Possible Total & \multicolumn{2}{|c|}{263} & \multicolumn{2}{|c|}{286} & \multicolumn{2}{|c|}{226} & \multicolumn{2}{|c|}{217} \\
\hline Percentage & \multicolumn{2}{|c|}{$82.19 \%$} & \multicolumn{2}{|c|}{$89.38 \%$} & \multicolumn{2}{|c|}{$70.63 \%$} & \multicolumn{2}{|c|}{$67.81 \%$} \\
\hline
\end{tabular}


Table C.8: Complete Results of Hand Lotion Resistance of 1725-295 and 295

\begin{tabular}{|c|c|c|c|c|c|c|c|c|}
\hline Product & \multicolumn{2}{|c|}{$1725-295$} & \multicolumn{2}{|c|}{295} & \multicolumn{2}{|c|}{$1725-295$} & \multicolumn{2}{|c|}{295} \\
\hline $\begin{array}{c}\text { Vaseline Intensive } \\
\text { Care }\end{array}$ & \multicolumn{2}{|c|}{1 Hour } & \multicolumn{2}{|c|}{1 Hour } & \multicolumn{2}{|c|}{24 Hour } & \multicolumn{2}{|c|}{24 Hour } \\
\hline & Initial & 1 hr. rec. & Initial & 1 hr. rec. & Initial & 1 hr. rec. & Initial & $1 \mathrm{hr}$. rec. \\
\hline Softening & 3 & 5 & 3 & 4 & 2 & 5 & 3 & 4 \\
\hline Swelling & 3 & 4 & 3 & 5 & 1 & 3 & 2 & 5 \\
\hline Loss of Gloss & 2 & 5 & 4 & 5 & 3 & 4 & 4 & 5 \\
\hline Stain & 4 & 5 & 4 & 5 & 5 & 5 & 3 & 5 \\
\hline Baby Magic Lotion & \multicolumn{2}{|c|}{1 Hour } & \multicolumn{2}{|c|}{1 Hour } & \multicolumn{2}{|c|}{24 Hour } & \multicolumn{2}{|c|}{24 Hour } \\
\hline & Initial & $1 \mathrm{hr}$. rec. & Initial & $1 \mathrm{hr} . \mathrm{rec}$. & Initial & $1 \mathrm{hr}$. rec. & Initial & $1 \mathrm{hr} . \mathrm{rec}$. \\
\hline Softening & 3 & 5 & 2 & 4 & 1 & 4 & 4 & 4 \\
\hline Swelling & 4 & 4 & 2 & 4 & 1 & 2 & 1 & 4 \\
\hline Loss of Gloss & 2 & 5 & 2 & 5 & 2 & 4 & 3 & 5 \\
\hline Stain & 4 & 5 & 4 & 5 & 4 & 5 & 3 & 5 \\
\hline \multirow[t]{2}{*}{\begin{tabular}{|l} 
Coppertone \\
\end{tabular}} & \multicolumn{2}{|c|}{1 Hour } & \multicolumn{2}{|c|}{1 Hour } & \multicolumn{2}{|c|}{24 Hour } & \multicolumn{2}{|c|}{24 Hour } \\
\hline & Initial & $1 \mathrm{hr}$. rec. & Initial & $1 \mathrm{hr} . \mathrm{rec}$. & Initial & $1 \mathrm{hr}$. rec. & Initial & $1 \mathrm{hr}$. rec. \\
\hline Softening & 3 & 3 & 2 & 4 & 1 & 1 & 2 & 4 \\
\hline Swelling & 2 & 3 & 3 & 4 & 1 & 1 & 1 & 2 \\
\hline Loss of Gloss & 2 & 4 & 2 & 4 & 1 & 1 & 3 & 4 \\
\hline Stain & 3 & 3 & 4 & 4 & 2 & 2 & 2 & 3 \\
\hline Lubriderm & \multicolumn{2}{|c|}{1 Hour } & \multicolumn{2}{|c|}{1 Hour } & \multicolumn{2}{|c|}{24 Hour } & \multicolumn{2}{|c|}{24 Hour } \\
\hline (Yellow) & Initial & $1 \mathrm{hr}$. rec. & Initial & $1 \mathrm{hr} . \mathrm{rec}$. & Initial & $1 \mathrm{hr}$. rec. & Initial & $1 \mathrm{hr}$. rec. \\
\hline Softening & 3 & 3 & 2 & 4 & 1 & 3 & 3 & 3 \\
\hline Swelling & 4 & 4 & 3 & 4 & 2 & 3 & 4 & 3 \\
\hline Loss of Gloss & 3 & 5 & 3 & 5 & 4 & 4 & 5 & 5 \\
\hline Stain & 5 & 5 & 4 & 5 & 5 & 5 & 5 & 5 \\
\hline TOTAL & 50 & 68 & 47 & 71 & 36 & 52 & 48 & 66 \\
\hline 160 Possible Total & \multicolumn{2}{|c|}{118} & \multicolumn{2}{|c|}{118} & \multicolumn{2}{|c|}{88} & \multicolumn{2}{|c|}{114} \\
\hline Percentage & \multicolumn{2}{|c|}{$73.75 \%$} & \multicolumn{2}{|c|}{$73.75 \%$} & \multicolumn{2}{|c|}{$55.00 \%$} & \multicolumn{2}{|c|}{$71.25 \%$} \\
\hline
\end{tabular}




\section{Appendix D - Data Tables for Top Coat Formulation}

Table D.1: Complete Adhesion Testing Results for Formulations 5 and 7 Versus Stock 5880

\begin{tabular}{|c|l|c|c|c|c|c|c|c|c|}
\hline Dry Adhesion & & $\mathbf{5 8 8 0}$ & Form 5 & Form 7 & Wet Adhesion & & $\mathbf{5 8 8 0}$ & Form 5 & Form 7 \\
\hline Aged Alkyd & 1 Day & 5 & 5 & 5 & Aged Alkyd & 1 Day & 0 & 5 & 5 \\
\hline & 5 Day & 5 & 5 & 4 & & 5 Day & 0 & 5 & 4 \\
\hline & 7 Day & 2 & 4 & 4 & & 7 Day & 0 & 4 & 5 \\
\hline Aluminum & 1 Day & 5 & 4 & 4 & Aluminum & 1 Day & 0 & 4 & 4 \\
\hline & 5 Day & 5 & 5 & 5 & & 5 Day & 0 & 4 & 5 \\
\hline & 7 Day & 5 & 5 & 5 & & 7 Day & 0 & 5 & 5 \\
\hline EZG & 1 Day & 2 & 0 & 0 & EZG & 1 Day & 2 & 2 & 3 \\
\hline & 5 Day & 2 & 0 & 0 & & 5 Day & 0 & 3 & 3 \\
\hline & 7 Day & 3 & 0 & 0 & & 7 Day & 0 & 4 & 4 \\
\hline HDG & 1 Day & 4 & 0 & 4 & HDG & 1 Day & 1 & 5 & 4 \\
\hline & 5 Day & 0 & 4 & 4 & & 5 Day & 0 & 4 & 4 \\
\hline & 7 Day & 0 & 4 & 0 & & 7 Day & 0 & 4 & 4 \\
\hline GSS & 1 Day & 0 & 1 & 0 & GSS & 1 Day & 0 & 4 & 4 \\
\hline & 5 Day & 0 & 2 & 2 & & 5 Day & 0 & 3 & 4 \\
\hline 7 Day & 0 & 2 & 0 & & 7 Day & 0 & 3 & 3 \\
\hline & 1 Day & 5 & 4 & 4 & CRS & 1 Day & 3 & 4 & 4 \\
\hline & 5 Day & 5 & 4 & 4 & & 5 Day & 4 & 4 & 4 \\
\hline 7 Day & 4 & 4 & 4 & & 7 Day & 3 & 4 & 4 \\
\hline & 1 Day & 3 & 4 & 4 & CRS2 & 1 Day & 3 & 4 & 4 \\
\hline Total (105) & 5 Day & 1 & 5 & 4 & & 5 Day & 1 & 4 & 4 \\
\hline Percentage & 7 Day & 1 & 4 & 4 & & 7 Day & 3 & 4 & 4 \\
\hline
\end{tabular}


Table D.2: Complete Results for QUV Exterior Exposure Testing of 5880, Formulation 5, and Formulation 7

\begin{tabular}{|l|l|c|c|c|c|c|c|}
\hline & & \multicolumn{3}{|c|}{ Aluminum } & \multicolumn{3}{c|}{ CRS } \\
\hline & Gloss & $\mathbf{5}$ & $\mathbf{5 8 8 0}$ & $\mathbf{7}$ & $\mathbf{5 . 0}$ & $\mathbf{5 8 8 0}$ & $\mathbf{7 . 0}$ \\
\hline & $20^{\circ}$ & 70.4 & 41.3 & 73.5 & 68.1 & 43.8 & 78.7 \\
\hline & $60^{\circ}$ & 89.5 & 77.4 & 88.6 & 88.7 & 78.7 & 89.8 \\
\hline & $85^{\circ}$ & 100.0 & 97.4 & 98.5 & 99.5 & 98.5 & 100.0 \\
\hline & $20^{\circ}$ & 1.7 & 5.8 & 1.3 & $5.6 / 30.7$ & 32.7 & 50.3 \\
\hline & $60^{\circ}$ & 7.7 & 38.5 & 3.1 & $31.1 / 65.9$ & 69.3 & 74.8 \\
\hline & $85^{\circ}$ & 10.1 & 70.6 & 3.4 & $54.3 / 91.4$ & 92.2 & 96.8 \\
\hline 14 Day Exposed & $20^{\circ}$ & 1.3 & 23.9 & 1.2 & 13.0 & 22.7 & 44.3 \\
\hline & $60^{\circ}$ & 9.2 & 69.8 & 5.3 & 44.0 & 61.2 & 78.8 \\
\hline & $85^{\circ}$ & 32.2 & 90.4 & 5.8 & 47.9 & 85.3 & 95.1 \\
\hline 21 Day Exposure & $20^{\circ}$ & 1.5 & 23.3 & 1.4 & 37.7 & 20.7 & 58.0 \\
\hline & $60^{\circ}$ & 5.4 & 68.6 & 7.8 & 65.6 & 60.9 & 86.7 \\
\hline & $85^{\circ}$ & 5.1 & 91.5 & 17.3 & 86.7 & 84.1 & 86.2 \\
\hline 28 Day Exposure & $20^{\circ}$ & 1.1 & 3.1 & 1.4 & 15.6 & 18.8 & 22.8 \\
\hline & $60^{\circ}$ & 6.1 & 22.8 & 4.2 & 63.1 & 57.4 & 61.1 \\
\hline & $85^{\circ}$ & 8.7 & 38.5 & 6.1 & 59.6 & 81.7 & 90.0 \\
\hline
\end{tabular}

Table D.3: Complete Results for Exterior Exposure Testing of 5880, Formulation 5, and Formulation 7

\begin{tabular}{|l|l|c|c|c|}
\hline & & $\mathbf{5}$ & $\mathbf{5 8 8 0}$ & $\mathbf{7}$ \\
\hline & Gloss & & & \\
\hline Initial & $20^{\circ}$ & 67.1 & 43.0 & 71.8 \\
\hline & $60^{\circ}$ & 81.7 & 79.4 & 86.9 \\
\hline & $85^{\circ}$ & 98.7 & 98.1 & 98.8 \\
\hline 14 Day Exposed & $20^{\circ}$ & 9.9 & 33.4 & 36.0 \\
\hline & $60^{\circ}$ & 30.0 & 70.7 & 65.7 \\
\hline & $85^{\circ}$ & 60.9 & 93.6 & 84.9 \\
\hline & Obs. & Rust spots & & \\
\hline 21 Days Exposed & $20^{\circ}$ & 49.6 & 38.7 & 43.5 \\
\hline & $60^{\circ}$ & 73.8 & 72.7 & 75.3 \\
\hline & $85^{\circ}$ & 86.3 & 84.8 & 80.5 \\
\hline & $20^{\circ}$ & 57.5 & 40.8 & 58.0 \\
\hline & $60^{\circ}$ & 83.6 & 75.6 & 82.3 \\
\hline & $85^{\circ}$ & 94.3 & 94.7 & 94.4 \\
\hline
\end{tabular}


Table D.4: Complete Adhesion Testing Results for 8A and 9B

\begin{tabular}{|l|l|l|l|l|l|c|c|}
\hline & & $\mathbf{8 A}$ & $\mathbf{9 B}$ & & & & \\
\hline & $\begin{array}{c}\text { Rheological } \\
\text { modifier }\end{array}$ & $\begin{array}{c}\text { Coalescent \& } \\
\text { Rheological } \\
\text { modifier }\end{array}$ & & & $\begin{array}{c}\text { Rheological } \\
\text { modifier }\end{array}$ & $\begin{array}{c}\text { Coalescent \& } \\
\text { Rheological } \\
\text { modifier }\end{array}$ \\
\hline Dry Adhesion & & & & Wet Adhesion & & & \\
\hline Aged Alkyl & 1 Day & 5 & 4 & Aged Alkyl & 1 Day & 0 & 0 \\
\hline & 3 Day & 5 & 3 & & 3 Day & 2 & 0 \\
\hline & 9 Day & 5 & 4 & & 9 Day & 3 & 0 \\
\hline CRS & 1 Day & 5 & 5 & CRS & 1 Day & 4 & 0 \\
\hline & 3 Day & 5 & 5 & & 3 Day & 4 & 0 \\
\hline 9 Day & 5 & 5 & & 9 Day & 4 & 1 \\
\hline Galvanized & 1 Day & 0 & 0 & Galvanized & 1 Day & 0 & 0 \\
\hline & 3 Day & 0 & 0 & & 3 Day & 0 & 0 \\
\hline 9 Day & 2 & 1 & & 9 Day & 0 & 0 \\
\hline Total (90) & & 32 & 27 & Total (90) & & 17 & 1 \\
\hline Percentage (\%) & & $35.56 \%$ & $30.00 \%$ & Percentage (\%) & & $18.89 \%$ & $1.11 \%$ \\
\hline
\end{tabular}

Table D.5: Complete Results for QUV Exposure Testing of 5880, Formulation 8A, and Formulation 9A

\begin{tabular}{|l|l|c|c|c|}
\hline & & $\mathbf{8 A}$ & $\mathbf{5 8 8 0}$ & $\mathbf{9 A}$ \\
\hline & Gloss & & & \\
\hline Initial & $20^{\circ}$ & 23.2 & 17.5 & 20.3 \\
\hline & $60^{\circ}$ & 59.0 & 47.9 & 48.6 \\
\hline & $85^{\circ}$ & 78.2 & 65.2 & 67.5 \\
\hline 7 Day exposed & $20^{\circ}$ & 25.1 & 17.5 & 20.4 \\
\hline & $60^{\circ}$ & 48.7 & 54.4 & 61.3 \\
\hline & $85^{\circ}$ & 57.6 & 65.8 & 77.8 \\
\hline & $20^{\circ}$ & 29.2 & 3.3 & 22.4 \\
\hline & $60^{\circ}$ & 69.8 & 28.7 & 69.7 \\
\hline & $85^{\circ}$ & 84.1 & 49.6 & 69.7 \\
\hline
\end{tabular}


Table D.6: Complete Results for Exterior Exposure Testing of 5880, Formulation 8A, and Formulation 9A

\begin{tabular}{|l|l|l|l|l|}
\hline & & $\mathbf{8 A}$ & $\mathbf{5 8 8 0}$ & $\mathbf{9 A}$ \\
\hline & Gloss & & & \\
\hline Initial & $20^{\circ}$ & 23.6 & 35.1 & 24.6 \\
\hline & $60^{\circ}$ & 50.4 & 70.2 & 53.1 \\
\hline & $85^{\circ}$ & 69.6 & 96.3 & 72.9 \\
\hline & $20^{\circ}$ & 42.8 & 37.1 & 44.2 \\
\hline & $60^{\circ}$ & 76.5 & 75.3 & 76.1 \\
\hline & $85^{\circ}$ & 93.0 & 93.2 & 86.3 \\
\hline 21 Days Exposed & $20^{\circ}$ & 40.3 & 38.7 & 42.2 \\
\hline & $60^{\circ}$ & 78.3 & 77.4 & 76.0 \\
\hline & $85^{\circ}$ & 80.9 & 93.8 & 94.7 \\
\hline
\end{tabular}


Table D.7: Chemical Resistance of 5880 and Formulation 9C After One Hour of Exposure and Twenty Four Hours of Exposure and One Hour Recovery Values

\begin{tabular}{|c|c|c|c|c|c|c|c|c|}
\hline Product & \multicolumn{2}{|c|}{5880 Stock } & \multicolumn{2}{|c|}{$9 \mathrm{C}$} & \multicolumn{2}{|c|}{5880 Stock } & \multicolumn{2}{|c|}{$9 \mathrm{C}$} \\
\hline & \multicolumn{2}{|c|}{1 Hour } & \multicolumn{2}{|c|}{1 Hour } & \multicolumn{2}{|c|}{24 Hour } & \multicolumn{2}{|c|}{24 Hour } \\
\hline WATER & Initial & 1 hr. rec. & Initial & 1 hr. rec. & Initial & 1 hr. rec. & Initial & 1 hr. rec. \\
\hline Softening & 2 & 4 & 4 & 5 & 3 & 5 & 5 & 5 \\
\hline Swelling & 2 & 5 & 2 & 5 & 1 & 2 & 5 & 5 \\
\hline Loss of Gloss & 2 & 5 & 4 & 5 & 5 & 5 & 5 & 5 \\
\hline Stain & 5 & 5 & 5 & 5 & 2 & 5 & 5 & 5 \\
\hline VINEGAR & Initial & 1 hr. rec. & Initial & $1 \mathrm{hr}$. rec. & Initial & 1 hr. rec. & Initial & $1 \mathrm{hr} . \mathrm{rec}$. \\
\hline Softening & 2 & 2 & 3 & 4 & 2 & 4 & 3 & 3 \\
\hline Swelling & 1 & 4 & 1 & 5 & 1 & 1 & 2 & 2 \\
\hline Loss of Gloss & 2 & 4 & 2 & 5 & 1 & 1 & 1 & 1 \\
\hline Stain & 4 & 5 & 5 & 5 & 1 & 1 & 1 & 1 \\
\hline ISOPROPANOL & Initial & $1 \mathrm{hr}$. rec. & Initial & $1 \mathrm{hr}$. rec. & Initial & $1 \mathrm{hr}$. rec. & Initial & $1 \mathrm{hr}$. rec. \\
\hline Softening & 1 & 1 & 1 & 3 & 2 & 2 & 1 & 2 \\
\hline Swelling & 1 & 5 & 1 & 2 & 1 & 1 & 1 & 1 \\
\hline Loss of Gloss & 3 & 5 & 1 & 4 & 1 & 1 & 1 & 3 \\
\hline Stain & 4 & 5 & 3 & 5 & 2 & 4 & 3 & 3 \\
\hline F410 & Initial & 1 hr. rec. & Initial & $1 \mathrm{hr} . \mathrm{rec}$. & Initial & 1 hr. rec. & Initial & $1 \mathrm{hr} . \mathrm{rec}$. \\
\hline Softening & 2 & 5 & 1 & 5 & 2 & 5 & 4 & 5 \\
\hline Swelling & 3 & 3 & 3 & 3 & 3 & 4 & 3 & 3 \\
\hline Loss of Gloss & 1 & 1 & 1 & 1 & 4 & 4 & 3 & 3 \\
\hline Stain & 4 & 5 & 5 & 5 & 3 & 4 & 1 & 1 \\
\hline AMMONIA & Initial & $1 \mathrm{hr}$. rec. & Initial & $1 \mathrm{hr}$. rec. & Initial & $1 \mathrm{hr} . \mathrm{rec}$. & Initial & $1 \mathrm{hr}$. rec. \\
\hline Softening & 3 & 4 & 4 & 4 & 3 & 5 & 4 & 5 \\
\hline Swelling & 2 & 5 & 3 & 5 & 2 & 4 & 2 & 4 \\
\hline Loss of Gloss & 5 & 5 & 5 & 5 & 5 & 5 & 3 & 5 \\
\hline Stain & 4 & 5 & 5 & 5 & 5 & 5 & 3 & 5 \\
\hline WINDEX & Initial & $1 \mathrm{hr}$. rec. & Initial & $1 \mathrm{hr}$. rec. & Initial & $1 \mathrm{hr} . \mathrm{rec}$. & Initial & $1 \mathrm{hr}$. rec. \\
\hline Softening & 3 & 5 & 4 & 4 & 3 & 5 & 5 & 5 \\
\hline Swelling & 3 & 5 & 5 & 4 & 3 & 4 & 2 & 2 \\
\hline Loss of Gloss & 2 & 3 & 5 & 5 & 3 & 4 & 4 & 4 \\
\hline Stain & 5 & 5 & 5 & 5 & 1 & 1 & 1 & 1 \\
\hline KETCHUP & Initial & 1 hr. rec. & Initial & $1 \mathrm{hr}$. rec. & Initial & 1 hr. rec. & Initial & $1 \mathrm{hr}$. rec. \\
\hline Softening & 3 & 4 & 4 & 5 & 3 & 4 & 5 & 5 \\
\hline Swelling & 5 & 5 & 4 & 5 & 3 & 5 & 5 & 5 \\
\hline Loss of Gloss & 5 & 5 & 5 & 5 & 5 & 5 & 5 & 5 \\
\hline Stain & 5 & 5 & 2 & 5 & 2 & 2 & 2 & 2 \\
\hline MUSTARD & Initial & 1 hr. rec. & Initial & $1 \mathrm{hr}$. rec. & Initial & $1 \mathrm{hr}$. rec. & Initial & $1 \mathrm{hr}$. rec. \\
\hline Softening & 4 & 4 & 4 & 4 & 3 & 5 & 4 & 5 \\
\hline Swelling & 4 & 5 & 3 & 5 & 2 & 4 & 4 & 4 \\
\hline Loss of Gloss & 5 & 5 & 5 & 5 & 5 & 5 & 5 & 5 \\
\hline Stain & 2 & 2 & 5 & 2 & 1 & 1 & 1 & 1 \\
\hline Total & 0 & 136 & 110 & 140 & 83 & 113 & 99 & 111 \\
\hline Total (320) & \multicolumn{2}{|c|}{99} & \multicolumn{2}{|c|}{250} & \multicolumn{2}{|c|}{196} & \multicolumn{2}{|c|}{210} \\
\hline Percentage & \multicolumn{2}{|c|}{$30.94 \%$} & \multicolumn{2}{|c|}{$78.13 \%$} & \multicolumn{2}{|c|}{$61.25 \%$} & \multicolumn{2}{|c|}{$65.63 \%$} \\
\hline
\end{tabular}


Table D.8: Hand Lotion Resistance of 5880 and Formulation 9C After One Hour of Exposure and Twenty Four Hours of Exposure and One Hour Recovery Values

\begin{tabular}{|c|c|c|c|c|c|c|c|c|}
\hline Product & \multicolumn{2}{|c|}{5880 Stock } & \multicolumn{2}{|c|}{$9 \mathrm{C}$} & \multicolumn{2}{|c|}{5880 Stock } & \multicolumn{2}{|c|}{$9 \mathrm{C}$} \\
\hline & \multicolumn{2}{|c|}{1 Hour } & \multicolumn{2}{|c|}{1 Hour } & \multicolumn{2}{|c|}{24 Hour } & \multicolumn{2}{|c|}{24 Hour } \\
\hline Vaseline & Initial & 1 hr. rec. & Initial & 1 hr. rec. & Initial & 1 hr. rec. & Initial & $1 \mathrm{hr}$. rec. \\
\hline Softening & 3 & 2 & 4 & 4 & 3 & 3 & 5 & 5 \\
\hline Swelling & 2 & 3 & 3 & 4 & 3 & 3 & 3 & 3 \\
\hline Loss of Gloss & 3 & 3 & 5 & 5 & 3 & 4 & 4 & 4 \\
\hline \multirow[t]{2}{*}{ Stain } & 5 & 5 & 5 & 5 & 5 & 5 & 5 & 5 \\
\hline & \multicolumn{2}{|c|}{1 Hour } & \multicolumn{2}{|c|}{1 Hour } & \multicolumn{2}{|c|}{24 Hour } & \multicolumn{2}{|c|}{24 Hour } \\
\hline Baby Magic & Initial & 1 hr. rec. & Initial & 1 hr. rec. & Initial & $1 \mathrm{hr}$. rec. & Initial & $1 \mathrm{hr}$. rec. \\
\hline Softening & 1 & 3 & 4 & 4 & 1 & 1 & 2 & 5 \\
\hline Swelling & 2 & 3 & 3 & 4 & 1 & 2 & 2 & 2 \\
\hline Loss of Gloss & 4 & 4 & 5 & 5 & 1 & 3 & 3 & 3 \\
\hline \multirow[t]{2}{*}{ Stain } & 4 & 5 & 5 & 5 & 3 & 4 & 3 & 4 \\
\hline & \multicolumn{2}{|c|}{1 Hour } & \multicolumn{2}{|c|}{1 Hour } & \multicolumn{2}{|c|}{24 Hour } & \multicolumn{2}{|c|}{24 Hour } \\
\hline Coppertone & Initial & $1 \mathrm{hr}$. rec. & Initial & $1 \mathrm{hr}$. rec. & Initial & 1 hr. rec. & Initial & $1 \mathrm{hr}$. rec. \\
\hline Softening & 1 & 1 & 2 & 3 & 1 & 1 & 2 & 3 \\
\hline Swelling & 2 & 3 & 2 & 2 & 1 & 2 & 2 & 2 \\
\hline Loss of Gloss & 2 & 2 & 1 & 1 & 1 & 1 & 2 & 4 \\
\hline \multirow[t]{2}{*}{ Stain } & 4 & 5 & 4 & 4 & 2 & 3 & 3 & 3 \\
\hline & \multicolumn{2}{|c|}{1 Hour } & \multicolumn{2}{|c|}{1 Hour } & \multicolumn{2}{|c|}{24 Hour } & \multicolumn{2}{|c|}{24 Hour } \\
\hline Lubriderm & Initial & 1 hr. rec. & Initial & 1 hr. rec. & Initial & $1 \mathrm{hr} . \mathrm{rec}$. & Initial & $1 \mathrm{hr}$. rec. \\
\hline Softening & 1 & 1 & 3 & 3 & 1 & 1 & 2 & 5 \\
\hline Swelling & 2 & 4 & 4 & 5 & 1 & 2 & 3 & 3 \\
\hline Loss of Gloss & 5 & 4 & 4 & 5 & 1 & 2 & 5 & 5 \\
\hline Stain & 5 & 5 & 5 & 5 & 5 & 5 & 4 & 5 \\
\hline TOTAL & 46 & 53 & 59 & 64 & 33 & 42 & 50 & 61 \\
\hline Total (160) & \multicolumn{2}{|c|}{99} & \multicolumn{2}{|c|}{123} & \multicolumn{2}{|c|}{75} & \multicolumn{2}{|c|}{111} \\
\hline Percentage & \multicolumn{2}{|c|}{$61.88 \%$} & \multicolumn{2}{|c|}{$76.88 \%$} & \multicolumn{2}{|c|}{$46.88 \%$} & \multicolumn{2}{|c|}{$69.38 \%$} \\
\hline
\end{tabular}


Table D.9: Results for Adhesion of 5880 and 9C Formulations With and Without Primer

\begin{tabular}{|c|c|c|c|c|c|c|}
\hline & & & 5880 & $\mathrm{~N} 295-5880$ & $9 \mathrm{C}$ & N295-9C \\
\hline \multirow[t]{21}{*}{ Dry Adhesion } & CRS & 1 Day & 2 & 4 & 0 & 4 \\
\hline & & 3 Day & 4 & 4 & 0 & 3 \\
\hline & & 7 Day & 4 & 4 & 0 & 4 \\
\hline & GSS & 1 Day & 1 & 3 & 0 & 3 \\
\hline & & 3 Day & 3 & 5 & 0 & 1 \\
\hline & & 7 Day & 1 & 1 & 0 & 1 \\
\hline & Aged Alkyl & 1 Day & 5 & & 4 & \\
\hline & & 3 Day & 4 & & 3 & \\
\hline & & 7 Day & 4 & & 3 & \\
\hline & HDG & 1 Day & 3 & 4 & 0 & 4 \\
\hline & & 3 Day & 1 & 4 & 0 & 4 \\
\hline & & 7 Day & 1 & 3 & 0 & 3 \\
\hline & EZG & 1 Day & 4 & 5 & 0 & 5 \\
\hline & & 3 Day & 3 & 5 & 0 & 5 \\
\hline & & 7 Day & 4 & 4 & 0 & 4 \\
\hline & Aluminum & 1 Day & 5 & & 5 & \\
\hline & & 3 Day & 5 & & 5 & \\
\hline & & 7 Day & 5 & & 5 & \\
\hline & Copper & 1 Day & 5 & & 5 & \\
\hline & & 3 Day & 5 & & 5 & \\
\hline & & 7 Day & 5 & & 5 & \\
\hline \multirow[t]{23}{*}{ Wet Adhesion } & CRS & 1 Day & 4 & 4 & 3 & 4 \\
\hline & & 3 Day & 4 & 3 & 4 & 2 \\
\hline & & 7 Day & 4 & 2 & 4 & 2 \\
\hline & GSS & 1 Day & 0 & 3 & 0 & 3 \\
\hline & & 3 Day & 1 & 3 & 1 & 3 \\
\hline & & 7 Day & 0 & 3 & 0 & 0 \\
\hline & Aged Alkyl & 1 Day & 0 & & 0 & 3 \\
\hline & & 3 Day & 0 & & 0 & \\
\hline & & 7 Day & 0 & & 0 & \\
\hline & HDG & 1 Day & 3 & 4 & 0 & \\
\hline & & 3 Day & 3 & 3 & 0 & 3 \\
\hline & & 7 Day & 3 & 2 & 0 & 3 \\
\hline & EZG & 1 Day & 4 & 3 & 0 & 3 \\
\hline & & 3 Day & 4 & 4 & 0 & 2 \\
\hline & & 7 Day & 3 & 3 & 0 & 3 \\
\hline & Aluminum & 1 Day & 0 & & 0 & 4 \\
\hline & & 3 Day & 3 & & 0 & \\
\hline & & 7 Day & 4 & & 0 & \\
\hline & Copper & 1 Day & 4 & & 4 & \\
\hline & & 3 Day & 4 & & 5 & \\
\hline & & 7 Day & 4 & & 5 & \\
\hline & Total $(210 / 120)$ & & 136 & 82 & 68 & 72 \\
\hline & Percentage $(\%)$ & & $75.56 \%$ & $68.33 \%$ & $37.78 \%$ & $60.00 \%$ \\
\hline
\end{tabular}


Table D.10: Gloss Measurements of Tinted 9C Formulations Over Three Weeks of Aging at Room Temperature and $120^{\circ} \mathrm{F}$

\begin{tabular}{|c|c|c|c|c|c|c|c|c|c|c|}
\hline & \multirow{3}{*}{$\begin{array}{c}\text { Initial } \\
9 \mathrm{C}\end{array}$} & \multicolumn{2}{|c|}{ Overnight } & \multicolumn{2}{|c|}{1 Weeks } & \multicolumn{2}{|c|}{2 Weeks } & \multicolumn{2}{|c|}{3 Weeks } \\
\hline & & & $9 \mathrm{C}$ & $9 \mathrm{C}$ & $9 \mathrm{C}$ & $9 \mathrm{C}$ & $9 \mathrm{C}$ & $9 \mathrm{C}$ & $9 \mathrm{C}$ & $9 \mathrm{C}$ \\
\hline & & & Oven & $\mathrm{RT}$ & Oven & RT & Oven & RT & Oven & RT \\
\hline \multirow[t]{3}{*}{ OY } & & 23.4 & 34.6 & 35.7 & 20.1 & 30.5 & 25.2 & 30.4 & 23.0 & 29.0 \\
\hline & $60^{\circ}$ & 71.2 & 77.7 & 76.1 & 68.6 & 73.9 & 67.6 & 73.1 & 64.1 & 72.8 \\
\hline & $85^{\circ}$ & 87.4 & 99.4 & 99.1 & 67.7 & 93.7 & 91.1 & 94.2 & 92.3 & 90.2 \\
\hline \multirow[t]{3}{*}{ LB } & $20^{\circ}$ & 33.7 & 18.0 & 36.7 & 10.5 & 32.1 & 9.1 & 34.2 & 7.4 & 32.9 \\
\hline & $60^{\circ}$ & 71.3 & 62.6 & 73.5 & 52.7 & 72.2 & 50.1 & 73.3 & 45.4 & 70.5 \\
\hline & $85^{\circ}$ & 93.5 & 96.9 & 97.4 & 90.9 & 94.1 & 90.1 & 95.3 & 91.6 & 96.1 \\
\hline \multirow[t]{3}{*}{$\mathrm{YO}$} & $20^{\circ}$ & 32.5 & 20.5 & 28.6 & 25.1 & 25.1 & 14.8 & 31.0 & 15.4 & 28.6 \\
\hline & 60 & 74.2 & 2 & 70.8 & 82.3 & 9 & 58.6 & 1 & 57.7 & 68.9 \\
\hline & $85^{\circ}$ & 94.5 & 96.9 & 96.4 & 68.2 & 95.0 & 93.2 & 95.2 & 92.5 & 94.7 \\
\hline \multirow[t]{3}{*}{ PG } & 20 & 33.4 & 28.5 & 33.0 & 19.9 & 26.5 & 18.4 & 30.2 & 19.7 & 35.6 \\
\hline & 60 & 69.4 & 70.6 & 75.4 & 65.2 & 72 & 63.1 & & 62.4 & 72.7 \\
\hline & $85^{\circ}$ & 93.5 & 98.0 & 98.9 & 91.1 & 89.3 & 93.9 & 96.1 & 92.6 & 95.7 \\
\hline \multirow[t]{3}{*}{$\mathrm{PB}$} & 20 & 32.5 & 23.8 & 34.0 & 8.0 & 25.3 & 18.0 & 31 & 15.5 & 32.6 \\
\hline & 60 & 72.8 & 67 & 73.9 & 52.5 & 71.4 & 61.0 & 73 & 59.5 & 70.9 \\
\hline & $85^{\circ}$ & 92.1 & 98.2 & 98.4 & 89.4 & 85.1 & 93.8 & 94.6 & 92.2 & 94.7 \\
\hline \multirow[t]{3}{*}{$\mathrm{RO}$} & $20^{\circ}$ & 30.5 & 28.4 & 31.9 & 17.4 & 3 & 22.0 & 30.1 & 21.3 & 30.8 \\
\hline & 60 & 73.6 & 70 & 73.3 & 65.6 & 71 & 65.1 & 73.1 & 63.2 & 70.7 \\
\hline & $85^{\circ}$ & 93.9 & 98.3 & 98.2 & 91.2 & 94.7 & 94.1 & 95.7 & 89.9 & 91.9 \\
\hline \multirow{3}{*}{ MY } & $20^{\circ}$ & 11.7 & 24.5 & 27.9 & 16.5 & 25 & 24.4 & 28.0 & 20.2 & 29.7 \\
\hline & 60 & 75.4 & 68.1 & 74.0 & 60.7 & 71.2 & 68.1 & 71 & 62.5 & 69.9 \\
\hline & $85^{\circ}$ & 61.8 & .9 & 97.5 & 92.7 & 9. & 94.4 & & 92.9 & 94.3 \\
\hline \multirow{3}{*}{$\mathrm{QV}$} & $20^{\circ}$ & 23.2 & 29.0 & 36.1 & 21.5 & 31.7 & 26.5 & 33.0 & 27.8 & 32.7 \\
\hline & 60 & 75.6 & 704 & 74.8 & 68.0 & 73 & 69.7 & 74.9 & 68.3 & 69.5 \\
\hline & $85^{\circ}$ & 81.9 & 98.1 & 98.8 & 88.5 & 9 & 95.0 & 0 & 93.9 & 94.6 \\
\hline \multirow[t]{3}{*}{$\mathrm{QR}$} & $20^{\circ}$ & 34.3 & 31.7 & 36.4 & 23.9 & 30.5 & 22.6 & 32.1 & 24.5 & 32.5 \\
\hline & $60^{\circ}$ & 75.5 & 73.1 & 75.7 & 69.4 & 74.0 & 67.8 & 74.0 & 66.3 & 70.8 \\
\hline & $85^{\circ}$ & 92.5 & 99.0 & 99.0 & 87.4 & 93.3 & 95.0 & 91.2 & 94.4 & 93.8 \\
\hline \multirow[t]{3}{*}{$\mathrm{UO}$} & $20^{\circ}$ & 29.9 & 24.0 & 30.7 & 21.0 & 26.5 & 18.1 & 30.6 & 19.2 & 32.7 \\
\hline & $60^{\circ}$ & 74.7 & 68.3 & 73.6 & 60.5 & 69.0 & 62.5 & 73.0 & 61.4 & 71.0 \\
\hline & $85^{\circ}$ & 92.9 & 97.8 & 98.6 & 86.7 & 93.1 & 94.5 & 91.3 & 93.6 & 95.4 \\
\hline \multirow[t]{3}{*}{$\mathrm{BU}$} & $20^{\circ}$ & 32.2 & 30.2 & 32.8 & 18.7 & 30.6 & 22.8 & 28.7 & 23.7 & 30.1 \\
\hline & $60^{\circ}$ & 72.9 & 70.7 & 74.6 & 66.7 & 71.7 & 65.3 & 72.3 & 65.4 & 70.0 \\
\hline & 85 & 93.0 & 98.5 & 99.4 & 89.4 & 95.0 & 94.7 & 87.7 & 94.2 & 94.7 \\
\hline
\end{tabular}


Table D.11: Results of Syneresis and Color Float Testing On Oven Samples of Tinted 9C and 5880 Formulations Over Three Weeks of Testing

\begin{tabular}{|c|c|c|c|c|c|c|c|c|c|}
\hline Overnight & OY & LB & YO & PG & PB & RO & MY & QV & QR \\
\hline $9 \mathrm{C}$ & & & Syn, CF & CF & CF & minor CF & CF & CF & CF \\
\hline 5880 & & Syn & & & minor Syn & minor CF & & minor CF & \\
\hline
\end{tabular}

\begin{tabular}{|c|c|c|c|c|c|c|c|c|c|}
\hline 1 Week & OY & LB & YO & PG & PB & RO & MY & QV & QR \\
\hline $9 \mathrm{C}$ & CF & CF & CF & CF, Syn & CF & CF & CF & CF & CF \\
\hline 5880 & CF & minor CF & CF & CF & minor CF & minor Syn & & Syn & CF \\
\hline
\end{tabular}

\begin{tabular}{|c|c|c|c|c|c|c|c|c|c|}
\hline 2 Week & OY & LB & YO & PG & PB & RO & MY & QV & QR \\
\hline $9 \mathrm{C}$ & CF & bad CF & CF, Syn & bad CF & bad CF & CF, Syn & bad CF & bad CF & bad CF \\
\hline 5880 & Syn & Syn & CF, Syn & CF & CF & CF, Syn & Syn & CF & CF \\
\hline
\end{tabular}

\begin{tabular}{|c|c|c|c|c|c|c|c|c|c|}
\hline 3 Week & OY & LB & YO & PG & PB & RO & MY & QV & QR \\
\hline $9 \mathrm{C}$ & CF & CF & Syn, CF & CF & CF & CF & CF & CF & CF \\
\hline 5880 & minor Syn & CF & Syn, CF & CF & CF & Syn & Syn & Syn & Syn \\
\hline
\end{tabular}

Syn $=$ Presence of Syneresis, CF = Presence of Color Float

Table D.12: Results for Initial Tinting 9C Compared to Initial Tinting of 5880

\begin{tabular}{|l|r|r|r|r|r|r|r|r|r|r|r|r|}
\hline & OY & \multicolumn{1}{c|}{ LB } & \multicolumn{1}{c|}{ YO } & \multicolumn{1}{c|}{ PG } & \multicolumn{1}{c|}{ PB } & \multicolumn{1}{c|}{ RO } & \multicolumn{1}{c|}{ MY } & \multicolumn{1}{c|}{ QV } & \multicolumn{1}{c|}{ QR } & \multicolumn{1}{c}{ UO } & BU & Averages \\
\hline$\Delta \mathrm{L}$ & 0.31 & -0.36 & 0.28 & 0.49 & 0.49 & 0.80 & 0.22 & 0.67 & 0.03 & 0.21 & 0.63 & 0.34 \\
\hline$\Delta \mathrm{a}$ & 0.91 & 0.05 & -0.20 & 0.42 & 0.20 & -0.53 & -0.13 & -0.38 & 0.32 & 0.00 & -0.22 & 0.04 \\
\hline$\Delta \mathrm{b}$ & -0.66 & 0.35 & -0.13 & -0.03 & 0.39 & -0.20 & -0.55 & 0.13 & -0.17 & 0.28 & -0.13 & -0.07 \\
\hline$\Delta \mathrm{E}$ & 0.75 & 0.50 & 0.36 & 0.65 & 0.66 & 0.98 & 0.61 & 0.78 & 0.37 & 0.35 & 0.68 & 0.61 \\
\hline Tint Strength & 110.26 & 99.01 & 102.59 & 105.44 & 105.40 & 109.09 & 107.15 & 105.75 & 98.72 & 100.97 & 106.83 & 104.66 \\
\hline
\end{tabular}


Results for Tinting 9C and 5880 After Aging Overnight at Room Temperature and at $120^{\circ} \mathrm{F}$ Compared to Initial Tinting Values.

Table D.13: 9C Room Temperature Aged Overnight Versus Initial 9C Tinting Values

\begin{tabular}{|l|r|r|r|r|r|r|r|r|r|r|r|r|}
\hline & \multicolumn{1}{|c|}{ OY } & \multicolumn{1}{c|}{ LB } & \multicolumn{1}{c|}{ YO } & \multicolumn{1}{c|}{ PG } & \multicolumn{1}{c|}{ PB } & \multicolumn{1}{c|}{ RO } & \multicolumn{1}{c|}{ MY } & \multicolumn{1}{c|}{ QV } & QR & UO & BU & Averages \\
\hline$\Delta \mathrm{L}$ & 0.18 & -0.01 & -0.06 & 0.02 & -0.12 & -0.18 & -0.01 & -0.01 & -0.02 & -0.05 & 0.02 & -0.02 \\
\hline$\Delta \mathrm{a}$ & -0.05 & 0.03 & 0.11 & -0.02 & -0.04 & 0.26 & -0.02 & 0.01 & 0.03 & 0.20 & 0.02 & 0.05 \\
\hline$\Delta \mathrm{b}$ & 0.12 & -0.01 & 0.61 & -0.01 & -0.15 & 0.18 & 0.34 & 0.03 & 0.04 & 0.16 & 0.03 & 0.12 \\
\hline$\Delta \mathrm{E}$ & 0.22 & 0.03 & 0.62 & 0.03 & 0.20 & 0.36 & 0.34 & 0.04 & 0.06 & 0.27 & 0.04 & 0.20 \\
\hline Tint Strength & 101.27 & 99.93 & 95.75 & 100.30 & 98.70 & 97.60 & 97.61 & 99.96 & 99.88 & 98.72 & 100.04 & 99.07 \\
\hline
\end{tabular}

Table D.14: 9C Elevated Temperature Aged Overnight Versus Initial 9C Tinting Values

\begin{tabular}{|l|r|r|r|r|r|r|r|r|r|r|r|r|}
\hline & \multicolumn{1}{c|}{ OY } & \multicolumn{1}{c|}{ LB } & \multicolumn{1}{c|}{ YO } & \multicolumn{1}{c|}{ PG } & \multicolumn{1}{c|}{ PB } & \multicolumn{1}{c|}{ RO } & \multicolumn{1}{c|}{ MY } & \multicolumn{1}{c|}{ QV } & QR & UO & BU & Averages \\
\hline$\Delta \mathrm{L}$ & -0.05 & -0.87 & -0.23 & -0.36 & -0.54 & -0.67 & -0.05 & -0.23 & -0.20 & -0.23 & -0.18 & -0.33 \\
\hline$\Delta \mathrm{a}$ & -0.24 & 0.11 & 0.26 & -0.54 & -0.10 & 0.70 & 0.12 & 0.16 & 0.24 & 0.51 & 0.10 & 0.12 \\
\hline$\Delta \mathrm{b}$ & 0.77 & 0.37 & 1.15 & 0.18 & -0.33 & 0.57 & 0.99 & 0.18 & 0.22 & 0.49 & 0.24 & 0.44 \\
\hline$\Delta \mathrm{E}$ & 0.81 & 0.95 & 1.21 & 0.67 & 0.64 & 1.13 & 1.00 & 0.33 & 0.38 & 0.74 & 0.32 & 0.74 \\
\hline Tint Strength & 93.26 & 96.24 & 90.97 & 95.92 & 95.51 & 91.68 & 93.37 & 98.52 & 98.34 & 95.99 & 96.37 & 95.11 \\
\hline
\end{tabular}

Table D.15: 5880 Room Temperature Aged Overnight Versus Initial 5880 Tinting Values

\begin{tabular}{|l|r|r|r|r|r|r|r|r|r|r|r|r|}
\hline & \multicolumn{1}{|c|}{ OY } & \multicolumn{1}{c|}{ LB } & \multicolumn{1}{c|}{ YO } & \multicolumn{1}{c|}{ PG } & \multicolumn{1}{c|}{ PB } & \multicolumn{1}{c|}{ RO } & MY & \multicolumn{1}{c|}{ QV } & QR & UO & BU & Averages \\
\hline$\Delta \mathrm{L}$ & 0.35 & 0.81 & 0.04 & 0.15 & 0.17 & 0.18 & 0.40 & 0.71 & 0.37 & 0.45 & 0.12 & 0.34 \\
\hline$\Delta \mathrm{a}$ & -0.03 & -0.04 & -0.01 & 0.15 & 0.04 & 0.02 & 1.78 & -0.69 & -0.55 & -0.63 & -0.02 & 0.00 \\
\hline$\Delta \mathrm{b}$ & 0.03 & -0.12 & 0.05 & -0.07 & 0.03 & -0.08 & -7.42 & 0.72 & 0.21 & -0.54 & -0.16 & -0.67 \\
\hline$\Delta \mathrm{E}$ & 0.35 & 0.82 & 0.07 & 0.22 & 0.18 & 0.20 & 7.64 & 1.23 & 0.69 & 0.95 & 0.21 & 1.14 \\
\hline Tint Strength & 104.40 & 104.90 & 99.96 & 101.78 & 101.52 & 101.55 & 162.69 & 112.03 & 105.28 & 108.03 & 102.59 & 109.52 \\
\hline
\end{tabular}

Table D.16: 5880 Elevated Temperature Aged Overnight Versus Initial 5880 Tinting Values

\begin{tabular}{|l|r|r|r|r|r|r|r|r|r|r|r|r|}
\hline & \multicolumn{1}{c|}{ OY } & \multicolumn{1}{c|}{ LB } & \multicolumn{1}{c|}{ YO } & \multicolumn{1}{c|}{ PG } & \multicolumn{1}{c|}{ PB } & \multicolumn{1}{c|}{ RO } & \multicolumn{1}{c|}{ MY } & \multicolumn{1}{l|}{ QV } & QR & UO & BU & Averages \\
\hline$\Delta \mathrm{L}$ & -0.03 & 1.46 & 0.02 & 0.13 & 0.10 & 0.03 & 0.34 & 1.11 & 0.10 & 0.36 & 0.08 & 0.34 \\
\hline$\Delta \mathrm{a}$ & 0.20 & -0.07 & 0.01 & 0.30 & 0.08 & 0.09 & 1.83 & -1.15 & 0.33 & -0.50 & 0.00 & 0.10 \\
\hline$\Delta \mathrm{b}$ & -0.80 & -0.22 & 0.24 & 0.02 & 0.05 & -0.02 & -7.38 & 1.35 & -0.14 & -0.42 & -0.29 & -0.69 \\
\hline$\Delta \mathrm{E}$ & 0.83 & 1.48 & 0.24 & 0.32 & 0.14 & 0.10 & 7.62 & 2.09 & 0.37 & 0.75 & 0.31 & 1.30 \\
\hline Tint Strength & 106.09 & 108.81 & 98.43 & 103.10 & 101.24 & 100.13 & 100.47 & 122.00 & 99.36 & 106.53 & 103.46 & 104.51 \\
\hline
\end{tabular}


Results for Tinting 9C and 5880 After Aging Seven Days at Room Temperature and at $120^{\circ} \mathrm{F}$ Compared to Initial Tinting Values.

Table D.17: 9C Room Temperature Aged One Week Versus Initial 9C Tinting Values

\begin{tabular}{|c|c|c|c|c|c|c|c|c|c|c|c|c|}
\hline & OY & LB & $\mathrm{YO}$ & $\mathrm{PG}$ & PB & RO & MY & $\mathrm{QV}$ & $\mathrm{QR}$ & UO & $\mathrm{BU}$ & Averages \\
\hline$\Delta \mathrm{L}$ & -0.04 & -0.39 & -0.98 & -0.37 & 0.05 & -0.80 & 0.62 & -0.24 & -0.13 & -0.53 & -0.04 & -0.26 \\
\hline$\Delta \mathrm{a}$ & -0.20 & 0.13 & -0.30 & -0.91 & 0.17 & 1.02 & 1.56 & 0.13 & 0.17 & 1.12 & 0.29 & 0.29 \\
\hline$\Delta \mathrm{b}$ & 0.82 & 0.42 & 3.98 & 0.17 & -0.23 & 0.68 & -5.68 & 0.35 & 0.47 & 0.81 & 0.42 & 0.20 \\
\hline$\Delta \mathrm{E}$ & 0.85 & 0.59 & 4.11 & 1.00 & 0.29 & 1.46 & 5.92 & 0.44 & 0.52 & 1.48 & 0.51 & 1.56 \\
\hline Tint Strength & 91.82 & 99.67 & 70.54 & 94.35 & 101.33 & 89.89 & 160.89 & 99.30 & 99.50 & 91.45 & 97.09 & 99.62 \\
\hline
\end{tabular}

TableD.18: 9C Elevated Temperature Aged One Week Versus Initial 9C Tinting Values

\begin{tabular}{|l|r|r|r|r|r|r|r|r|r|r|r|r|}
\hline & \multicolumn{1}{|c|}{ OY } & \multicolumn{1}{c|}{ LB } & \multicolumn{1}{c|}{ YO } & \multicolumn{1}{c|}{ PG } & \multicolumn{1}{c|}{ PB } & \multicolumn{1}{c|}{ RO } & MY & \multicolumn{1}{c|}{ QV } & QR & UO & BU & Averages \\
\hline$\Delta \mathrm{L}$ & 0.12 & 0.03 & 0.10 & 0.17 & -0.01 & -0.25 & 0.20 & 0.13 & 0.18 & 0.07 & 0.08 & 0.07 \\
\hline$\Delta \mathrm{a}$ & -0.09 & 0.02 & 0.18 & -0.16 & 0.02 & 0.53 & 0.03 & -0.03 & -0.05 & 0.31 & 0.05 & 0.07 \\
\hline$\Delta \mathrm{b}$ & 0.23 & 0.00 & 0.74 & -0.08 & -0.34 & 0.28 & 0.55 & 0.09 & 0.16 & 0.19 & 0.00 & 0.17 \\
\hline$\Delta \mathrm{E}$ & 0.27 & 0.04 & 0.77 & 0.25 & 0.34 & 0.65 & 0.58 & 0.16 & 0.25 & 0.37 & 0.10 & 0.34 \\
\hline Tint Strength & 99.00 & 100.19 & 96.25 & 100.66 & 99.77 & 95.99 & 98.58 & 101.32 & 101.73 & 99.49 & 101.11 & 99.46 \\
\hline
\end{tabular}

Table D.19: 5880 Room Temperature Aged One Week Versus Initial 5880 Tinting Values

\begin{tabular}{|c|c|c|c|c|c|c|c|c|c|c|c|c|}
\hline & $\mathrm{OY}$ & LB & $\mathrm{YO}$ & PG & $\mathrm{PB}$ & RO & MY & $\mathrm{QV}$ & $\mathrm{QR}$ & UO & $\mathrm{BU}$ & Averages \\
\hline$\Delta \mathrm{L}$ & 0.21 & 1.88 & 0.16 & 0.12 & 0.12 & 0.05 & 0.48 & 0.99 & 0.93 & 0.41 & 0.19 & 0.50 \\
\hline$\Delta \mathrm{a}$ & -0.05 & -0.12 & 0.08 & 0.29 & 0.18 & 0.19 & 1.93 & -1.03 & -1.88 & -0.39 & 0.05 & -0.07 \\
\hline$\Delta \mathrm{b}$ & 0.16 & -0.46 & 0.38 & 0.01 & -0.04 & -0.02 & -7.17 & 1.25 & 0.94 & -0.41 & -0.40 & -0.52 \\
\hline$\Delta \mathrm{E}$ & 0.27 & 1.94 & 0.42 & 0.32 & 0.22 & 0.19 & 7.44 & 1.90 & 2.30 & 0.70 & 0.44 & 1.47 \\
\hline Tint Strength & 100.87 & 110.65 & 98.88 & 103.32 & 101.79 & 99.79 & 160.12 & 119.72 & 117.45 & 106.55 & 105.93 & 111.37 \\
\hline
\end{tabular}

Table D.20: 5880 Elevated Temperature Aged One Week Versus Initial 5880 Tinting Values

\begin{tabular}{|c|c|c|c|c|c|c|c|c|c|c|c|c|}
\hline & OY & LB & $\mathrm{YO}$ & PG & $\mathrm{PB}$ & $\mathrm{RO}$ & MY & QV & $\mathrm{QR}$ & $\mathrm{UO}$ & $\mathrm{BU}$ & Averages \\
\hline$\Delta \mathrm{L}$ & 0.20 & 2.34 & 0.18 & 0.17 & 0.19 & 0.17 & 0.51 & 1.62 & 1.09 & 0.51 & 0.12 & 0.65 \\
\hline$\Delta \mathrm{a}$ & -0.03 & -0.12 & 0.03 & 0.24 & 0.09 & 0.06 & 1.88 & -1.55 & -2.09 & -0.65 & 0.00 & -0.19 \\
\hline$\Delta \mathrm{b}$ & 0.02 & -0.36 & 0.11 & -0.11 & -0.07 & -0.11 & -7.41 & 1.78 & 0.87 & -0.57 & -0.32 & -0.56 \\
\hline$\Delta \mathrm{E}$ & 0.20 & 2.37 & 0.22 & 0.31 & 0.22 & 0.21 & 7.67 & 2.87 & 2.51 & 1.01 & 0.34 & 1.63 \\
\hline Tint Strength & 102.31 & 114.48 & 100.99 & 102.50 & 101.73 & 101.26 & 163.47 & 132.20 & 119.15 & 108.62 & 104.27 & 113.73 \\
\hline
\end{tabular}


Results for Tinting 9C and 5880 After Aging Fourteen Days at Room Temperature and at $120^{\circ} \mathrm{F}$ Compared to Initial Tinting Values.

Table D.21: 9C Room Temperature Aged Two Week Versus Initial 9C Tinting Values

\begin{tabular}{|c|c|c|c|c|c|c|c|c|c|c|c|c|}
\hline & OY & LB & $\mathrm{YO}$ & PG & PB & $\mathrm{RO}$ & MY & $\mathrm{QV}$ & $\mathrm{QR}$ & $\mathrm{UO}$ & $\mathrm{BU}$ & Averages \\
\hline$\Delta \mathrm{L}$ & 0.30 & 0.32 & 0.28 & 0.22 & 0.16 & -0.03 & 0.30 & 0.19 & 0.14 & 0.19 & 0.17 & 0.20 \\
\hline$\Delta \mathrm{a}$ & -0.10 & -0.01 & 0.03 & -0.11 & 0.04 & 0.37 & 0.08 & -0.01 & 0.15 & 0.13 & 0.00 & 0.05 \\
\hline$\Delta \mathrm{b}$ & 0.01 & -0.12 & 0.27 & -0.17 & -0.28 & 0.15 & 0.58 & -0.06 & -0.02 & -0.07 & -0.09 & 0.02 \\
\hline$\Delta \mathrm{E}$ & 0.32 & 0.34 & 0.40 & 0.30 & 0.33 & 0.40 & 0.66 & 0.20 & 0.21 & 0.24 & 0.20 & 0.33 \\
\hline Tint Strength & 103.43 & 101.64 & 100.85 & 100.93 & 100.89 & 98.35 & 99.55 & 101.55 & 101.10 & 101.58 & 102.47 & 101.12 \\
\hline
\end{tabular}

Table D.22: 9C Elevated Temperature Aged Two Week Versus Initial 9C Tinting Values

\begin{tabular}{|l|r|r|r|r|r|r|r|r|r|r|r|r|}
\hline & \multicolumn{1}{c|}{ OY } & \multicolumn{1}{c|}{ LB } & \multicolumn{1}{c|}{ YO } & \multicolumn{1}{c|}{ PG } & \multicolumn{1}{c|}{ PB } & \multicolumn{1}{c|}{ RO } & MY & \multicolumn{1}{c|}{ QV } & QR & UO & BU & Averages \\
\hline$\Delta \mathrm{L}$ & 0.37 & 0.72 & 0.06 & -0.29 & -0.94 & -0.73 & 0.43 & -0.04 & 0.00 & 0.10 & 0.02 & -0.03 \\
\hline$\Delta \mathrm{a}$ & -0.16 & 0.09 & 0.35 & -0.94 & -0.31 & 1.05 & 2.04 & 0.11 & 0.16 & 0.41 & 0.34 & 0.29 \\
\hline$\Delta \mathrm{b}$ & 0.48 & 0.33 & 1.06 & 0.12 & -1.17 & 0.69 & -6.96 & 0.22 & 0.43 & 0.31 & 0.49 & -0.36 \\
\hline$\Delta \mathrm{E}$ & 0.63 & 0.79 & 1.12 & 0.99 & 1.53 & 1.46 & 7.27 & 0.25 & 0.46 & 0.52 & 0.59 & 1.42 \\
\hline Tint Strength & 99.69 & 106.59 & 94.55 & 95.02 & 90.12 & 90.24 & 160.25 & 100.94 & 100.80 & 99.52 & 96.90 & 103.15 \\
\hline
\end{tabular}

Table D.23: 5880 Room Temperature Aged Two Week Versus Initial 5880 Tinting Values

\begin{tabular}{|c|c|c|c|c|c|c|c|c|c|c|c|c|}
\hline & OY & LB & $\mathrm{YO}$ & PG & $\mathrm{PB}$ & $\mathrm{RO}$ & MY & $\mathrm{QV}$ & $\mathrm{QR}$ & UO & $\mathrm{BU}$ & Averages \\
\hline$\Delta \mathrm{L}$ & 0.49 & 2.25 & 0.25 & 0.21 & 0.24 & 0.26 & 0.48 & 1.72 & 0.89 & 0.27 & 0.14 & 0.65 \\
\hline$\Delta \mathrm{a}$ & -0.08 & -0.12 & -0.05 & 0.21 & 0.10 & 0.02 & 1.78 & -1.61 & -1.58 & -0.08 & -0.01 & -0.13 \\
\hline$\Delta \mathrm{b}$ & -0.16 & -0.46 & -0.04 & -0.11 & -0.05 & -0.18 & -7.50 & 1.84 & 0.67 & -0.19 & -0.27 & -0.59 \\
\hline$\Delta \mathrm{E}$ & 0.52 & 2.30 & 0.26 & 0.31 & 0.27 & 0.32 & 7.73 & 2.99 & 1.93 & 0.33 & 0.30 & 1.57 \\
\hline Tint Strength & 107.43 & 113.28 & 102.07 & 102.72 & 102.13 & 102.27 & 164.00 & 133.85 & 114.44 & 103.09 & 103.58 & 113.53 \\
\hline
\end{tabular}

Table D.24: 5880 Elevated Temperature Aged Two Week Versus Initial 5880 Tinting Values

\begin{tabular}{|c|c|c|c|c|c|c|c|c|c|c|c|c|}
\hline & OY & LB & $\mathrm{YO}$ & PG & $\mathrm{PB}$ & $\mathrm{RO}$ & MY & $\mathrm{QV}$ & $\mathrm{QR}$ & $\mathrm{UO}$ & $\mathrm{BU}$ & Averages \\
\hline$\Delta \mathrm{L}$ & 0.52 & 1.81 & 0.22 & 0.11 & 0.09 & 0.07 & 0.53 & 1.07 & 0.95 & 0.30 & 0.21 & 0.53 \\
\hline$\Delta \mathrm{a}$ & -0.09 & -0.10 & 0.04 & 0.18 & 0.17 & 0.23 & 1.88 & -1.02 & -1.75 & -0.17 & 0.03 & -0.05 \\
\hline$\Delta \mathrm{b}$ & 0.10 & -0.49 & 0.37 & 0.00 & -0.09 & 0.02 & -7.19 & 1.16 & 0.82 & -0.26 & -0.37 & -0.54 \\
\hline$\Delta \mathrm{E}$ & 0.54 & 1.88 & 0.43 & 0.21 & 0.22 & 0.24 & 7.45 & 1.88 & 2.15 & 0.43 & 0.43 & 1.44 \\
\hline Tint Strength & 105.12 & 110.19 & 99.33 & 102.77 & 101.45 & 99.89 & 161.40 & 120.14 & 117.19 & 104.21 & 105.59 & 111.57 \\
\hline
\end{tabular}


Results for Tinting 9C and 5880 After Aging Twenty-One Days at Room Temperature and at $120{ }^{\circ} \mathrm{F}$ Compared to Initial Tinting Values.

Table D.25: 9C Room Temperature Aged Three Week Versus Initial 9C Tinting Values

\begin{tabular}{|c|c|c|c|c|c|c|c|c|c|c|c|c|}
\hline & OY & $\mathrm{LB}$ & $\mathrm{YO}$ & PG & $\mathrm{PB}$ & $\mathrm{RO}$ & MY & $\mathrm{QV}$ & $\mathrm{QR}$ & UO & $\mathrm{BU}$ & Averages \\
\hline$\Delta \mathrm{L}$ & 0.50 & 0.01 & 0.19 & 0.17 & 0.03 & -0.24 & 0.35 & 0.15 & 0.18 & 0.25 & 0.20 & 0.16 \\
\hline$\Delta \mathrm{a}$ & -0.16 & 0.01 & 0.10 & -0.23 & 0.00 & 0.61 & 0.06 & 0.00 & 0.21 & 0.20 & 0.04 & 0.08 \\
\hline$\Delta \mathrm{b}$ & 0.40 & -0.05 & 0.63 & -0.14 & -0.44 & 0.34 & 0.61 & 0.03 & -0.06 & 0.00 & -0.01 & 0.12 \\
\hline$\Delta \mathrm{E}$ & 0.66 & 0.08 & 0.66 & 0.32 & 0.44 & 0.74 & 0.71 & 0.16 & 0.28 & 0.31 & 0.20 & 0.41 \\
\hline $\mathrm{cmc} \mathrm{DE}$ & 0.31 & 0.06 & 0.37 & 0.16 & 0.26 & 0.49 & 0.35 & 0.06 & 0.13 & 0.17 & 0.11 & 0.22 \\
\hline Tint Strength & 102.60 & 100.26 & 97.67 & 100.31 & 99.46 & 95.67 & 99.73 & 101.45 & 101.37 & 101.79 & 102.25 & 100.23 \\
\hline
\end{tabular}

TableD.26: 9C Elevated Temperature Aged Three Week Versus Initial 9C Tinting Values

\begin{tabular}{|c|c|c|c|c|c|c|c|c|c|c|c|c|}
\hline & OY & LB & $\mathrm{YO}$ & PG & $\mathrm{PB}$ & $\mathrm{RO}$ & MY & $\mathrm{QV}$ & $\mathrm{QR}$ & $\mathrm{UO}$ & $\mathrm{BU}$ & Averages \\
\hline$\Delta \mathrm{L}$ & 0.51 & 0.35 & 0.02 & -0.52 & -1.04 & -0.87 & 0.46 & -0.40 & -0.11 & 0.12 & 0.07 & -0.13 \\
\hline$\Delta \mathrm{a}$ & -0.21 & 0.10 & 0.39 & -1.42 & -0.32 & 1.17 & 2.26 & 0.23 & 0.44 & 0.54 & 0.36 & 0.32 \\
\hline$\Delta \mathrm{b}$ & 0.79 & 0.41 & 1.18 & 0.19 & -1.36 & 0.78 & -6.26 & 0.34 & 0.33 & 0.34 & 0.55 & -0.25 \\
\hline$\Delta \mathrm{E}$ & 0.97 & 0.55 & 1.24 & 1.53 & 1.74 & 1.65 & 6.67 & 0.57 & 0.56 & 0.65 & 0.66 & 1.53 \\
\hline Tint Strength & 98.92 & 104.42 & 93.75 & 91.19 & 89.49 & 88.88 & 152.70 & 98.12 & 99.50 & 99.23 & 97.05 & 101.20 \\
\hline
\end{tabular}

Table D.27: 5880 Room Temperature Aged Three Week Versus Initial 5880 Tinting Values

\begin{tabular}{|c|c|c|c|c|c|c|c|c|c|c|c|c|}
\hline & OY & LB & $\mathrm{YO}$ & PG & $\mathrm{PB}$ & $\mathrm{RO}$ & MY & QV & $\mathrm{QR}$ & $\mathrm{UO}$ & $\mathrm{BU}$ & Averages \\
\hline$\Delta \mathrm{L}$ & 0.55 & 2.99 & 0.27 & 0.22 & 0.28 & 0.22 & 0.59 & 1.98 & 1.17 & 0.47 & 0.16 & 0.81 \\
\hline$\Delta \mathrm{a}$ & -0.09 & -0.17 & -0.01 & 0.28 & 0.13 & 0.06 & 1.85 & -1.82 & -2.13 & -0.45 & 0.00 & -0.21 \\
\hline$\Delta \mathrm{b}$ & -0.05 & -0.50 & 0.13 & -0.11 & -0.04 & -0.12 & -7.39 & 2.07 & 0.89 & -0.46 & -0.29 & -0.53 \\
\hline$\Delta \mathrm{E}$ & 0.56 & 3.03 & 0.30 & 0.37 & 0.31 & 0.26 & 7.64 & 3.39 & 2.59 & 0.80 & 0.33 & 1.78 \\
\hline Tint Strength & 107.51 & 118.60 & 101.38 & 103.44 & 102.61 & 101.80 & 165.10 & 139.87 & 120.72 & 107.20 & 104.38 & 115.69 \\
\hline
\end{tabular}

Table D.28: 5880 Elevated Temperature Aged Three Week Versus Initial 5880 Tinting Values

\begin{tabular}{|c|c|c|c|c|c|c|c|c|c|c|c|c|}
\hline & OY & LB & $\mathrm{YO}$ & PG & $\mathrm{PB}$ & $\mathrm{RO}$ & MY & QV & $\mathrm{QR}$ & $\mathrm{UO}$ & $\mathrm{BU}$ & Averages \\
\hline$\Delta \mathrm{L}$ & 0.58 & 1.80 & 0.25 & 0.11 & 0.13 & 0.07 & 0.61 & 1.21 & 1.03 & 0.40 & 0.22 & 0.58 \\
\hline$\Delta \mathrm{a}$ & -0.10 & -0.10 & 0.06 & 0.25 & 0.20 & 0.24 & 1.90 & -0.13 & -1.82 & -0.21 & 0.05 & 0.03 \\
\hline$\Delta \mathrm{b}$ & 0.14 & -0.47 & 0.41 & 0.00 & -0.08 & 0.02 & -7.10 & 1.25 & 0.87 & -0.34 & -0.37 & -0.52 \\
\hline$\Delta \mathrm{E}$ & 0.60 & 1.87 & 0.48 & 0.28 & 0.26 & 0.25 & 7.37 & 2.07 & 2.26 & 0.56 & 0.43 & 1.49 \\
\hline Tint Strength & 105.50 & 110.10 & 99.37 & 103.27 & 101.92 & 100.03 & 162.54 & 122.42 & 118.35 & 105.62 & 105.67 & 112.25 \\
\hline
\end{tabular}

